\title{
Fabrication of a Micro-hotplate for Application as an Infrared Emitter
}

\author{
by
}

\author{
Amrita V. Singh
}

\begin{abstract}
A thesis submitted to the Faculty of Graduate and Postdoctoral Affairs in partial fulfilment of the requirements for the degree of
\end{abstract}

Masters Of Applied Science

in

Electrical and Computer Engineering

Carleton University

Ottawa, Ontario

@2015

Amrita V. Singh 


\section{Abstract}

The aim of this research is to design, fabricate and characterize a micro-hotplate which is suitable for application as an infrared source. For the heater material, Nichrome Ni-Cr (80/20) $w t \%$ an alloy of $\mathrm{Ni}($ nickel) and $\mathrm{Cr}$ (chromium) is used. Nichrome exhibits high resistivity, low temperature coefficient of resistance (TCR) and is resistant to natural processes of oxidation and corrosion, these qualities make nichrome a suitable material for a microhotplate. The heater resistance versus applied voltage is measured, and a value for TCR has been obtained by using a four point probe on thermo-chuck with the temperature ranges of $20^{\circ} \mathrm{C}$ to $180^{\circ} \mathrm{C}$. NiCr structures integrated on micro-hotplates are simultaneously heated and the corresponding resistance is measured using a source-meter that applies bias voltage and measures current. The calculated TCR has been found only to be valid for the temperature ranges of $20^{\circ} \mathrm{C}$ to $180^{\circ} \mathrm{C}$, and the device self annealed during the testing, thus ending with a changes in TCR. The micro-hotplate heater resistance is found to be stable after it has been passed through several conditioning steps. 


\section{Acknowledgement}

It is a genuine pleasure to express my sincere gratitude to my supervisor, Dr. Niall Tait, Chairman, Department of Electronics. His helpful attitude greatly assisted me in completing my work. His scholarly advice and knowledge helped immeasurably. I would like to thank my committee members, Professors Garry Tarr, Tom Smy and Rony Amaya who all showed interest in reviewing my work.

This work would not have been possible without the help of a number of people to whom I would like to extend my thanks. I am grateful to Blazenka, Anna, Angela and Rob for giving the right advice at the right time and for being a source of motivation. I would to thank my friend Muhammad Osama Ali for his constant support and guidance.

Finally and most importantly, I want to thank my husband Vikram Jeet Singh and my daughter, Arianna (Rio) who have had much to sacrifice because of my busy schedule, but provided me with constant motivation to complete my degree.

I seek the blessings of my parents Daljit Singh and Balbir Kaur and my in-laws Sada Singh and Satinder Kaur and thank them for all of their advice and support. I thank Veerji Dr. Param Vir Singh and Kiranpreet Kaur for always being there with me. Last but not least, I thank cutie pie Evelyn for being the best playmate with my Rio. 


\section{List Of Acronyms}

MEMS :Micro-electro-mechanical systems

IR : Infrared

PECVD : Plasma-enhanced chemical vapor deposition

LPCVD : Low pressure chemical vapor deposition

LED : light emitting diode

SOI : Silicon on insulator

3D : Three dimensional

DRIE : Deep reactive-ion etching

RIE : Reactive ion etching

TCR : Temperature coefficient of resistance

SOI : Silicon on insulator

MB : Micro bridge

M : Membrane

CMOS :Complementary metal oxide semiconductor

MHP : micro-hotplate

TMAH : Tetra methyl ammonium hydroxide

ULP : Ultra low power

IPA : Isopropyl alcohol 
HMDS : Hexamethyldisilazane

BOE : Buffered oxide etch

DI : De-ionized

PR : Photoresist

SCCM : Standard cubic centimetre per minute

LOR : Lift-off resist

SPA : Semiconductor parameter analyser

GPIB : General purpose interface bus 


\section{Contents}

1 Motivation 11

1.1 Thesis Outline . . . . . . . . . . . . . . . . . . . . . . . . 12

2 Introduction $\quad 14$

2.0.1 Techniques of micro machining $\ldots \ldots \ldots \ldots \ldots \ldots \ldots$

2.0 .2 Micro-hotplate Materials Selection . . . . . . . . . . . . . . 23

3 Literature Review $\quad 26$

4 Design $\quad 5$

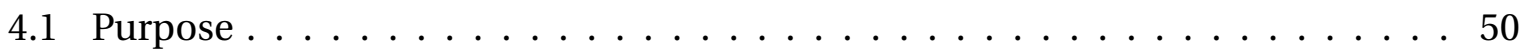

4.2 Design considerations $\ldots \ldots \ldots \ldots \ldots \ldots$

$4.2 .1 \quad$ Heater Element material . . . . . . . . . . . . . . . . . . . . . . . 50

4.2 .2 Heater geometry $\ldots \ldots \ldots \ldots \ldots \ldots \ldots$

4.2 .3 Heatloss from the heater . . . . . . . . . . . . . . . . . . . . . . 53

5 Device Fabrication $\quad 57$

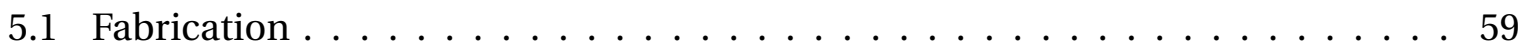

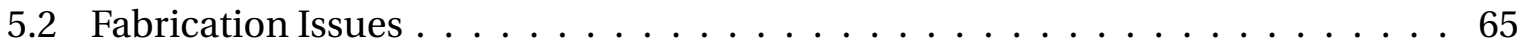

6 Results and Discussion $\quad 68$ 


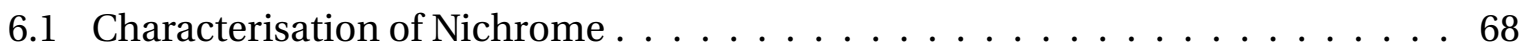

6.1.1 Theoretical Value of Sheet Resistance at Room Temperature . . . . . . . 70

6.1.2 Measured Value of Sheet Resistance at Room Temperature . . . . . . 71

6.1.3 Temperature Coefficient of Resistance (TCR) . . . . . . . . . . . . . . 73

6.2 micro-hotplate Testing $\ldots \ldots \ldots \ldots \ldots \ldots$

6.2 .1 Original Test Plan $\ldots \ldots \ldots \ldots \ldots \ldots \ldots$

6.2 .2 Modified Test Plan . . . . . . . . . . . . . . . . . . . 79

6.2.3 Non-Linear Resistance Behaviour . . . . . . . . . . . . . . . . . . 79

6.2 .4 Repeatability . . . . . . . . . . . . . . . . . 80

6.2 .5 Optical Emission $\ldots \ldots \ldots \ldots \ldots \ldots \ldots \ldots$

6.2.6 Voltage increase and decrease with the same steps . . . . . . . . . . 82

$\begin{array}{lll}7 & \text { Conclusion and Future Work } & \mathbf{8 4}\end{array}$

$\begin{array}{lll}\text { Appendix A Layout and Run sheet } & 91\end{array}$

$\begin{array}{lll}\text { Appendix B Shipley Photoresist } & 98\end{array}$ 


\section{List of Figures}

2.1 Membrane type hotplate . . . . . . . . . . . . . . . . . . . . 19

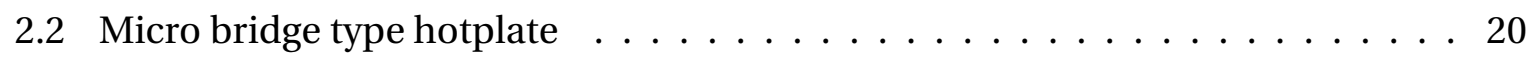

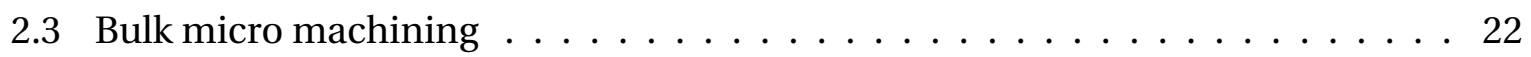

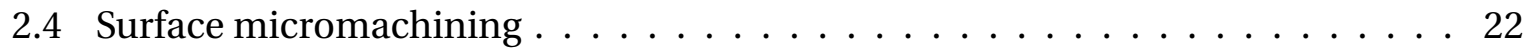

3.1 Cross sectional view of the Silicon micro machined infrared emitter based SOI

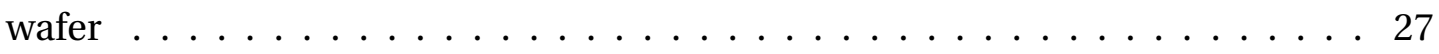

3.2 Power Vs Temperature characteristics . . . . . . . . . . . . . . . 28

3.3 New recommended design $\ldots \ldots \ldots \ldots$

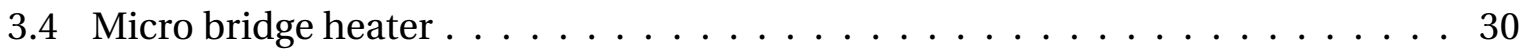

3.5 Resistance Vs Temperature characteristics $\ldots \ldots \ldots \ldots$

3.6 Temperature Vs Power characteristics . . . . . . . . . . . . . . . . 31

3.7 Surface Micro-machining of Suspended micro hotplate by Guo ～. . . . . . 31

3.8 Power Vs Temperature characteristics $\ldots \ldots \ldots \ldots$. . . . . . . . . . . . 32

3.9 Silicon Bulk Micro machining in backside by RIE of Suspended micro hotplate

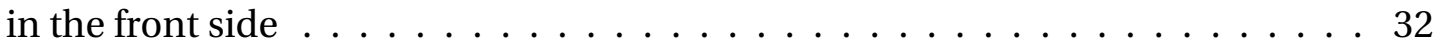

3.10 Power Vs Temperature characteristics . . . . . . . . . . . . . . . . . . 33 
3.11 The schematic cross sectional view of the hotplate and the top view of the heater geometry . . . . . . . . . . . . . . . . . 34

3.12 Resistance Vs Power characteristics . . . . . . . . . . . . . . . . 35

3.13 Resistance Vs Temperature characteristics . . . . . . . . . . . . . . . . 35

3.14 The Schematic Cross Section of the micro-hotplate by Mele . . . . . . . . . . 37

3.15 Resistance versus temperature characteristics $\ldots \ldots \ldots$. . . . . . . . . 38

3.16 Power versus temperature characteristics $\ldots \ldots \ldots \ldots$. . . . . . . . . . 38

3.17 The 3D Model of micro-hotplate-Lei . . . . . . . . . . . . . . . . . . . 39

3.18 Temperature Vs power characteristics . . . . . . . . . . . . . . . 40

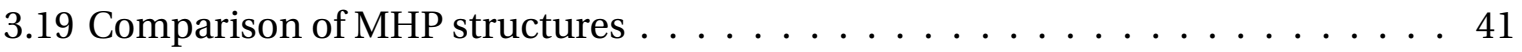

3.20 The schematic cross sectional view of the suspended Tungsten micro-hotplate-

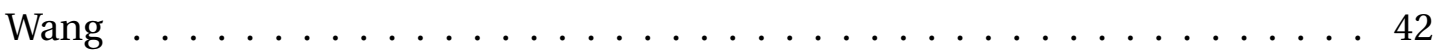

3.21 Resistance Vs Temperature characteristics . . . . . . . . . . . . . . . . . 42

3.22 Power Vs Temperature characteristics . . . . . . . . . . . . . . . . 43

3.23 The process flow for micro-hotplate fabrication . . . . . . . . . . . . 44

3.24 Micro heater resistivity and temperature of the hotplate . . . . . . . . . . . 45

3.25 Hotplates with various heaters, contacts and suspended arms $\ldots \ldots$. . . . 46

3.26 Process flow for hotplate - Elmi $\ldots \ldots \ldots \ldots \ldots \ldots$. . . . . . . . 47

3.27 Temperature Versus Applied power $-\mathrm{Pit}=400 \mu m) \ldots \ldots \ldots$. . . . 48

3.28 Temperature Versus Applied power $-\mathrm{Pit}=4 \mu m) \ldots \ldots \ldots \ldots$

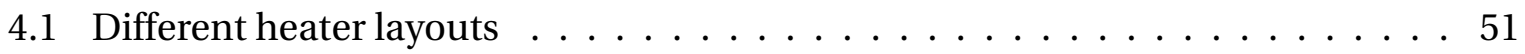

4.2 Schematic of nichrome heater in L-Edit software . . . . . . . . . . . . . 52

4.3 Cross section showing parallel layers $\ldots \ldots \ldots \ldots$. . . . . . . . . . 54

4.4 Layout of Device $($ Design 9$) \ldots \ldots \ldots \ldots \ldots \ldots$ 
5.1 Process Flow $\ldots \ldots \ldots \ldots \ldots \ldots \ldots$

5.2 Micro-hotplate suspended structure . . . . . . . . . . . . . . . . . 64

5.3 Nichrome Etching . . . . . . . . . . . . . . . . . . 67

6.1 Vander Pauw structure . . . . . . . . . . . . . . . . . . . . 69

6.2 Temperature controlled thermo-chuck . . . . . . . . . . . . 73

6.3 Resistance vs Temperature for Test Structure . . . . . . . . . . . . . . . . . 74

6.4 Normalised Resistance vs Temperature for Test Structure . . . . . . . . . . . 75

6.5 Layout of Device $($ Design 9$) \ldots \ldots \ldots \ldots \ldots \ldots$

6.6 Measured current vs. voltage $\ldots \ldots \ldots \ldots \ldots \ldots \ldots$

6.7 Resistance vs voltage during initial cycling $\ldots \ldots \ldots \ldots$

6.8 Resistance vs voltage repeatability measurements . . . . . . . . . . . . 81

6.9 Thermal emission from the device $\ldots \ldots \ldots \ldots$. . . . . . . . . 82

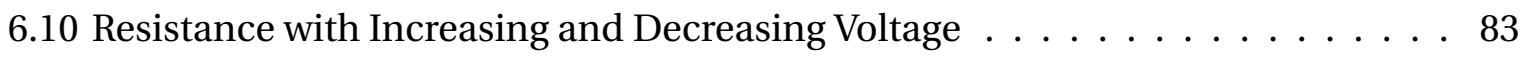

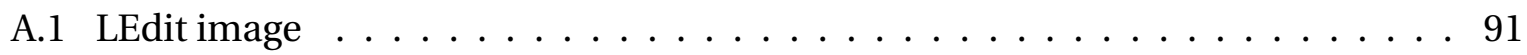




\section{List of Tables}

2.1 Summary of heater material used $\ldots \ldots \ldots \ldots \ldots$

2.2 Properties of heater material $\ldots \ldots \ldots \ldots \ldots \ldots \ldots$

3.1 Comparison of various designs used in past $1 \ldots \ldots \ldots \ldots$

3.2 Comparison of various designs used in past $2 \ldots \ldots \ldots \ldots$

3.3 Brief description of the properties of the tested MHP $\ldots \ldots \ldots \ldots$

3.4 Comparison of MHP - heater structures $\ldots \ldots \ldots \ldots$. . . . . . . 40

3.5 Comparison of various designs used in past $-3 \ldots \ldots \ldots \ldots$

3.6 Various designs with different layout geometry $\ldots \ldots \ldots$. . . . . . . 46

4.1 Material Properties of the layers for micro-hotplate $\ldots \ldots \ldots 6$

6.1 Resistance versus Temperature $\ldots \ldots \ldots \ldots \ldots \ldots \ldots$. . . . . . . 74

6.2 Number of Squares of design $9 \ldots \ldots \ldots \ldots \ldots$ 


\section{Chapter 1}

\section{Motivation}

The presence of a large concentration of a gas like $\mathrm{CO}_{2}$ can reduce workplace productivity and lead to various health problems [2]. Research on ventilation systems in highly occupied places such as offices has shown that areas with high amount of indoor pollutants can lead to poor health conditions and can affect work efficiency. One of the major constituents of these pollutants is exhaled $\mathrm{CO}_{2}$. So it is useful to have a sensor which can detect the concentration of the undesirable gas.

Moreover many people must work in hazardous environments, however the risk of injury or death could be reduced through continuous monitoring of the local gas composition. It is likely that many who have died in confined spaces were unaware of the potential hazards facing them.

Gas monitoring systems have been used in certain industrial settings for a long time and the technology has advanced significantly with the availability of more sophisticated and lowercost electronic equipment.

The motivation for this thesis came from the need for a sensitive, low power gas sensor that could detect gas leaks in high occupancy locations. Presently there is a growing demand 
and variety of applications for miniaturized gas sensors. Due to this, a variety of different gas sensors have been researched and developed and many of them used micro electromechanical systems(MEMS) technology and techniques of micro fabrication.

\subsection{Thesis Outline}

The main aim of the thesis is to describe the fabrication, testing and characterization of a low power, micro bridge(MB) based infrared (IR) emitter. There are various techniques to sense the presence of gases. Some of these techniques are based on chemical sensing. One way to detect these gases is by using the fact that each gas gets ionised at a specific breakdown voltage. This type of gas sensor interacts with these gases and identifies them by measuring the current discharge in the device.

Another efficient way to detect the presence of these gases is by using infrared technology. Many gases absorb unique wavelengths, with carbon dioxide absorbing a wavelength of 4.2$4.3 \mu \mathrm{m}$ in the IR spectrum [3]. Infrared technology has many applications which include but are not limited to automotive, food, forestry and textile industries.

A MEMS micro-hotplate has been developed for use as an infrared emitter for gas sensing applications. The micro-hotplate was fabricated using complementary metal oxide semiconductor (CMOS) compatible processes and bulk micro-machining techniques. A suspended structure is very important for thermal isolation. Wet anisotropic etching in tetramethyl-ammonium-hydroxide (TMAH) was used to create a suspended structure resulting in thermal isolation and efficient heating performance. Nichrome was used as a heater material due to its high temperature stability. Experiments were completed to characterize the TCR of the Nichrome resistors and the temperature behaviour of the micro-hotplate 
structure. Different micro-hotplate configurations were compared to investigate heating efficiency.

Chapter 2 provides the overview of different materials used, their properties and configurations.

Chapter 3 covers a literature review for this research. This chapter highlights the research that has been conducted using MEMS technology in fabricating various types of microhotplate.

Chapter 4 has the design considerations for fabricating the micro-hotplate. It includes the design parameters and design calculations involved in developing the hotplate.

Chapter 5 describes the fabrication of the micro-hotplate. It includes the process flow and the fabrication process involved in developing the hotplate and discussion of issues occurred during the fabrication.

Chapter 6 presents the testing procedure and associated results performed on the microhotplate.

Lastly chapter 7 outlines the conclusion of the research work and suggestions on some of the future possibilities to improve and upgrade the micro-hotplate and the related process. 


\section{Chapter 2}

\section{Introduction}

Conventional gas detectors include the extensively used, relatively small pellistors. Pellistors are used for the detection and estimation of combustible gases. They work on the principle of detection of gas by measuring the heat of combustion. They typically require large power consumption (hundreds of milli-Watts to Watts) and have slow response time (tens of seconds). Advancement in micro fabrication processing has led to pellistors which require lower power consumption. With MEMS technology, micro-hotplates (MHP) have been built and are capable of reaching operating temperatures of $500^{\circ} \mathrm{C}$ at a power level of $100 \mathrm{~mW}[4]$. All of the different types of gas sensors need to achieve and optimise some of the main characteristics like low power, low cost and fast time response. Yet there is another type of micro-hotplate which is fabricated and characterised for its focus on meeting the same criteria, which is explained in this thesis.

Sophisticated technology is of little use if it fails to selectively detect the hazard of interest. There are three key hazards that are typically monitored :

- Combustibles (flammables)gases like methane, propane, gasoline.

- Oxygen-deficiency and enrichment. 
- Toxics gases like carbon monoxide, toxic hydrocarbons and various other site-related toxics.

Depending on the sensor configuration, gas detection equipment can help identify the hazard and protect the lives of people in that environment. The gas measurement techniques include metal - oxide sensors, capacitive gas sensors, calorimetric gas sensors and optical sensors. Apart from optical sensors, most of the existing methods depend on calculating the change of an electrical quantity of the active material for the sensor.

Advantages of the existing technology for gas sensing include:

- Simple and inexpensive MEMS fabrication process .

- Miniature size.

- High operating temperature.

Disadvantages of this method include:

- Reduced selectivity due to shortfall of sensitive material for every gas (crosstalk).

- Short term life, as materials react with gas leading to degradation of active material of the sensor.

The IR optical gas sensor has advantages over these sensors. The infrared absorption is not dependent on chemical reactions. It is not prone to contamination of the surface and has long term life. The IR absorption measurement is considered more selective than other sensors. In this thesis, an integrated suspended infrared emitter is designed and fabricated on silicon substrate. Infrared spectroscopy uses the characteristic absorption of the molecules in the mid-infrared and permits estimation of the species and concentration. A main component for all spectroscopic systems is the radiation source [14]. Three main types of radiation sources for infrared applications include:

- Lasers 
- Light emitting diodes (LED) and

- Thermal emitters.

Lasers have a high but narrowband emission and are not always available for every wavelength and moreover they are very costly. Infrared LEDs offer a feasible alternative for wavelengths $<5 \mu m$, although the intensity is relatively low. To reduce cost, very often thermal emitters are used as radiation source [5]. Thermal emitters are broadband sources, but their emission can not exceed the radiation power of an ideal black body emitter. This means that the resolution of spectroscopic systems is usually limited by the relative low emission of the available thermal sources. The emissivity and emitted radiation of the commercially available thermal emitter is limited as compared to the ideal black body radiator. Significant parameters for using thermal sources in infrared measurement technologies are the size of the light source, emissivity, the temperature of the emitting surface and the cost. In this work a micro-hotplate is developed, with characteristics suitable for applications as a thermal infrared radiation source.

Micro-hotplates have been used in a diversity of applications which include but are not limited to gas sensors, integrated circuits, actuators and also in microscopy for in-situ inspection of nano materials in transmission electron microscope [6]. In MEMS technology the hotplates are used for sensing applications primarily in which the sensing material is deposited on the membrane combined with an electrical signal transducer [7].

Advantages of a micro-hotplate include: 
- miniature size

- low power consumption

- high sensitivity

- fast response

- high yield

Disadvantages of a micro-hotplate include:

- high fabrication cost per unit.

- power consumption (defects occurring during fabrication).

To design the micro-hotplate the heat transfer mechanisms need to be considered. For low power operation, thermal isolation is required, which can be achieved through micro machining techniques were discussed later in this chapter.

The development of heat transfer is concerned with two things:

- temperature

- flow of Heat

Temperature shows the amount of thermal energy present, whereas heat flow shows the movement of thermal energy from one place to another. On a micro scale level, thermal energy is analogous to the kinetic energy of molecules. The greater the temperature of the material, the greater the thermal turbulence of its constituent molecules. Mechanisms of heat transfer include:

- Thermal conduction - the transfer of heat energy by diffusion and collisions of particles and in the presence of temperature gradient. This occurs through a solid media. The equation for heat transfer in one dimension is as follows

$$
q_{\text {cond }}=-k \cdot \frac{d T}{d x}
$$


Where $q_{\text {cond }}$ in the heat flux in $\left(W / m^{2}\right)$ and $k$ is the thermal conductivity. $\frac{d T}{d x}$ is the temperature gradient.

- Thermal convection, the transfer of heat from one place to another by the movement of fluids. It is of two types:

Natural convection, in which buoyancy occurs due to initial temperature gradient within the fluid, which results in the movement within the fluid thus producing heat transfer. The equation for heat transfer in this is as

$$
q_{\mathrm{conv}}^{\prime \prime}=h \cdot\left(T_{\mathrm{s}}-T \infty\right)
$$

Where $q_{\text {conv }}$ in the heat flux in $\left(W / m^{2)}\right.$ and $\mathrm{h}$ is the thermal convection coefficient. This coefficient depends on surface geometry, fluid viscosity, thermal diffusivity and fluid velocity [8].

Forced thermal convection, which takes place when heat is transferred to a body because of fluid displacement. This occurs when an external source like a stirrer, pump or fan forces the displacement and flow of liquid. The equation for this heat transfer is similar to the natural thermal convection equation.

- Radiation - where the heat transfer occurs through electromagnetic radiation within a void or air filled medium. The equation for this heat transfer is,

$$
E=\varepsilon \sigma \cdot T_{\mathrm{R}}^{4}
$$

Where $\mathrm{E}$ is the emitted power and $T_{\mathrm{R}}$ is the absolute temperature in Kelvins and $\varepsilon$ is the radiative emissivity .

In the past many designs have been fabricated by researchers with heaters confined ei- 
ther by a membrane or a micro-bridge. There are primarily two types of design for microhotplate, which are discussed below.

Membrane type, usually realized by back side etching. In this type the membrane is supported by the silicon substrate along the perimeter, which limits thermal isolation. The design of a SOI(Silicon on insulator) - based device using a tungsten heater element is shown in figure 2.1.

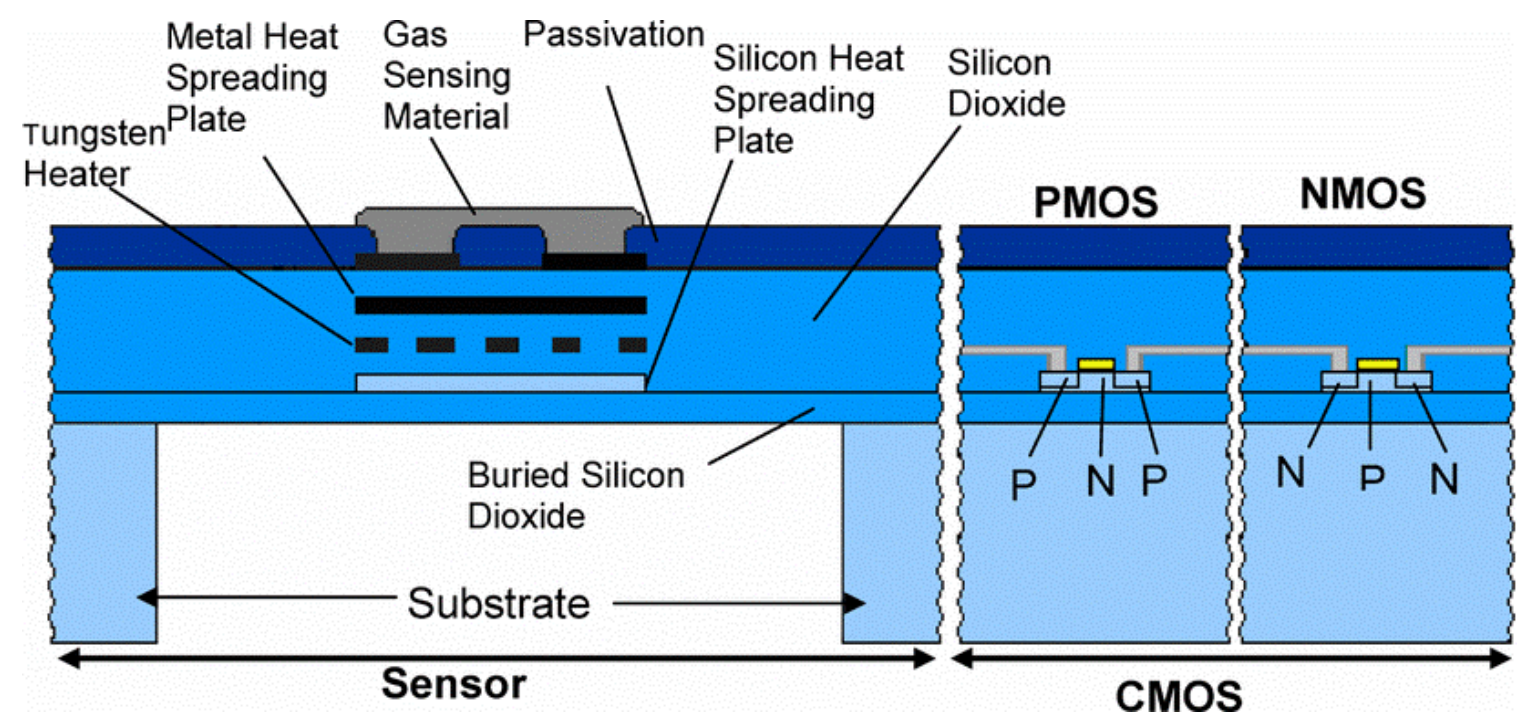

Figure 2.1: Membrane type hotplate - Tungsten SOI chip [9]Copyright $\odot ~ 2008$, IEEE.

Suspended type, or micro-bridge, usually realized by front side etching. In this type a heated plate is connected to the substrate by support beams. The layout and cross section of the micro-hotplate is shown in figure 2.2. 


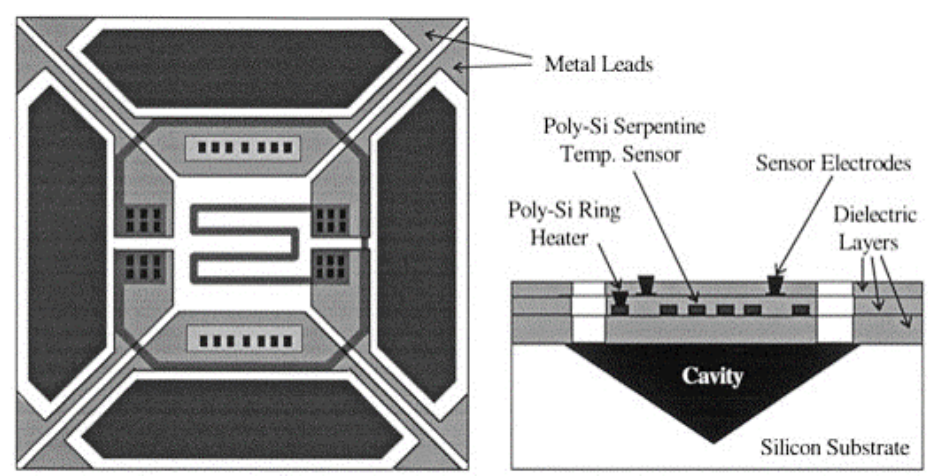

Figure 2.2: Micro-bridge type hotplate-Layout and cross section of the micro hotplate [10] Copyright $\odot$ 1997, IEEE.

This type has superior thermal confinement as heat can only flow through the supporting beams. But the mechanical reliability is lower due to supporting beams. For both the cases the membrane is on top of the cavity which is etched in the substrate [10].

The designing of MEMS can be implemented with different materials and fabrication techniques. The heater is the most important part of the micro-hotplate.

Silicon is the commonly used material due to widespread development and use in microelectronics. One of the first micro-sensors, was the silicon pressure sensor. The first large volume pressure sensor was marketed in 1974 by National Semiconductor(Vittorio, 2001) [31]. For a micro fabricated sensor, the basic processes for fabrication are:

- Deposition of material layer

- Patterning by Photo lithography

- Etching

We can accomplish high yield by using polymers. In this the basic processes for fabrication are injection molding and stereo lithography. Metal deposition consists of processes like:

- Electroplating

- Evaporation

- Sputtering Process 


\subsubsection{Techniques of micro machining}

Bulk micro-machining is the fabrication of 3D (three dimensional) structures in the substrate material using wet and/or dry etching methods combined with etching masks and etch stop layers. Figure 2.3 shows a fabricated structure using this technique. Bulk micro machining is enabled by selective and anisotropic etching techniques:

-Etchants such as ethylene diamine pyrocatechol (EDP), Potassium hyroxide (KOH) and Hydrazine $\mathrm{N}_{2} \mathrm{H}_{2}$ allow crystal-plane selective etching which leads to self-limiting etching and good dimensional control.

- $\mathrm{SiO}_{2}$ (Silicon dioxide) and $\mathrm{Si}_{3} \mathrm{~N}_{4}$ (silicon nitride) are readily produced and form good etch masks for most anisotropic etchants.

The only drawback of the wet anisotropic is the micro structure geometry, which is defined by internal crystal structure. This makes difficult to fabricate multiple interconnected micro mechanical structures of free geometry. 

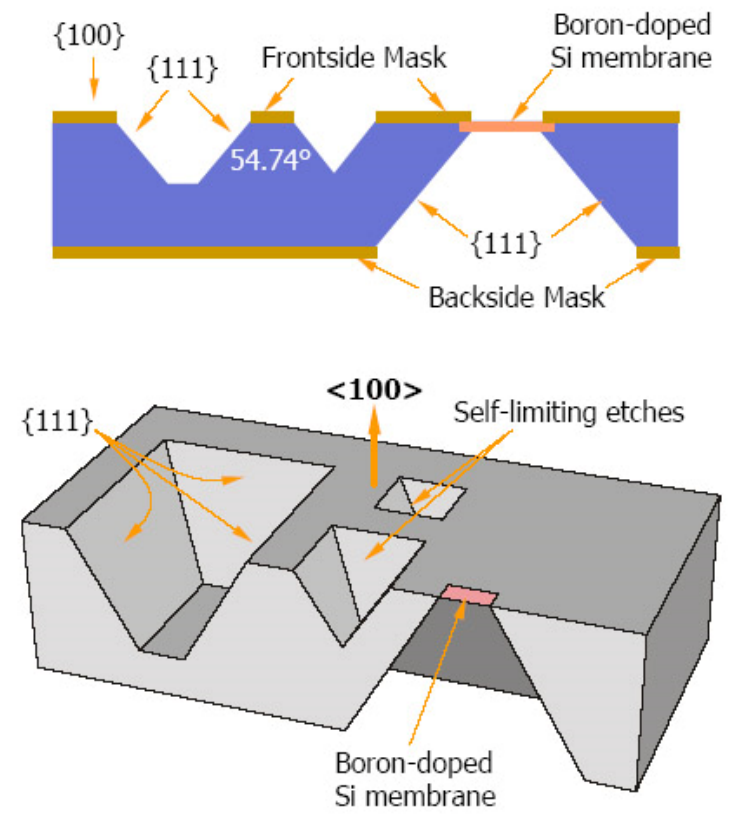

Figure 2.3: Bulk micromachining technique [12](Copyright @ 2006, IEEE).

Surface micro-machining makes use of the substrate as a mechanical support on which various layers of sacrificial and structural material are deposited and patterned to form micro mechanical structures. The polysilicon surface micromachining uses $\mathrm{SiO}_{2}$ (silicon dioxide) as sacrificial material and polysilicon as structural material. Figure 2.4 shows a structure fabricated by this technique.

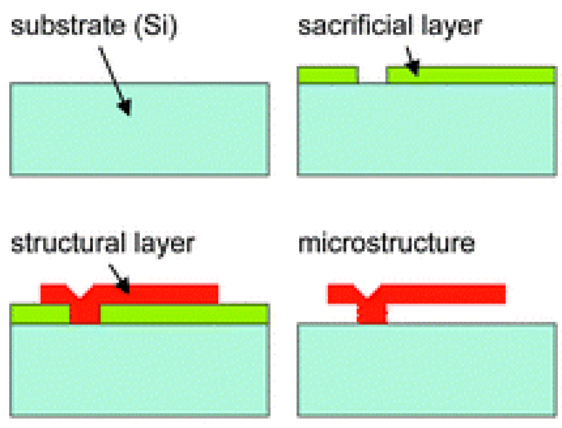

Figure 2.4: Surface micromachining technique Copyright @ 2002, Royal Society of Chemistry [11]. 
Most devices use either a front side (surface micro machining) or backside (bulk micro machining) membrane type heater. In this work the micro-hotplate consists both a front and backside micro machined device, comprised of a thin membrane with supported heaters. The main interest of this approach is to combine the bigger membrane into the supporting type which reduces the thermal losses through the substrate. Also, this design bypasses the small air gap between heater and underlying substrate. At such short distances between heater and thermally highly conductive silicon substrate (acting as a thermal ground/mass), the thermal conduction through the air does become a significant factor. Considering the power consumption of the whole device is to be between $30 \mathrm{~mW}$ and $50 \mathrm{~mW}$ this is a very significant source of thermal loss. A new design will therefore have to avoid creating a small air gap between heater and substrate, but rather remove all the material beneath the heater through bulk micromachining.

A detailed structure analysis and testing of the devices thermal properties will be presented later in this work. Nichrome is used as the heater electrode material. The selection of the material used in fabrication is discussed in the following chapter.

\subsubsection{Micro-hotplate Materials Selection}

The material choice is of great importance to the device properties. The current materials either have high TCR or are sensitive to oxidation due to high temperature operation [1]. New materials are being investigated for use in a micro-hotplate, in an attempt to improve upon the device properties. Materials used in micro-hotplates must survive high operating temperatures in potentially corrosive atmospheres and provide good mechanical strength to resist thermally induced stresses. They should also have relatively low thermal conduc- 
tivity to reduce thermal conduction loss.

Some material for membranes in MEMS processing are $S i_{3} N_{4}$, SiC (Silicon carbide) and $\mathrm{SiO}_{2}$, although this material creates membranes that almost always exhibit compressive stress causing bending of the membrane. $S i_{3} N_{4}$ is used for thin heater membranes because of its intrinsic tensile stress producing flat membranes. Mechanical stress of these membranes is a drawback to their stability. SiC has very high mechanical strength as well as thermal resistance, but its oxidation rate is smaller(one order of magnitude) than the other silicon compounds [13]. For heater material candidate materials include:

Au(gold), Pt(Platinum), W(Tungsten), Mo(Molybdenum), Al(aluminium)

, NiCr(Nichrome).

Platinum is stable at temperatures up to about $1000{ }^{\circ} \mathrm{C}$ and is basically inert. The specific electrical conductivity of Pt is comparably low for a metal thin film layer. That is why Pt is commonly used as heater where the layer thickness satisfy for the low specific conductivity. Thin film Pt-layers need to be patterned using processes like sputter etching, making their processing difficult and increasing the fabrication cost, besides Pt itself being an expensive material. Some of the materials that have been used as heater in the past are shown in table 2.1 .

Ti, TiW, WC and various other combinations are used as contact metals or as adhesion and barrier layers between substrates and Au based materials. Mo has medium electrical conductivity. It is difficult to pattern and requires a protective passivation layer [13].

Gold $(\mathrm{Au})$ at high temperature has high diffusion rates. Diffusion barrier layers are required to avoid the diffusion of the Au into the underlying substrate. The melting point of gold is much higher than Aluminium (Al). The electrical conductivity is also very high. Au can operate up to temperatures of $650^{\circ} \mathrm{C}$. 


\begin{tabular}{|c|c|c|c|}
\hline Heater material & Structure type & Power $(\mathrm{mW})$ & Temperature ${ }^{\circ} \mathrm{C} /$ Reference \\
\hline Poly Si & Membrane & 50 & $300[9]$ \\
\hline $\mathrm{Pt}$ & Microbridge & 73 & $300[9]$ \\
\hline $\mathrm{Pt}$ & Microbridge & 6 & $300[9]$ \\
\hline $\mathrm{Pt}$ & Microbridge & 30 & $300[9]$ \\
\hline $\mathrm{Pt}$ & Microbridge & 23 & $300[9]$ \\
\hline $\mathrm{Pt}$ & Microbridge & 24 & $300[9]$ \\
\hline $\mathrm{Pt}$ & Membrane & 60 & $300[9]$ \\
\hline $\mathrm{W}$ & Membrane & 14 & $300[9]$ \\
\hline $\mathrm{Pt}$ & Microbridge & 300 & $300-400[14]$ \\
\hline $\mathrm{Mo}$ & Microbridge & & roomtemp - 700 [6] \\
\hline Poly Si & Microbridge & 250 & $350[15]$ \\
\hline $\mathrm{Pt}$ & Microbridge & 4.8 & $60[16]$ \\
\hline
\end{tabular}

Table 2.1: Summary of Heater material used in past.

Nichrome is the Nickel-Chromium non magnetic alloy resistance wire. The Nickel $80 \%$ Chromium $20 \%$ is the commonly used alloy because of its :

- low TCR

- high resistivity

- high stability

- easy availability

- low thermal conductivity

These unique properties made it a good choice for use as a heater element in the microhotplate. Moreover it can operate reliably upto $1200^{\circ} \mathrm{C}$. The table 2.2 shows the material properties of Nichrome. It is corrosion resistant. The physical colour is silvery grey.

\begin{tabular}{|c|c|c|c|c|c|c|}
\hline Material & $\mathrm{Al}$ & $\mathrm{Au}$ & $\mathrm{Pt}$ & $\mathrm{Mo}$ & $\mathrm{NiCr}$ & $\mathrm{W}$ \\
\hline Density $\left(\mathrm{Kg} / \mathrm{m}^{3}\right)$ & 2700 & 19300 & 21500 & 10200 & 8400 & 1925 \\
\hline Thermal conductivity $\lambda(\mathrm{W} / \mathrm{mK})$ & 237 & 317 & 71.6 & 138 & 11.3 & 173 \\
\hline Melting point $T_{m} /{ }^{\circ} \mathrm{C}$ & 660 & 1064 & 1768.4 & 2623 & 1400 & 3422 \\
\hline Specific heat capacity $(\mathrm{J} / \mathrm{KgK})$ & 897 & 129 & 133 & 251 & 450 & 132 \\
\hline Resistivity $* 10^{-8} \Omega \mathrm{m}$ & 2.65 & 2.4 & 10.6 & 5.34 & 100 & 5.6 \\
\hline
\end{tabular}

Table 2.2: Properties for different material for Heater [13]. 


\section{Chapter 3}

\section{Literature Review}

This research is focused on fabricating low cost and low power micro-hotplates. MHPs are suspended MEMS devices with embedded resistive heaters.

Table 3.1,3.2 and 3.5 shows a comparison of designs studied for the fabrication of the MHP. The comparison is done on the basis of power consumed for a specific range of output temperatures as well as the device size and radiation intensity per unit area.

Kun [17] fabricated a silicon infrared emitter for gas detection systems. The thin film ar-

\begin{tabular}{|c|c|c|c|c|}
\hline Reference & {$[17]$} & {$[18]$} & {$[19]$} & {$[20]$} \\
\hline Heater/Hotplate Area $\left(\mu m^{2}\right)$ & 5250000 & 40000 & 36100 & 160000 \\
\hline Power $(\mathrm{mW})\left(300^{\circ} \mathrm{C}\right)$ & $500 @ 440^{\circ} \mathrm{C}$ & $55.68 @ 200^{\circ} \mathrm{C}$ & 45 & 40 \\
\hline Heater element & PolySi & $\mathrm{Pt}$ & $\mathrm{Pt}$ & $\mathrm{Ti} / \mathrm{Pt}$ \\
\hline Heater/hotplate shape & Rectangular & Square & Square & Square \\
\hline Etching & Back & Front & Front & Back \\
\hline Arm Width & & & $60 \mu m X 60 \mu m$ & $60 \mu m$ \\
\hline No.of arms & & 4 & 4 & 4 \\
\hline Type-Technology & MB-SOI & MB & MB/M & MB \\
\hline Gap $(\mu m)$ & & 200 & 3 & 300 \\
\hline MB/M material & Silicon & Oxide-Nitride & Oxide-Nitride & Oxide-Nitride \\
\hline
\end{tabular}

Table 3.1: Comparison chart showing different designs fabricated. 
rangement as shown in Figure 3.1 is created by DRIE of a silicon substrate. On the heavily doped poly silicon layer, silicon dioxide is deposited and aluminium electrodes are added. The thermal conductivity of silicon dioxide is $1.4 \mathrm{~W} / \mathrm{mK}$ and that of Silicon is $125 \mathrm{~W} / \mathrm{mK}$. The $\mathrm{p}++$ doped silicon layer gives mechanical strength and can also absorb infrared radiation. The silicon dioxide layer acts as a thermal insulating layer to reduce the thermal losses to the substrate. The thickness of the poly silicon is $0.5 \mu m$, the $\mathrm{p}++$ doped silicon is $5 \mu m$ and the buried silicon dioxide is $1.5 \mu \mathrm{m}$ [17]. The size of the overall design is $2100 * 2500 * 0.5 \mu \mathrm{m}^{3}$.

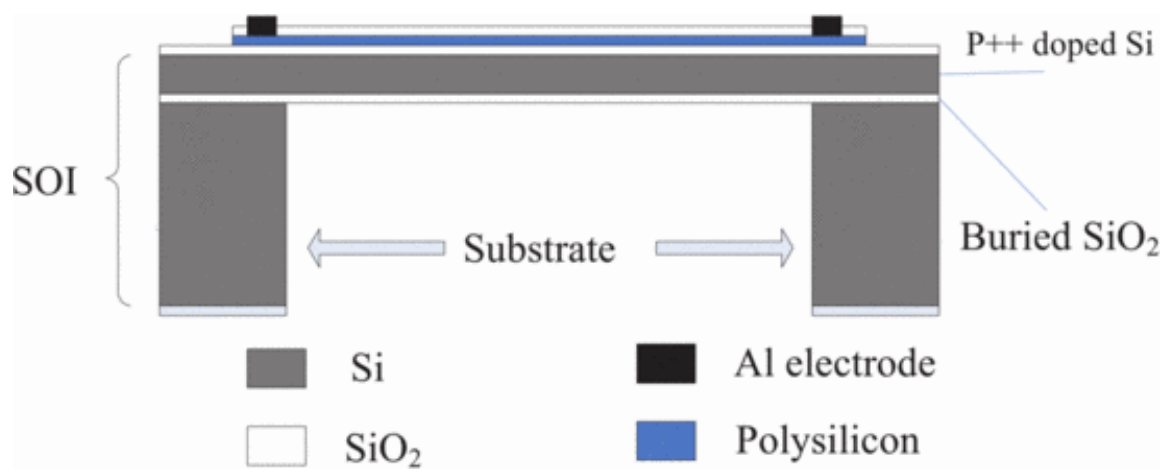

Figure 3.1: The schematic cross sectional view of the Silicon micro machined infrared emitter based SOI wafer [17](Copyright @ 2010 , IEEE).

Any variation in the thickness of the polysilicon will affect the temperature versus power consumption. Simulated results for the dimensions of polysilicon thin film $2100 * 2500$ with thickness of $0.5 \mu \mathrm{m}$ and also with $0.3 \mu \mathrm{m}$ are shown in figure 3.2.

Transient simulations were conducted to calculate the response time of the device with poly silicon as a thin film membrane. Results show that within $17 \mathrm{~ms}$ the temperature increases to $90 \%$ of the equilibrium temperature. The stability of the membrane is greatly affected by stress. With the increase in temperature (higher than $500^{\circ} \mathrm{C}$ ) membrane fracture was observed. The equation for calculating the thermal stress is given as

$$
\sigma=\left(E_{p} /\left(1-v_{p}\right)\right)\left(\varepsilon_{p}(T)-\varepsilon_{s}(T)\right) \Delta T
$$




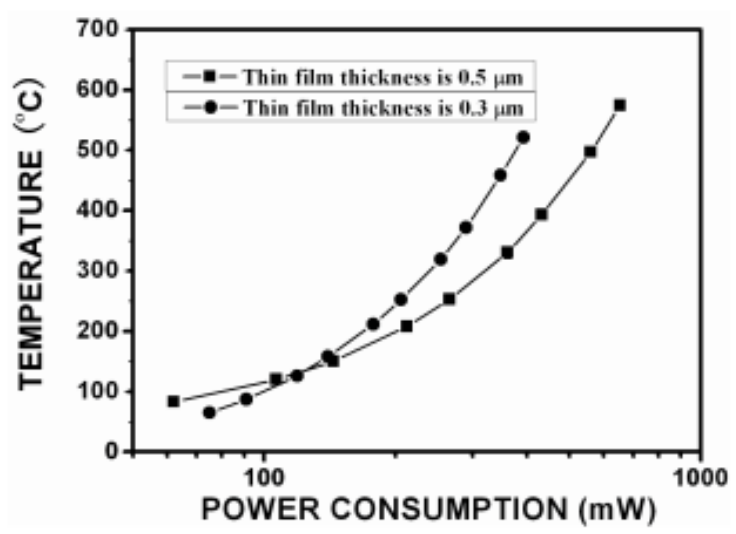

Figure 3.2: The Characteristics showing the maximum temperature versus the power consumption for different thickness for the membrane [17](Copyright @ 2010 , IEEE).

Where: $\sigma$ is the thermally induced stress, $E_{p}$ is Young's modulus of polysilicon film, $v_{p}$ Poisson's ratio of the poysilicon film, $\epsilon_{p}$ is the thermal expansion coefficient of polysilicon thin film, $\epsilon_{s}$ is the thermal expansion coefficient of silicon dioxide thin film, $\Delta T$ is the temperature difference between the thin films.

The stress induced is calculated by this equation and is nearly $32 \mathrm{MPa}$ with $\Delta T$ of $300^{\circ} \mathrm{C}$. The simulation results present that the maximum stress $150 \mathrm{MPa}$ is at the center of the membrane and minimum at the edges. So in order to minimize the thermal stress a bridge structure as shown in figure 3.3 is recommended, with the same size as the existing structure. The poly silicon thin film is divided into 9 parts through etching of the front side. Then simulation is again done to express the maximum thermal stress which is $81 \mathrm{MPa}$ with $\Delta T$ of $400^{\circ} \mathrm{C}$. The simulated maximum temperature is concluded to be $439^{\circ} \mathrm{C}$ with the applied voltage of $15.4 \mathrm{~V}$ and the power consumption of $500 \mathrm{~mW}$. The response time is $17 \mathrm{~ms}$. The results are in agreement with measured values of the fabricated device.

An integrated catalytic combustion $H_{2}$ sensor was fabricated by Eui [18]. Suspended micro heaters were connected in the Wheatstone bridge configuration with low power design for operation of the sensor using a battery. The sensor was fabricated with two sensing ele- 


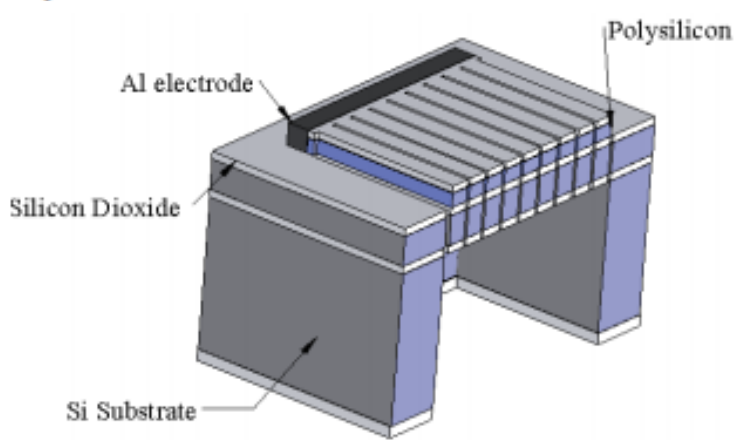

Figure 3.3: The Cross section view of the new recommended bridge structure design [17](Copyright $\odot$ 2010, IEEE).

ments and two reference elements. The process requires only two photo masks which adds to the cost effectiveness and simplicity of the design and makes it suitable for mass production. Figure 3.4 shows this design.

The substrate should be a good heat conductor as well as an electrical insulator. For this sensor device the starting material was a $4 \mathrm{in}$. N type Si wafer with thickness $520 \mu \mathrm{m}$ and with resistivity of $1-10 \Omega \mathrm{cm}$. A $\mathrm{Si}_{2}$ layer of thickness $1.6 \mu \mathrm{m}$ was deposited by thermal oxidation at $1100^{\circ} \mathrm{C}$. A lithography process was employed to pattern the cavity and a Ti/Au layer for an electroplating seed-layer was e-beam evaporated. The heater was made of Platinum with thickness $2.8 \mu \mathrm{m}$. The metal patterning is done by wet etching and anisotropic etching from the front side of the wafer was used to form the suspended structure. The micro heaters were released across a $200 \mu m$ deep cavity by Pt bridges and the area of the hotplate was $200 \mu m * 200 \mu m$ [18].

The TCR measurements were done in a controlled oven and the resistance was measured after stabilizing the required temperature. The resistance of the micro heater was measured as a a function of applied voltage.

$$
R(T)=R\left(T_{0}\right) \times\left[1+\alpha\left(T-T_{0}\right)\right]
$$




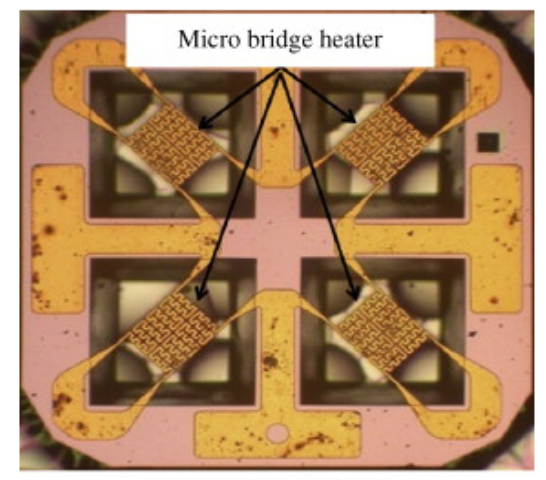

Figure 3.4: The fabricated sensor : Micro bridge heater (Copyright @ 2010 Elsevier B.V. All rights reserved).

Where: $R(T)$ and $R\left(T_{0}\right)$ is resistance at temperature $T$ and $T_{0}$ and $\alpha$ is the TCR.

Figure 3.5 and Figure 3.6 show the resistance versus applied voltage and temperature versus power for this device respectively.

With the increase in power the temperature of the sensor increases. At voltage $0.5 \mathrm{~V}$ the

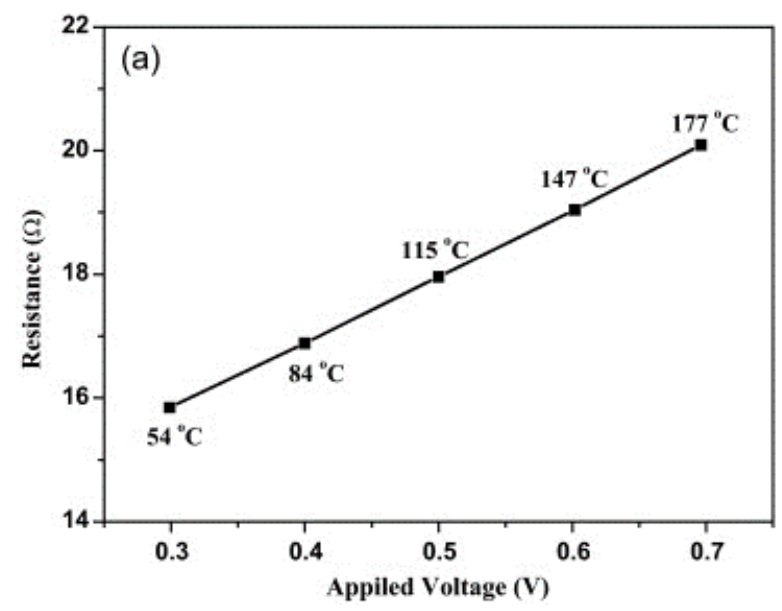

Figure 3.5: The resistance of the single micro heater as a function of applied voltage (Copyright $\odot 2010$ Elsevier B.V. All rights reserved).

power consumed is only $13.92 \mathrm{~mW}$ at $115^{\circ} \mathrm{C}$. The total power consumption is $55.68 \mathrm{~mW}$, which is due to excellent thermal insulation contributed by the suspended configuration.

Another MHP is fabricated with surface micro machining technique because of the simple process and compatibility with CMOS. The MHP dimensions are $190 \mathrm{X} 190 \mu \mathrm{m}^{2}$, comprised 


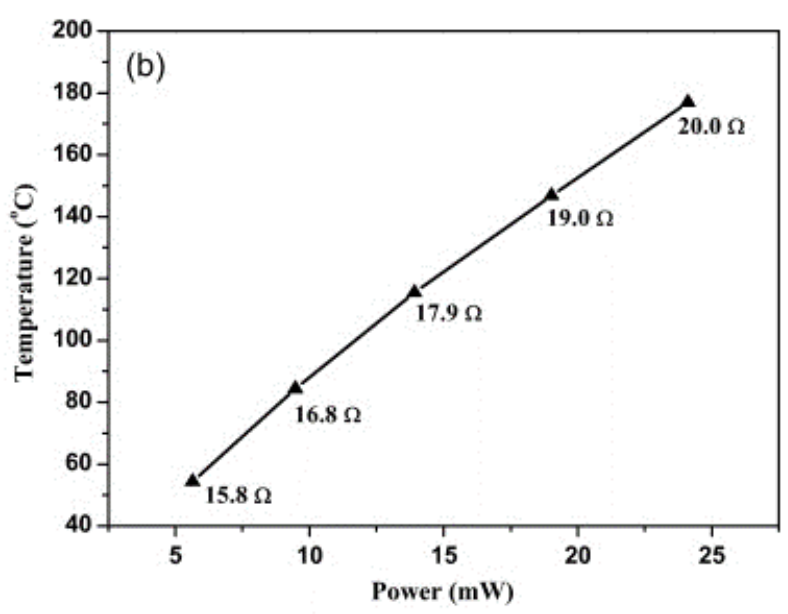

Figure 3.6: The temperature of the single micro heater with changing heater power (Copyright $@ 2010$ Elsevier B.V. All rights reserved).

of an oxide/low-stress nitride/oxide multilayer membrane and the air gap between the substrate and the MHP is $2.8 \mu \mathrm{m}$. The etching windows are $60 \mu \mathrm{m}$ wide and $60 \mu \mathrm{m}$ long. For high temperature stability and low voltage ,Platinum is used as a heater element. The structure of Pt is serpentine and Tin oxide active layer is deposited on top of the heater. The polysilicon sacrificial layer is removed by $25 \% \mathrm{TMAH}$ at $85^{\circ} \mathrm{C}$ for 3 hour 30 minutes. The annealing process took place at a temperature from $700^{\circ} \mathrm{C}$ to $950^{\circ} \mathrm{C}$ for half an hour. The figure 3.7 shows the 100nm Pt and 20nm Ti-tungsten deposition using lift-off and sputtering process [19].

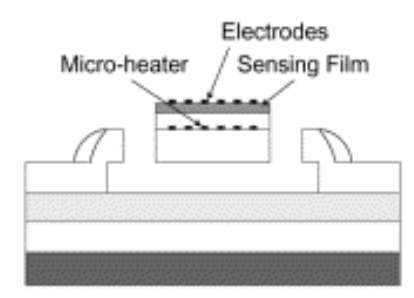

Figure 3.7: Surface Micro-machining of Suspended micro hotplate) [19](Copyright $\odot$ 2007, IEEE).

The thermal reaction of MHP annealing at various temperatures are expressed in Figure 3.8. At $950^{\circ} \mathrm{C}$, the annealing process allows $300^{\circ} \mathrm{C}$ at $23 \mathrm{~mW}$ power consumption. Also at temperatures $900^{\circ} \mathrm{C}, 800^{\circ} \mathrm{C}$ and $700^{\circ} \mathrm{C}$ similar temperature is achieved at 31,36 and $53 \mathrm{~mW}$ 
of power consumption respectively. It is seen from figure 3.8 that micro hotplates which were annealed at $950^{\circ} \mathrm{C}$ were able to reach $300^{\circ} \mathrm{C}$ for power as low as $23 \mathrm{~mW}$.

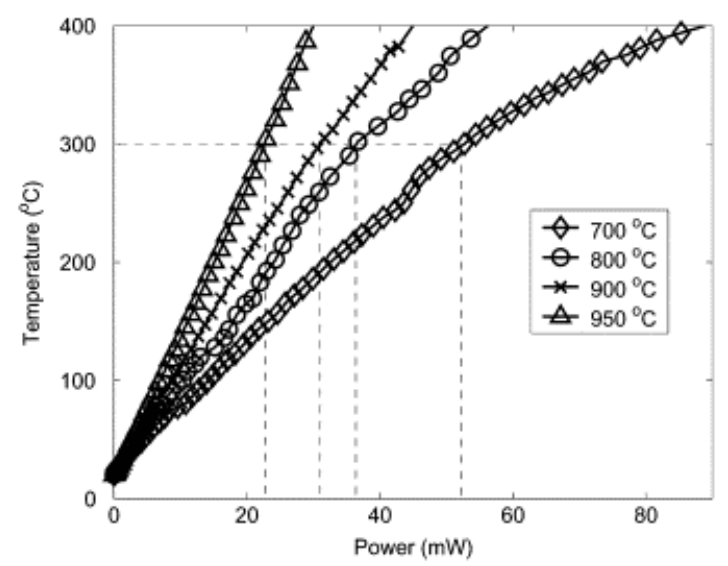

Figure 3.8: Thermal response of MHPs annealing at various temperatures [19](Copyright @ 2007, IEEE).

A micro-hotplate using $\mathrm{BaSnO}_{2}$ sensing layer on a inter-digited platinum electrode was designed by J.C.Belemonte [20]. This was deposited on a $\mathrm{Si}_{2}$ layer to act as an insulator. Platinum, as heater element forms a double spiral, supported by a $S i_{3} N_{4}$ dielectric layer suspended structure. The area of the suspended membrane is $400 \mu m \mathrm{X} 400 \mu \mathrm{m}$, and the size

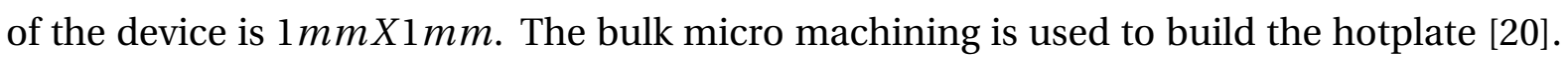
Figure 3.9 shows the fabricated MHP by Belmonte.

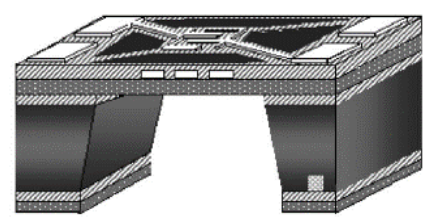

Figure 3.9: Silicon Bulk Micro machining in backside by RIE of Suspended micro hotplate in the front side [20](Copyright $\odot 2005$ Elsevier B.V. All rights reserved).

Thermal simulations conclude that since this device is thermally isolated, it can be easily 
integrated to be a part of an array of multi micromachined devices [20]. The only drawbacks mentioned are concerned with the stability. Either changing the material deposition process or changing the design of the suspended arms, can reduce the stress in the bridge design and avoid breakage of the arms. Figure 3.10 shows low power consumption as the temperature of the heater goes upto $400^{\circ} \mathrm{C}$ with input of $50 \mathrm{~mW}$. The TCR $1.9 E^{-3} \Omega / K$ is also in compliance with the platinum based element [20]. Table 3.2 shows the characteristics of the four designs described next.

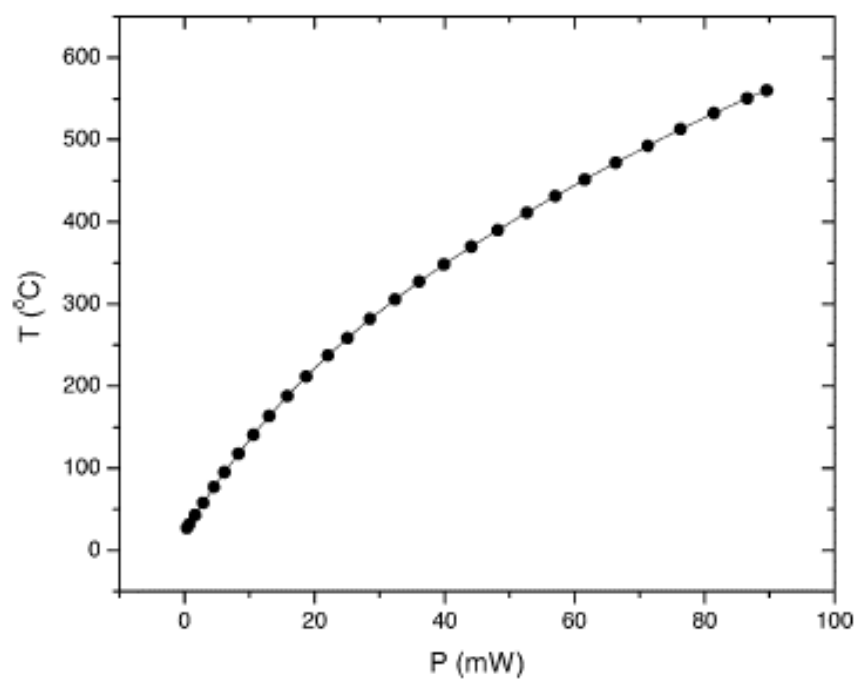

Figure 3.10: The power consumption versus the temperature variation [20](Copyright @ 2005 Elsevier B.V. All rights reserved).

\begin{tabular}{|c|c|c|c|c|}
\hline Reference & {$[21]$} & {$[22]$} & {$[23]$} & {$[24]$} \\
\hline Heater/Hotplate Area $\left(\mu \mathrm{m}^{2}\right)$ & 108900 & 108000 & 14700 & 1600 \\
\hline Power $\left(300^{\circ} \mathrm{C}\right)(\mathrm{mW})$ & 35 & 20 & 15 & $11 @ 200^{\circ} \mathrm{C}$ \\
\hline Power $\left(600^{\circ} \mathrm{C}\right)(\mathrm{mW})$ & & 50 & 34 & 30 \\
\hline Heater element & low stress TiN & Molybdenum & Pt & Tungsten \\
\hline Heater/hotplate shape & Square & Square & Rectangular & Square \\
\hline Etching & Back & Back & Front & Front \\
\hline Arm Width & & & $25 \mu m \times 150 \mu m$ & $30 \mu m \times 15 \mu m$ \\
\hline No.of arms & & & 2 & 4 \\
\hline Type-Technology & MB & M-SOI/CMOS & MB & MB-CMOS \\
\hline Gap $(\mu m)$ & 525 & 525 & & 0.34 \\
\hline MB/M material & Oxide-Nitride & Oxide-Nitride & Oxide-Nitride & PSG-metal-2 \\
\hline
\end{tabular}

Table 3.2: Comparison chart showing different designs fabricated. 
Another device was reported by by J.F Creemer. He fabricated a MHP with TiN (Titanium Nitride) as the heater. TiN has ability to achieve high temperature due to high melting point of $2950^{\circ} \mathrm{C}$. Also it has low electrical resistivity $20 \mu \Omega \mathrm{cm}$. The thermal conductivity of the material is reasonable $15 \mathrm{Wm}^{-1} \mathrm{~K}^{-1}$, which gives low conductive heat losses. The hotplate was fabricated on the (100) plane of Silicon wafer which is $100 \mathrm{~mm}$ wide and $525 \mu \mathrm{m}$ thick. The wet oxide thickness is around $200 \mathrm{~nm}$ and the low stress SiN thickness is $500 \mathrm{~nm}$ deposited by LPCVD (low pressure chemical vapor deposition) at $850^{\circ} \mathrm{C}$. The contact holes to the bond pads are exposed by plasma etching. The windows in the back side are opened in the nitride to create a mask for etching the substrate. The etch is done by solution of potassium hydroxide to suspend the membranes [21]. The figure 3.11 shows the cross sectional view of the hotplate. The TiN was deposited by dc magnetron sputtering. The thickness of the heater is $200 \mathrm{~nm}$.

The heater used three different types of material high stress TiN, low stress TiN and Pt. The

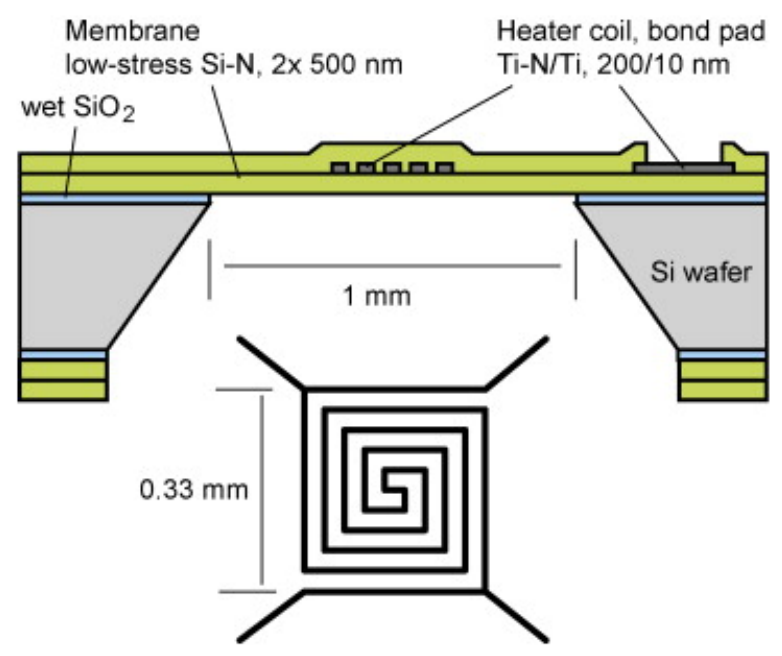

Figure 3.11: The schematic cross sectional view of the hotplate and the top view of the heater geometry [21](Copyright $\odot$ 2005, IEEE).

temperature of the heater is measured by determining the resistance of the heater and the power dissipated. The characteristics are drawn from semiconductor parameter analyser 
measurements. The sheet resistance is calculated by VanderPauw technique. The maximum applied voltage is $14 \mathrm{~V}, 100 \mathrm{~V}$ and $9 \mathrm{~V}$ for high stress TiN, low stress TiN and Pt respectively.

The dissipated power with TiN as heater is $40 \%$ greater than with Pt heater for the same tem-

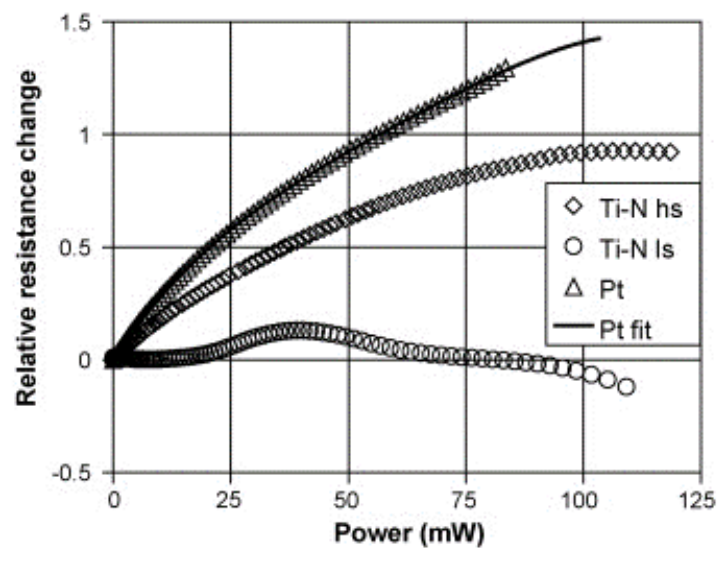

Figure 3.12: Resistance change with respect to Power,for High stress TiN (TiN hs), Low stress TiN(TiN ls) and Platinum(Pt) [21](Copyright @ (2005, IEEE).

perature as seen in figure 3.12 and 3.13. The TCR of TiN high stress is nearly $1.4 \times 10^{-3} /{ }^{\circ} \mathrm{C}$ and the TiN ls has a non linear change, the value of resistance for the low stress TiN decreases instead of increasing at high temperature.

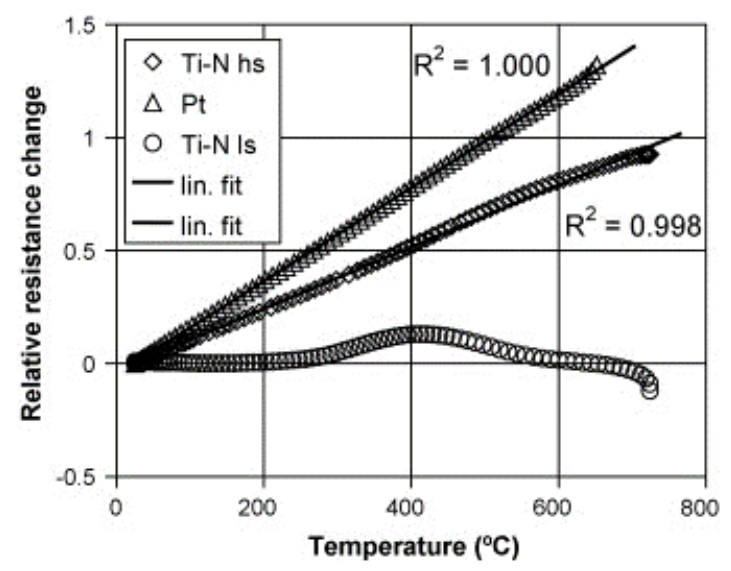

Figure 3.13: Resistance change with respect to temperature, for High stress TiN (TiN hs), Low stress TiN(TiN ls) and Platinum(Pt) [21] ) (Copyright @ 2005 , IEEE).

The paper concludes that the devices with TiN heaters are able to attain higher temperatures than devices with Pt heaters. The TiN heaters emit more light than the Pt heaters due 
to higher emissivity, but as the design is not optimized for uniform temperature distribution, a variation in emission intensity of around $15 \%$ could be expected. The failure of the heater is due to rupture of the SiN membrane because of mechanical stress and reduced strength of the SiN at increased temperatures. The peeling off is due to imbalance in the thermal coefficients of the SiN and TiN.

The hotplate with TiN can withstand temperature upto $700^{\circ} \mathrm{C}$. The TCR seems good for high stress TiN, but high stress levels leads to various problems in the fabrication.

Mele [22] fabricated a microhotplate using molybdenum as a heater metal for high temperature. The material used in the fabrication of micro-hotplate has a great importance for the performance. The Molybdenum material has a high melting point of $2693^{\circ} \mathrm{C}$ and the patterning of this material is simple using techniques like dry or wet etching. There is no requirement of the adhesion layer. Also it is CMOS compatible. A disadvantage of this material is that it easily forms an oxide above $300^{\circ} \mathrm{C}$. To protect it against oxidation, it is protected by a layer of PECVD $\mathrm{SiO}_{2}$. Figure 3.14 shows the device fabricated by Mele.

The micro-hotplate is comprised of $0.35 \mathrm{~mm}$-wide spiral resistor which are released on the membrane of LPCVD SiN having area $1 \mathrm{~mm}$ xlmm. The metal wire thickness is around $0.2 \mu \mathrm{m}$ and the width is $18 \mu \mathrm{m}$ and the gap is $12 \mu \mathrm{m}$. The starting Si wafer has a thickness of $525 \mu \mathrm{m}$. Initially thermal $\mathrm{SiO}_{2}$ is deposited to enhance the adhesion so that low stress LPCVD SiN is firmly deposited. The Molybdenum is deposited by sputtering. It is patterned by wet etching with $25 \% \mathrm{TMAH}$ at room temperature. The $200 \mathrm{~nm}$ of Mo is etched in less than 1min. The wafer is cleaned with IPA( isopropyl alcohol)and acetone with final oxygen plasma treatment at $600 \mathrm{~W}, 0.6 \mathrm{mbar}$ and $250 \mathrm{ml} / \mathrm{min}$ oxygen flow for $1 \mathrm{~min}$ [22]. 


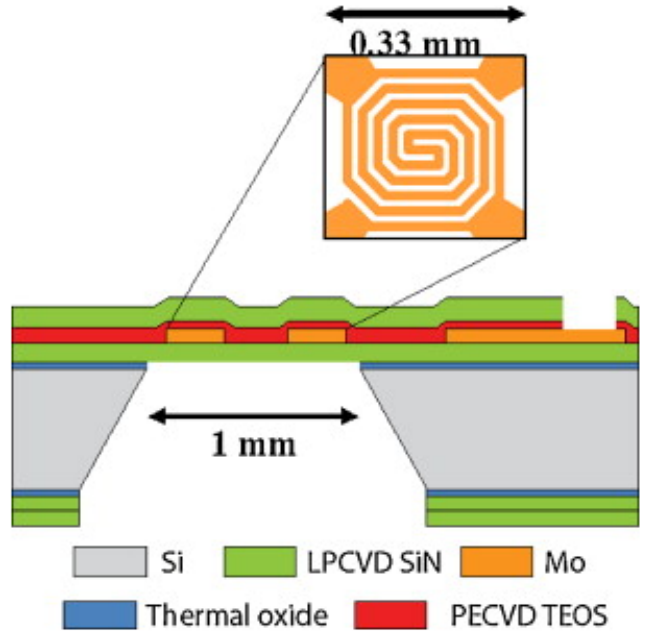

Figure 3.14: (The Schematic Cross Section of the micro-hotplate ) [22] (Copyright @ 2011 Elsevier B.V. All rights reserved).

The layer of Mo was characterised by resistivity and TCR. The value for TCR is calculated from the relative change of resistance with temperature see equation 3.2.

The resistance of Mo is $138 \Omega$ with the standard deviation of $7 \Omega$. The spread in the Mo MHP is due to less uniformity in wet etching as compared with Pt MHP. The change is linear in nature. TCR was measured in air (metrology well) as well as on hot chuck. The values for the TCR are taken at five heating and cooling cycles up to a maximum temperature of $700^{\circ} \mathrm{C}$, no change in TCR was observed after all these cycles. As the equipment can operate to $700^{\circ}$ the assumption is made that the value for TCR is unchanged at higher temperatures. 


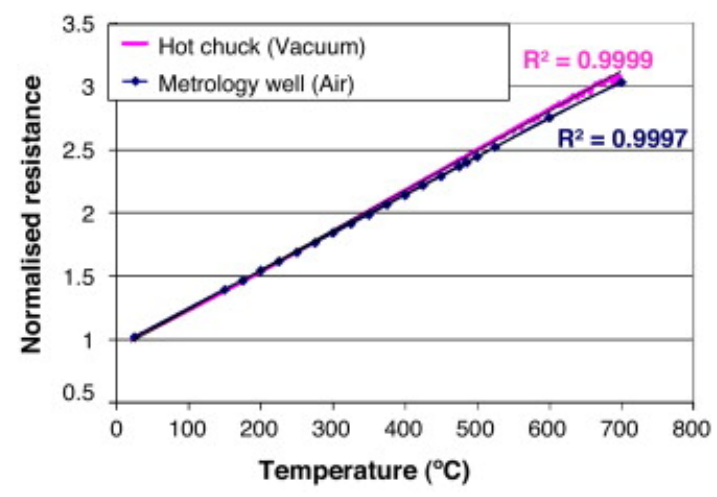

Figure 3.15: Resistance versus temperature for Molybdenum micro-hotplate [22] (Copyright $\odot 2011$ Elsevier B.V. All rights reserved).

The value of change in resistance is measured after the device is protected by a coating of PECVD $\mathrm{SiO}_{2}$ and LPCVD SiN. The normalised resistance versus temperature curve in figure 3.15 shows that the relationship is linear from $20^{\circ} \mathrm{C}$ to $700^{\circ} \mathrm{C}$ [22].

As can be seen from figure 3.16, the power consumption is dependent on the area of the heater and the membrane area. So In this heater area is $108 \times 10^{-3} \mu m^{2}$. At temperature $300^{\circ} \mathrm{C}$ the power consumption is $0.21 \mathrm{~mW} / 1000 \mu \mathrm{m}^{2}$, which is comparable with the values in literature which can be seen in table 3.1,3.2 and 3.5. Some parameters were tested as

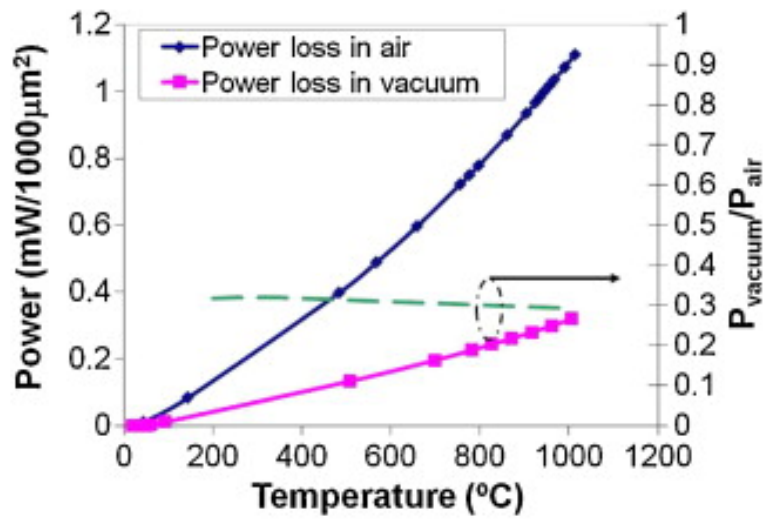

Figure 3.16: Power consumption versus operating temperature for Molybdenum micro-hotplate with heater area $108 \times 10^{-3} \mu m^{2}$ [22](Copyright $\odot 2011$ Elsevier B.V. All rights reserved).

shown in table 3.3 as sample 1 Platinum at $850^{\circ} \mathrm{C}$, sample 2 Molybdenum at $850^{\circ} \mathrm{C}$, sample 3 Molybdenum at $1100^{\circ} \mathrm{C}$. 


\begin{tabular}{|c|c|c|c|}
\hline Sample & sample 1 & sample 2 & sample 3 \\
\hline Maximum operating temperature ${ }^{\circ} \mathrm{C}$ & 650 & 850 & 900 \\
\hline Failure temperature ${ }^{\circ} \mathrm{C}$ & 700 & 1250 & 1250 \\
\hline Resistance drift for $24 \mathrm{hr}$ at $600^{\circ} \mathrm{C}$ & 3 & 0 & 0 \\
\hline Resistance drift for $24 \mathrm{hr}$ at $1000^{\circ} \mathrm{C}$ & - & 8.5 & 5.8 \\
\hline
\end{tabular}

Table 3.3: Brief description of the properties of the tested MHP the data on the maximum operating temperature refers to measurement of 5 different devices on the wafer while data on the resistance drift refer to measurement on 2 different devices [22] (Copyright () 2011 Elsevier B.V. All rights reserved.).

The suspended membrane type micro-hotplate was fabricated by Lei, with high heating efficiency for catalytic gas sensor. The suspended structure allows better thermal isolation. The sensor consists of a micro-hotplate with a Pt heater element, coated with a catalytic surface layer. And the concentration of the gas can be measured by the change in the resistor value. Figure 3.17 shows the 3D model of device fabricated by Lei.

The device consists of a $70 \mu m \times 210 \mu m$ rectangular MHP with platinum Pt as a heater

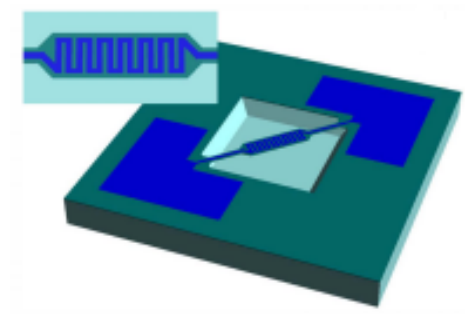

Figure 3.17: The 3D Model of micro-hotplate (Copyright @ 2012, IEEE) .

resistor supported by two $25 \mu \mathrm{m} \times 150 \mu \mathrm{m}$ beams. The silicon pit beneath the structure is created by wet chemical anisotropic etching to thermally isolate the heater.

The fabrication is done on double side polished $\mathrm{N}$ type $<100>\mathrm{Si}$ Wafer with $\mathrm{SiO}_{2} 200 \mathrm{~nm}$ thermally grown at $1100^{\circ} \mathrm{C}$. Then a layer of $\operatorname{Si} N_{x}$ was deposited on each side by LPCVD at $800^{\circ} \mathrm{C}$. The Pt/Ti electrodes are patterned by lift-off process. Then the final $\mathrm{SiO}_{2} / \mathrm{Si} N_{x}$ is selectively etched by RIE to open the front etch windows and the membrane is released in a solution of TMAH at $80^{\circ} \mathrm{C}$. The electro thermal characteristics is evaluated by applying the stable voltages. The MHP is heated upto $400^{\circ} \mathrm{C}$ with low power consumption of $18 \mathrm{~mW}$ 
[23]. Figure 3.18 shows the Power versus Temperature for this MHP. The temperature can be calculated by:

$$
T=\left(R-R_{0}\right) /\left(\alpha\left(R_{0}\right)\right)+25
$$

Where: $R_{0}$ is original resistance, $T$ is the temperature in ${ }^{\circ} C$ and $\alpha$ is the TCR of Pt.

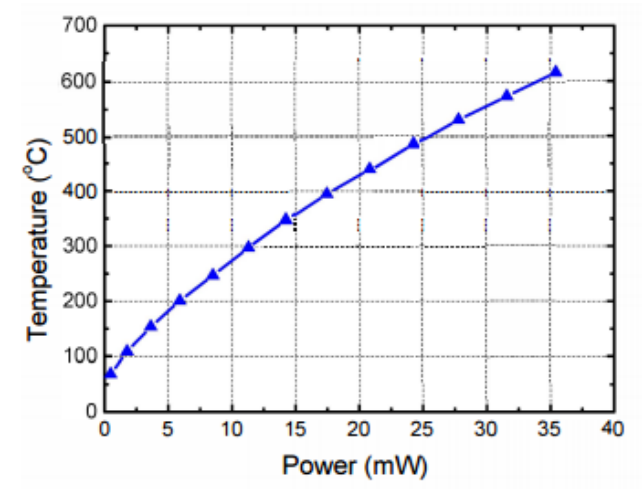

Figure 3.18: The temperature versus power of the micro-hotplate [23](Copyright $\odot 2012$, IEEE).

\begin{tabular}{|c|c|c|c|c|}
\hline micro-hotplate & shape & Active area $\left(\mu m^{2}\right)$ & Power $400^{\circ} \mathrm{C}$ & $\mathrm{PPAA}\left(\mathrm{mW} / \mu m^{2}\right)$ \\
\hline Rectangular with 2 beams & Fig 3.19 & 17070 & $18 \mathrm{~mW}$ & $1.05 \times 10^{-3}$ \\
\hline Square with 4 beams & Fig 3.20 & 2500 & $9 \mathrm{~mW}$ & $3.60 \times 10^{-3}$ \\
\hline Circular with 4 beams & Fig 3.21 & 4780 & $14 \mathrm{~mW}$ & $2.93 \times 10^{-3}$ \\
\hline Square with 4 beams & Fig 3.22 & 10000 & $12 \mathrm{~mW}$ & $1.20 \times 10^{-3}$ \\
\hline
\end{tabular}

Table 3.4: Comparison between the two beam micro-hotplate and another three micro-hotplate with different structures .

The table 3.4 shows the comparison between the two beam micro-hotplate and three different micro-hotplate structures with four beams. The active area of the two beam is larger than any other three micro-hotplates, which means it requires more power to reach the same temperature. The PPAA (power per active area ) is $30 \%$ in contrast with the existing microhotplates, which reflects that the two beam micro-hotplate has greater efficiency. Figure 3.19 different structures of micro-hotplate as reported by Lei. 


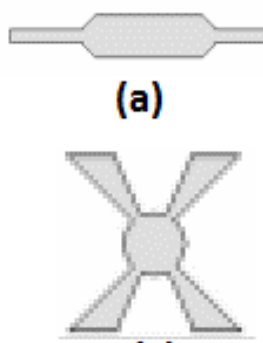

(c)

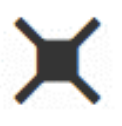

(b)

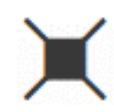

(d)

Figure 3.19: Micro-hotplate : rectangular with two beam structure) [23](Copyright @ 2012, IEEE).

Wang has fabricated a micro-hotplate based on tungsten for pressure sensing application using standard CMOS process. Tungsten has high melting point and it is resistant to electro migration. It also acts as an barrier to prevent diffusion and the reaction between the metal and the silicon. The tungsten is used as a heater element in the form as serpentine resistor. The anchor of the resistor is connected to metal 2 leaving metal 1. A poly 2 is used as sacrificial layer underneath the tungsten. The MHP is realized in $0.5 \mu \mathrm{m}$ CMOS process which has two poly silicon layers and three metal layers. The etching of windows and bond pads are done at the same time and the poly 2 is revealed. The Poly 2 is etched away to suspend the Tungsten MHP, through TMAH etching for 8 hours. The hotplate with area $40 \mu m \mathrm{X} 40 \mu m$ is released by four arms with length $30 \mu m$ and width $15 \mu m$. The gap between the substrate and the MHP is $0.34 \mu \mathrm{m}$ [24]. Figure 3.20 shows the cross sectional view of this MHP.

The sheet resistance of the tungsten is approximately $0.15 \Omega / \square$ for tungsten via plug having $\mathrm{L} / \mathrm{W}$ as $1 \mu \mathrm{m} / 0.5 \mu \mathrm{m}$ with resistance $0.3 \Omega$. The smaller the resistor, the smaller is the sheet resistance is . This is due to fact that tungsten is complexed as comprised of tungsten, titanium and titanium nitride that can affect the sheet resistance. The width change of the resistor could be the cause. The resistor has been enclosed in the IC package and then it is exposed to temperature starting from $35^{\circ} \mathrm{C}$ to $150^{\circ} \mathrm{C}$. The TCR of tungsten is $1.5 \times 10^{-3} /{ }^{\circ} \mathrm{C}$. 


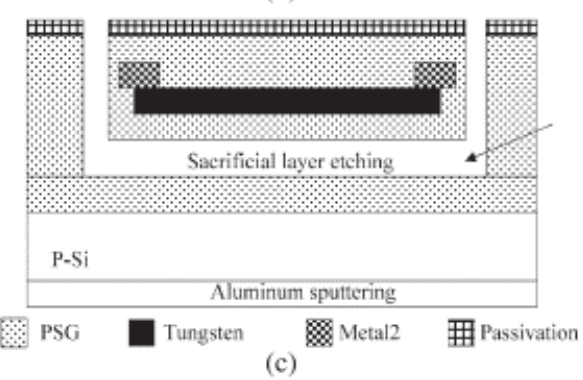

Figure 3.20: The schematic cross sectional view of the suspended Tungsten micro-hotplate [24](Copyright (C) 2009, IEEE).

The temperature is calculated from the measured resistance with the temperature coeffi-

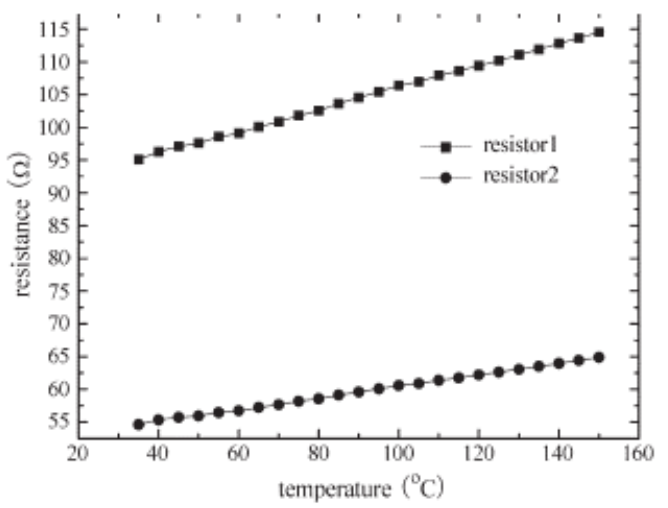

Figure 3.21: The Temperature coefficient of the Tungsten Resistors [24](Copyright $@$ 2009, IEEE).

cient of the resistance. Figure 3.21 shows the Temperature versus Resistance relation for this micro-hotplate. The power can be deduced from the voltage and the current measured. The thermal impedance (shown in figure 3.22) of the tungsten MHP is nearly $17^{\circ} \mathrm{C} / \mathrm{mW}$. Because in standard CMOS process, tungsten has a property of high temperature coefficient, so various sensing based products can be advanced with it. 


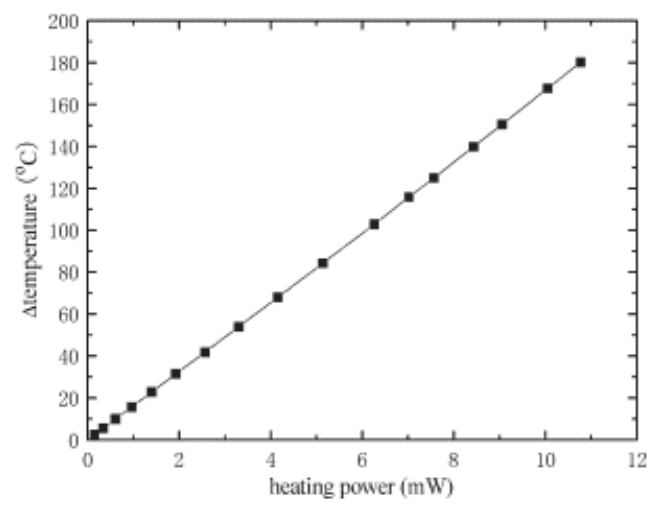

Figure 3.22: The slope of thermal impedance of the Tungsten Resistors [24] (Copyright @ 2009, IEEE).

\begin{tabular}{|c|c|c|}
\hline Reference & {$[3]$} & {$[25]$} \\
\hline Year & 2011 & 2006 \\
\hline Heater/Hotplate Area $\left(\mu m^{2}\right)$ & 17671 & 20106 \\
\hline Power $(\mathrm{mW})\left(300^{\circ} \mathrm{C}\right)$ & 10 & 8 \\
\hline Power $(\mathrm{mW})\left(600^{\circ} \mathrm{C}\right)$ & 30 & \\
\hline Heater element & $\mathrm{Pt}$ & $\mathrm{Pt}$ \\
\hline Heater/hotplate Shape & Circular & Circular \\
\hline Etching & Front & Front \\
\hline Arm Width & $30 \mu m$ x150 $\mu m$ & \\
\hline No.of arms & 2 & \\
\hline Type-Technology & MB & MB \\
\hline Gap $(\mu m)$ & & \\
\hline MB/M material & Oxide-Nitride & Oxide-Nitride \\
\hline
\end{tabular}

Table 3.5: Comparison chart showing different designs fabricated.

P. Barritault reported novel IR source based on free standing micro-hotplate which operates at $650^{\circ} \mathrm{C}$. The main idea for developing the source is to provide a broad IR wavelength range to test and calibrate state of the art room temperature IR detectors while maintaining source power consumption lower than $50 \mathrm{~mW}$.

The device is designed to minimize the thermal mass and to low the power consumption. The membrane is based on two $100 \mathrm{~nm}$ thick $\mathrm{Si}_{3} N_{4}$ layers,embedding the metallic resistor. A $\mathrm{Si}_{3} \mathrm{~N}_{4}$ is deposited on 200nm Si wafer through LPCVD, then a TiN(10nm)/ Pt(30nm/TiN(10nm) metal stack was deposited. The material Pt is used due to its mechanical, electrical and 
chemical stability at high temperatures. The TiN layers act as barriers for providing extra mechanical and electrical robustness. The resistor is encapsulated in $100 \mathrm{~nm} \mathrm{Si} O_{2}$ deposited at $400^{\circ} \mathrm{C}$. The whole device is annealed at $800^{\circ} \mathrm{C}$ for 1 hour. The free standing hotplate geometry is achieved by the front side TMAH wet etching. The etching discloses the $<111>$ plane of $<100>$ Si wafer. The arms of the membrane are at an angle to ensure the etching of Si beneath the membrane [3]. Figure 3.23 shows the process flow as reported by Barritault. The TCR of resistor is measured by the equation 3.2. Where : $R_{0}$ is resistance at $T_{0}=25^{\circ} \mathrm{C}$

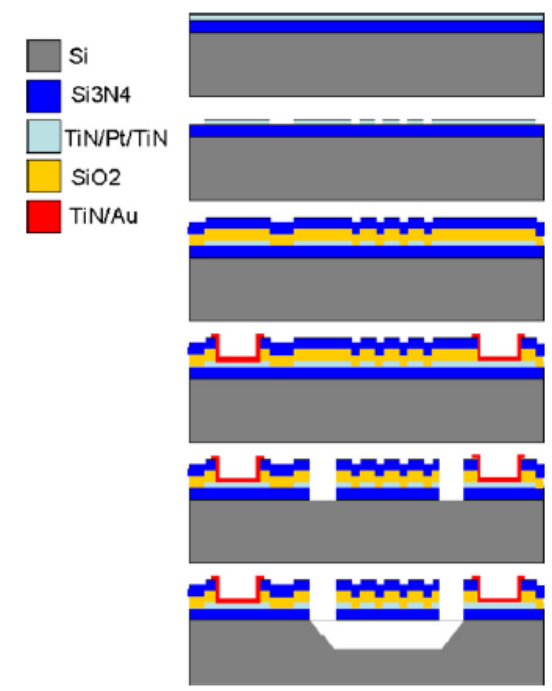

Figure 3.23: The process flow for micro-hotplate fabrication (Copyright $\odot 2011$ Elsevier B.V. All rights reserved).

and $\alpha$ is the TCR.

The TCR value is lower than value reported in the literature. Assuming $\alpha$ is constant with temperature when the micro heater is self heated by a current, the temperature can be calculated by measuring the resistance. Figure 3.24 shows the relationship of resistance versus Sourced current and temperature versus power of the MHP

The fabrication and characterization of the device working at $650^{\circ} \mathrm{C}$ to be used for carbon dioxide detection is reported. To minimize the thermal mass and to reduce the power con- 

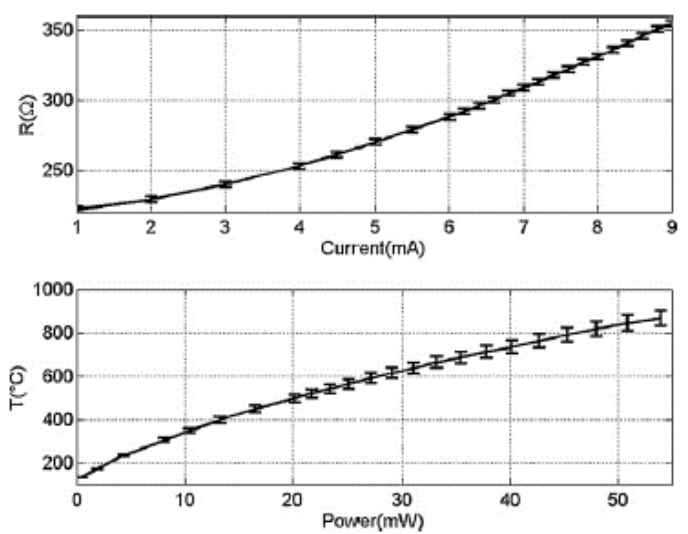

Figure 3.24: (a)Resistance of the hotplate versus Sourced current.(b) temperature of the hotplate versus power [3](Copyright ( 2011 Elsevier B.V. All rights reserved).

sumption, fabrication is done on a free standing membrane. The design of the heater is developed to keep the temperature variation below $5 \%$, which is achieved by filling the space between the resistor and the metallic spacer fabricated with the similar metal stack as used for the resistor.

An ULP (ultra low power) hotplate was fabricated by Elmi in with the front side bulk micro machining technique. The main criteria behind the concept is the fabrication of ULP hotplate best suited for metal oxide sensor design and efficient operation with low power consumption of $10 \mathrm{~mW}$ at high temperature. The hotplates used Pt heater material,as it has high thermal resistivity and low electrical resistivity. The suspended dielectric structure released by the front side bulk micro machining. The heater is circular in shape which allows to get a uniformly distributed good temperature refraining the use of huge silicon or aluminium temperature expanding structures. Different layouts with number, length and shape of arms which supports the hotplate geometry are studied and simulations are conducted to determine the effect on temperature distribution of the layout geometries [25]. Figure 3.25 shows these layout geometries and table 3.6 shows the types of contact and number of arms for these geometries. 

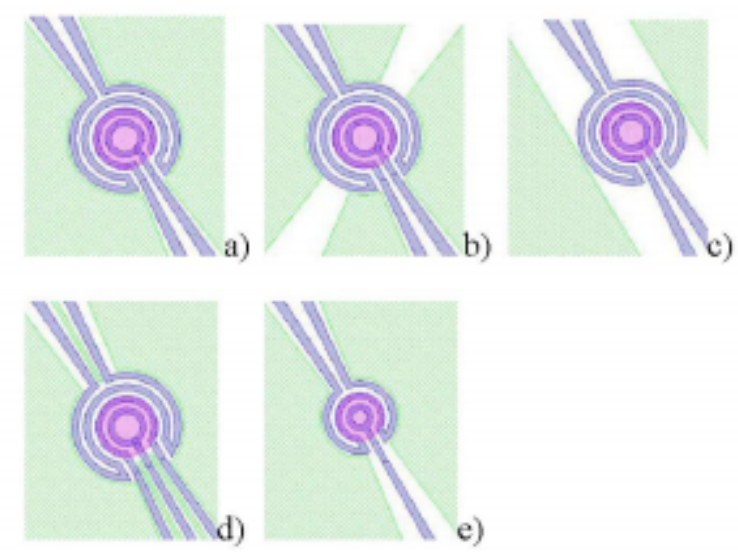

Figure 3.25: Hotplates with various heaters, contacts and suspended arms [25](Copyright $\odot ~ 2006$, IEEE).

\begin{tabular}{|l|c|c|c|}
\hline & shape & contacts & arms \\
\hline a) & Circular & Normal electrode & Minimal arms \\
\hline b) & Circular & Normal electrode & extended arms \\
\hline c) & Circular & Normal electrode & Bridge arms \\
\hline d) & Circular & self insulated electrode & Minimal arms \\
\hline e) & Circular & single electrode & Minimal arms \\
\hline
\end{tabular}

Table 3.6: Different heater,contacts and suspended arms layout shown in fig 3.25 [25] Copyright $\odot$ 2006, IEEE.

The process of fabrication begins with the deposition of structural stack $\left(\mathrm{SiO}_{2} / \mathrm{Si}_{3} \mathrm{~N}_{4} /\right.$ $\mathrm{SiO}_{2}$ ) on a single side polished Silicon wafer. Then after RIE (reactive ion etching) of the deposited stack, platinum deposit and lift-off patterning is done. For the adhesion of Pt, the deposition of very fine layer of $\mathrm{TiN}$ is inserted. The $\mathrm{SiO}_{2}$ passivation layer is stacked over the heater for insulation. The Silicon underneath the hotplate is selectively removed by TMAH (Tetra Methyl Ammonium hydroxide) etching. The fabrication process is shown in the figure 3.26 . 


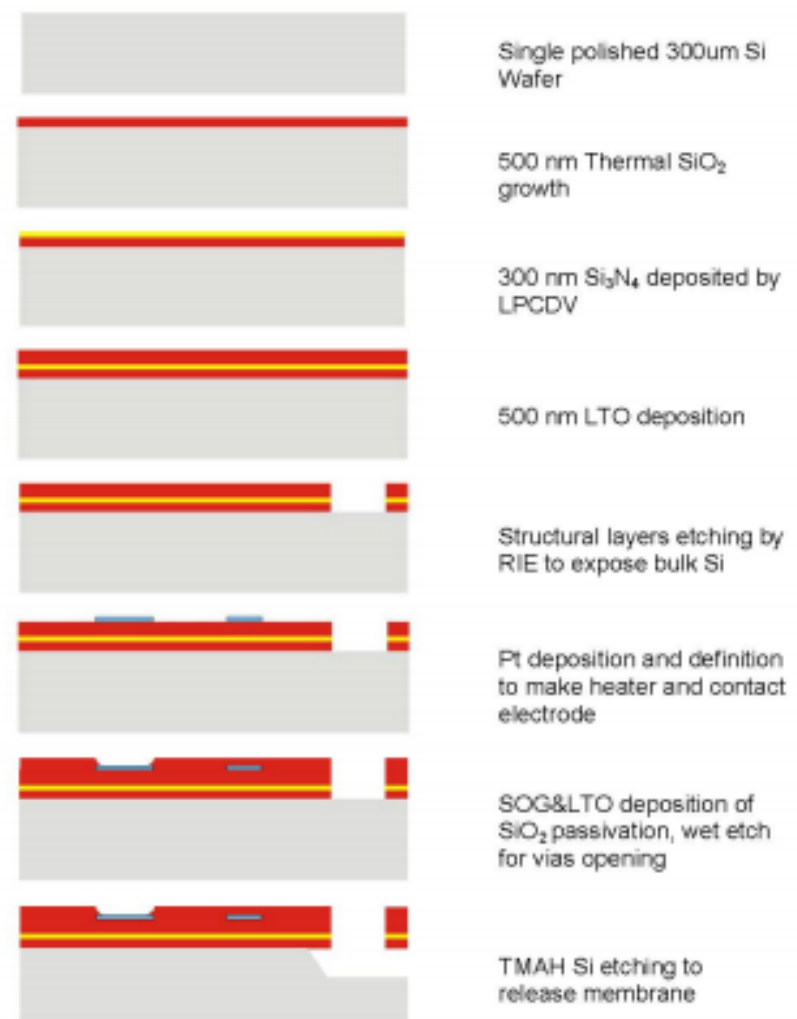

Figure 3.26: Fabrication process flow for hotplate) [25](Copyright $@ 2006$, IEEE).

The thermal characterization of the hotplate was done. Firstly the TCR value of Pt is measured using four point testing. The resistance is measured at various temperatures $50,100,150$ and $200^{\circ} \mathrm{C}$. The results are presented for two different wafers U10 and W4 are $0.0032361 K^{-1}$ and $0.0031768 K^{-1}$. Also, the temperature versus power is calculated and plotted with the various combination of the structure parameters. The figure 3.27 and 3.28 shows the power versus temperature characteristics for different shapes. This shows that devices with smaller metallization width and larger pits have low power consumption and the wider the pit dimensions the less is power consumption. The pit $400 \mu m$ needs only 8.9 $\mathrm{mW}$ power to attain operating temperature of $400^{\circ} \mathrm{C}$.

The thermal constant is also evaluated by applying a small amount of current $(0.3 \mathrm{~mA})$, to trace the decay of heater resistance and a very brief thermal time constant of $1.5 \mathrm{~ms}$ is seen. The results confirms the design selection in terms of layout and technical aspect. 


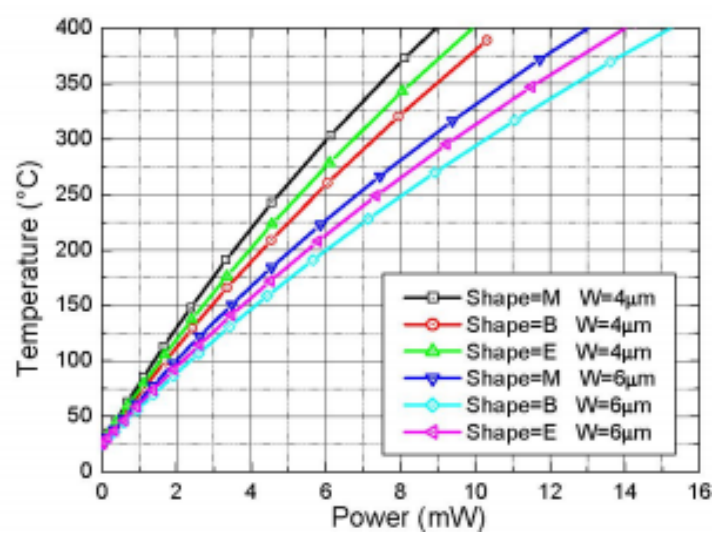

Figure 3.27: Hotplate temperature versus Power applied for various shapes and metallization width 'W': No passivation and Pit $=400 \mu \mathrm{m}$ ) [25] (Copyright @ 2006, IEEE).

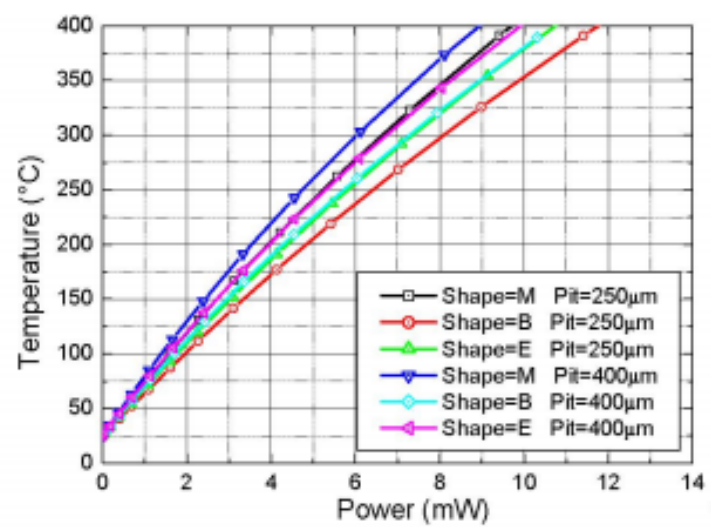

Figure 3.28: Hotplate temperature versus Power applied for various shapes and pit width: No passivation and Pit $=4 \mu m)$ [25] (Copyright $\odot$ 2006, IEEE).

The papers are published in literature to realised different power consumption with different micro-hotplate design. Some of them caught our attention, especially those with very low power density [3, 23, 24]. Elmi [25], showed a fivefold improvement in power efficiency by increasing the pit height to $400 \mu \mathrm{m}$ using front-side bulk micro machining. The comparison of all the designs gives an idea about the layout, geometry for the heater and the material for the heater. The material properties reflects the key features for the better performance of the micro hotplate. Therefore, it is very important to come up with new design for a sensing application, with low power consumption, low manufacturing cost, sensor density and high sensitivity and selectivity. 
We came up with new design of micro-hot plate, utilizing nichrome as heater material with the conventional design with different number of arms. Our focus is to come up with different design of micro hotplate which consumes much less power and have low fabrication cost than previously reported structure. 


\section{Chapter 4}

\section{Design}

\subsection{Purpose}

A goal of this thesis is to come up with a new design of a micro-hotplate for a gas sensing application which consumes low power and makes efficient use of area. The micro-hotplate should be designed such that it gives a uniform temperature distribution to sensing layer and requires a minimum input power to achieve an operating temperature of $400^{\circ} \mathrm{C}$.

\subsection{Design considerations}

\subsubsection{Heater Element material}

Gas sensing applications require sensors that operate at high temperature. Heater design is important to the efficiency, temperature uniformity and overall device performance. Figure 4.1 shows several possible heater layouts. To achieve the desired temperature distribution, heater geometry and materials have to be selected carefully. Use of high thermal conductivity film can provide uniform temperature distribution over the heater surface. To achieve a 


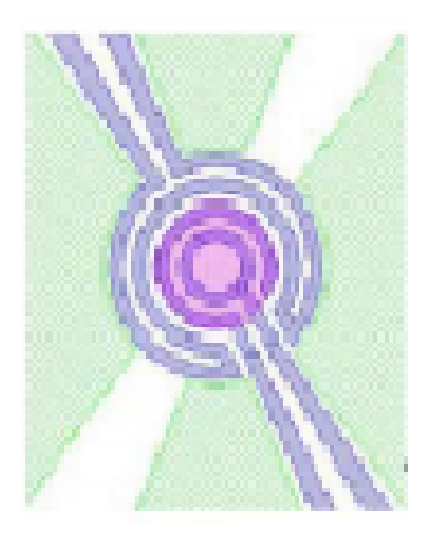

a

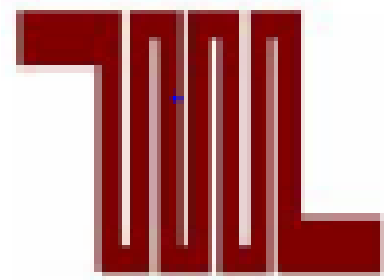

b

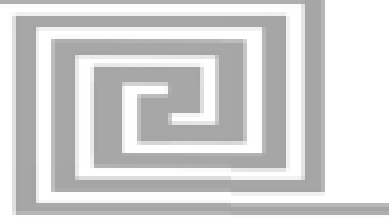

C

Figure 4.1: Different heater layouts- a: Circular shaped b: Meander shaped c:Spiral shaped

desired temperature with minimum power input:

- surface area should be small,

- hotplate supports should be thin to minimize thermal conduction losses,

- materials should be chosen with low thermal conductivity.

Materials like polysilicon, platinum, titanium nitride and molybdenum have been used in published examples. Platinum has high thermal and electrical resistivity and polysilicon stability is very poor at high temperature. Molybdenum has high melting point and it can be patterned by dry or wet etching but it oxidises above $300^{\circ} \mathrm{C}$. Also, TiN can withstand high temperature due to high melting point but the stress levels create problems during fabrication. Nichrome which is an alloy of nickel and chromium has often been used for heater elements in micro-hotplates due to its high resistivity, low thermal conductivity, and high melting point of $1400^{\circ} \mathrm{C}$ [26]. In this design, a meander shape heater element made up of Nickel-chromium $(80 / 20)$ is fabricated with thickness $50 \mathrm{~nm}$ and an effective surface area of $80 \mu \mathrm{m} \times 80 \mu \mathrm{m}$. A layer of $\mathrm{Si}_{3} N_{4}$ is deposited over the $\mathrm{NiCr}$ to provide electrical insulation and 
to protect the heater from environmental conditions.

\subsubsection{Heater geometry}

The heat loss from the micro-hotplate originates from conduction through the membrane or support arms, convection to the air and radiation. The convection loss is directly dependent on the heater area and the loss in radiation is insignificant at typical operating temperature [27]. It is essential to have thin support arms to achieve low power consumption [28] however the arms must be capable of providing robust mechanical support.

For the geometry of the heater, various designs have been reviewed in the literature and were considered for design of the micro-hotplate for this project. The design with two supporting arms shown in figure 3.19(a) has high efficiency [23] due to a small number of arms. The meander structure with two and four arms is also considered for achieving a uniform temperature distribution. The parallel meander heater geometry which results in uniform heat distribution [29] is also being used to design the heater for this work. There are total 22 designs with different heater geometries. The geometries being used are shown in Figure 4.1.

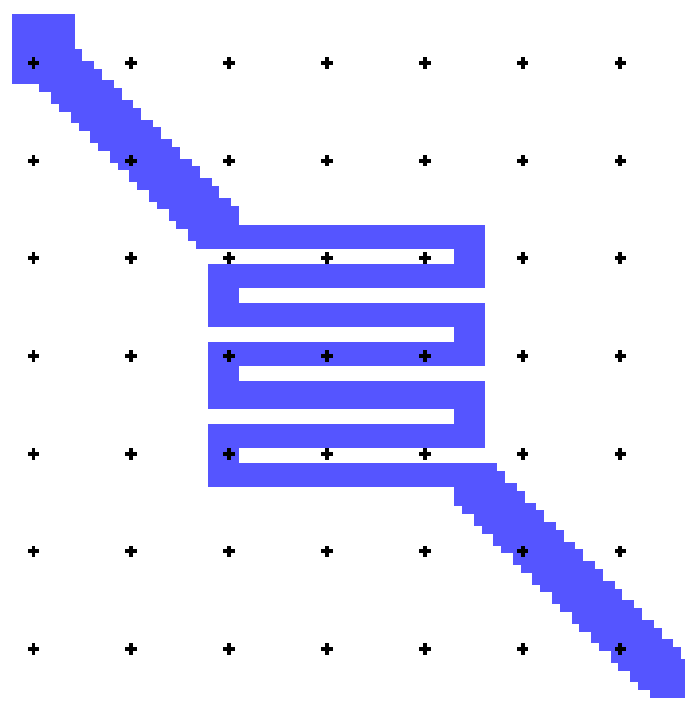

Figure 4.2: Schematic of Nichrome heater in L-Edit software . 


\subsubsection{Heatloss from the heater}

During the application of the electric current to the heating resistor, the electrical energy changes into thermal energy in the active area of the heater and heat transfer takes place. There is a conductive heat loss through the supporting arms/beams, convective heat loss to the surrounding air as well as to the substrate below the suspended heater. For better heating efficiency the heater should be well isolated. Here for heatloss calculation, only conductive loss is considered assuming that the device does not lose any heat to surrounding air.

According to Wein displacement law, the wavelength of thermal radiation emitted by the black body is inversely proportional to absolute temperature of the black body. The equation is

$$
\lambda=\frac{2900 \mu m / K}{\Delta T}
$$

Where : $2900 \mu \mathrm{m} / \mathrm{K}$ is the Wein displacement constant.

For peak emission suitable for detecting $\mathrm{CO}_{2}$ with wavelength $(\lambda=4.2 \mu \mathrm{m})$, a MHP is required to operate at $690 \mathrm{~K}$ or $417^{\circ} \mathrm{C}$. To calculate the power needed to maintain a temperature of $417^{\circ} \mathrm{C}$, equation

$$
\Delta T=P \cdot R_{T H}
$$

Where:

$\Delta T$ is the change in temperature

$\mathrm{P}$ is the required input power to maintain this temperature and

$R_{T H}$ is the thermal resistance of the arms.

The arm dimensions had to be designed such that the MHP would maintain the desired temperature. 


\section{Arm Dimension}

One of the major sources of heat loss is conduction through the arms. The heat loss is directly related to the thermal resistance of the support arms. A larger number of arms results in more heat loss by conduction. The thermal resistance of the arms was calculated using equation 4.2 ,

$$
R_{T H}=\frac{1}{K} \cdot \frac{l}{w \cdot t}
$$

Where:

$R_{T H}$ is the thermal resistance of the arms, $K$ is the thermal conductivity, $l$ is the length of the arms, $w$ is the the width of the arm and $t$ is the thickness of the layer.

The arms consisted of an oxide layer with nichrome and nitride on top of it. So the total thermal resistance of each arm was the parallel combination of the individual thermal resistance of oxide, nichrome and nitride. Figure 4.3 shows a cross section through a support arm.

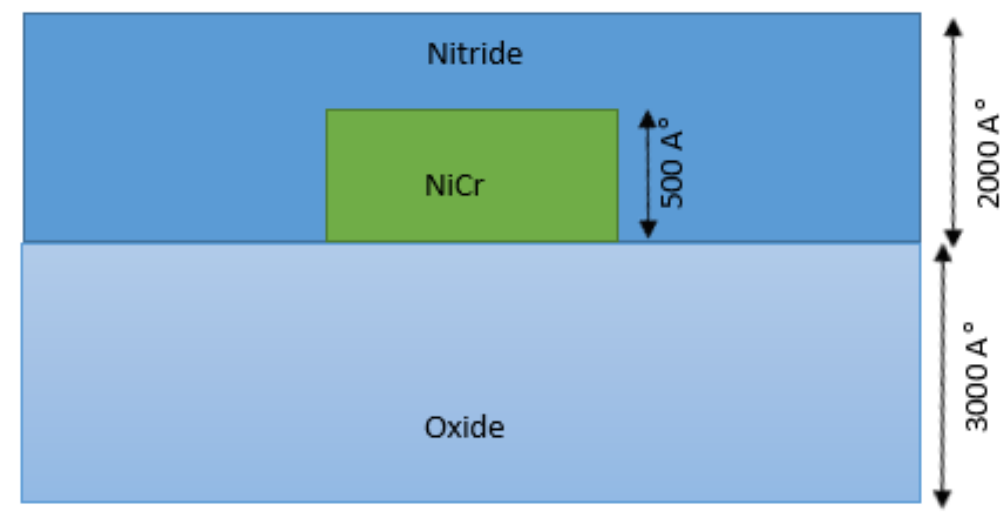

Figure 4.3: Cross section showing Parallel layers. 
The operating power goal for the MHP was to be around $7 \mathrm{~mW}$. The $\Delta T$ was $390^{\circ} \mathrm{C}\left(417^{\circ} \mathrm{C}\right.$ - $27^{\circ} C$ ). By using equation 4.1, the value of $R_{T H}$ required to meet this goal was calculated as $55714 \mathrm{~K} / \mathrm{W}$. As seen in equation 4.2, the length, width and thickness of the plate had to be such that the equivalent thermal resistance of the total arms was around $55714 \mathrm{~K} / \mathrm{W}$. The arms were designed according to this criteria. Figure 4.4 shows the dimensions for design 9 below.

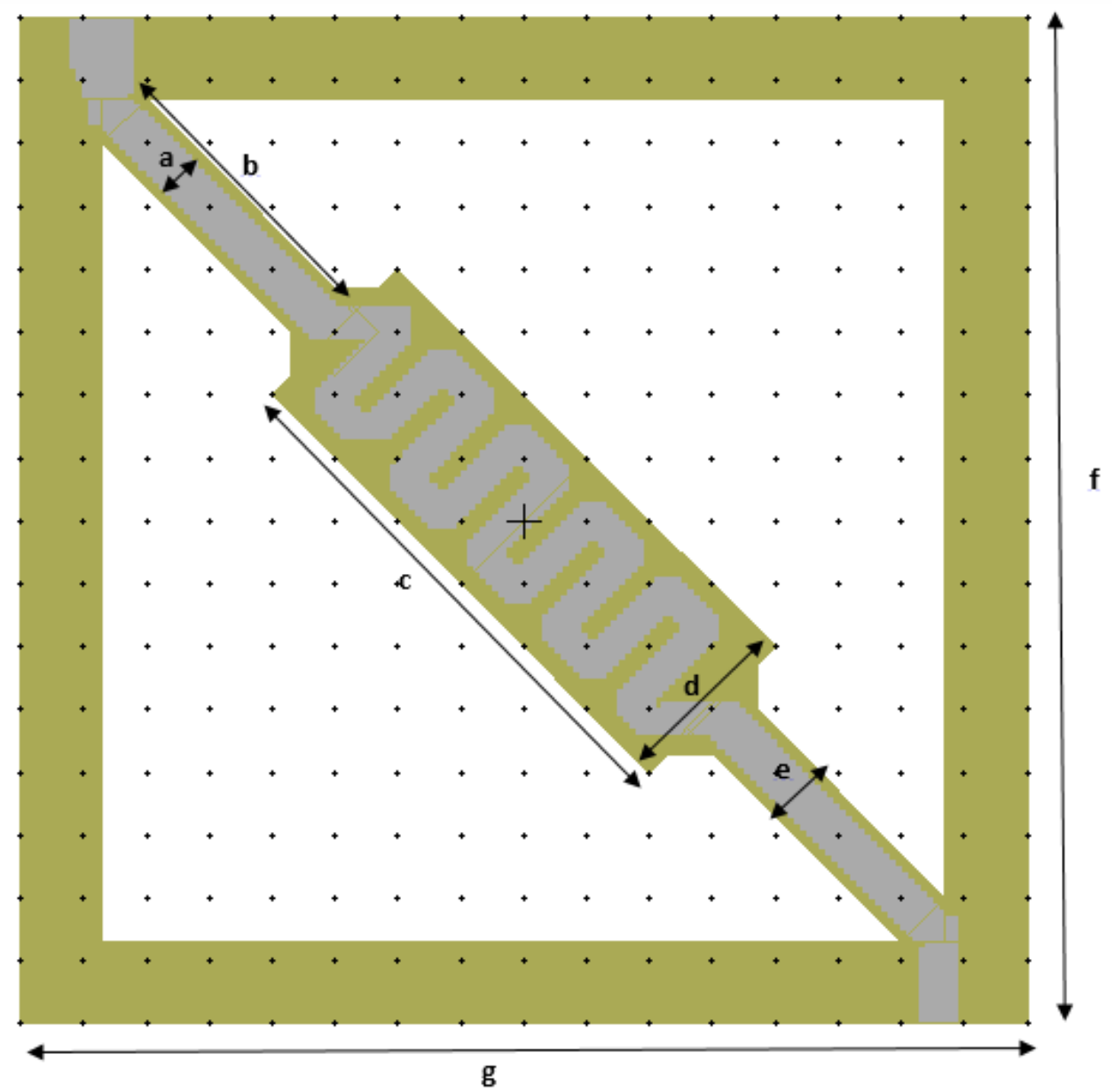

Figure 4.4: Layout of Device (Design 9): a $17.85 \mu m$, b $142.85 \mu m$, c $210.71 \mu m$, d 71.43 $\mu m$, e $25.00 \mu m$, f $400.00 \mu m$ and $\mathrm{g} 400.00 \mu \mathrm{m}$. 
Table 4.1 shows the material used for the MHP and the characteristics that were used to calculate the thermal resistance and heat loss.

The thickness of the support arms presents a design trade-off, as thin arms results in less ro-

\begin{tabular}{|c|c|c|c|}
\hline & $\mathrm{SiO}_{2}$ & $\mathrm{NiCr}$ & $\mathrm{Si}_{3} N_{4}$ \\
\hline Thermal Conductivity $(\mathrm{W} / \mathrm{m} . \mathrm{K})$ & 1.5 & 17 & 43 \\
\hline Thermal Expansion Coefficient $\left(\mathrm{K}^{-1}\right)$ & $0.75 * 10^{-6}$ & $16 * 10^{-6}$ & $3.7 * 10^{-6}$ \\
\hline Specific Heat $(\mathrm{J} / \mathrm{Kg} \mathrm{K})$ & 730 & 500 & 1100 \\
\hline Electrical Conductivity $\left(10^{-8} \Omega \cdot m\right)$ & $1 E+027$ & 240 & $1.0 e+21$ \\
\hline Young's Modulus $(\mathrm{GPa})$ & 74.8 & 245 & 297 \\
\hline Poisson's Ratio $(\mathrm{S} / \mu \mathrm{m})$ & 0.19 & 0.325 & 0.28 \\
\hline Density $\left(\mathrm{Mg} m^{3}\right)$ & 2.65 & 8.65 & 3.25 \\
\hline
\end{tabular}

Table 4.1: Material Properties of the layers for micro-hotplate structure.

bust structure but also lower conductive heat loss. In this work heater designs with two,three and four arms were fabricated. Various designs were studied and reviewed using the four beam or two beam supporting arms for their design. 


\section{Chapter 5}

\section{Device Fabrication}

Once the device was designed, the next step was to decide on the fabrication process. The device was to be processed within the Carleton University Microfabrication Facility. Nichrome, which was used as the heater element, was not a regular metal being deposited at this facility, so some research and trials were conducted before the actual deposition. Since it was not a standard process in the lab, an appropriate etchant had to be identified for Nichrome. Furthermore, silicon nitride was used as a passivation layer on top of nichrome, however there was no Chemical Vapor Deposition (CVD) equipment available at the time of fabrication. The silicon nitride for passivation was deposited by magnetron sputtering. Gold was used for contact pads. Gold has excellent electrical conductivity and is far less susceptible to corrosion than the $\mathrm{Al}$ and $\mathrm{Cu}$. Since TMAH was used to etch silicon to suspend the microhotplate, Gold seemed to be a better option as it is non reactive [30]. Figure 5.1 outlines the process flow for the whole fabrication process. 


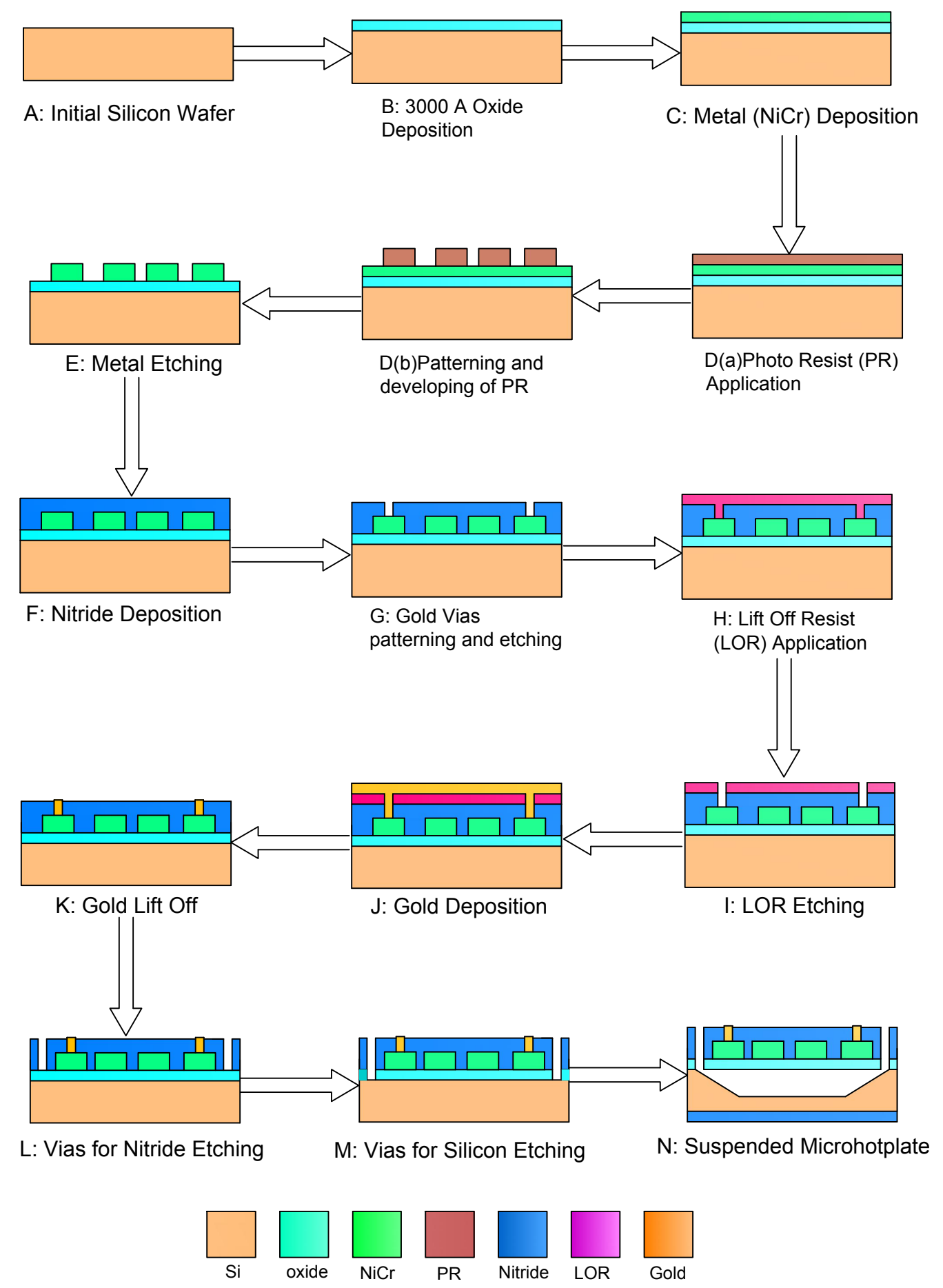

Figure 5.1: Process Flow Summary. 


\subsection{Fabrication}

The starting material is $<100>$ p-type silicon. The micro hotplate needs electrical insulation material to be deposited on the silicon surface and in this device thermal oxide is used. For this work, silicon wafers are oxidized at $1100^{\circ} \mathrm{C}$ to form a $3000 A^{\circ}$ layer of wet oxide. The actual thickness was $3198 A^{\circ}$ measured on Nano metric Nanospec/ AFT. This Nanospec is used to measure different films. An average of 5 measurements was used, providing accuracy of $1 A^{\circ}$.

The Nichrome metal was deposited using a thermal evaporation process in a Balzers cryopumped chamber using an Airco Temescal Model CV8 electron beam supply with an Inficon IC/4 Plus deposition controller. NiCr is deposited from a small tungsten basket at $80 \mathrm{~V}$ bias, which produces a deposition rate around $2 A^{\circ} / s$ and provides the desired thickness of $500 A^{\circ}$. For metal patterning, the mask CU-320 - 01 is used. The minimum feature size in Carleton microfabrication facility is $2.5 \mu \mathrm{m}$. The wafer is primed using vapour phase hexamethyldisilazane (HMDS) in a Sitek Process Solutions Yield Engineering LP-III oven. The HMDS is applied as an adhesion promoter for photoresist S1811. S1811 is a positive photoresist which is flood coated and spread on a wafer at $1000 \mathrm{rpm}$ for 10 seconds, then spun at $4000 \mathrm{rpm}$ for 30 seconds. The resist is soft baked at $105^{\circ} \mathrm{C}$ for one minute. The resist is exposed using the mask aligner Karl Suss MA6. To find the energy dose received by the photoresist:

$$
\text { Dose }=\text { Intensity } \cdot \text { Time }
$$

Where:

dose is total energy absorbed by the resist and determines exposure characteristics, intensity is the measured lamp intensity $=\left(6 \mathrm{~mW} / \mathrm{cm}^{2}\right)$, 
time is the exposure time.

$$
\begin{gathered}
\text { Time }=\frac{\text { Dose }}{\text { Intensity }}=\frac{150 \mathrm{~mJ} / \mathrm{cm}^{2}}{6 \mathrm{~mW} / \mathrm{cm}^{2}} \\
\text { Time }=25 \mathrm{~s}
\end{gathered}
$$

An exposure time of 25 seconds was used, followed by 60 seconds of immersion in MF-321 to develop the S1811 photo resist. After developing, the resist was hard-baked at $125^{\circ} \mathrm{C}$ for three minutes followed by a de-scum $\mathrm{O}_{2}$ plasma in a Technics PE-II etcher for one minute at 100W and 300 mTorr pressure.

Metal etching was accomplished using Nichrome Etchant TFN from Transene(Nitric acid and Ceric Ammonium Nitrate). The etchant is compatible with both positive and negative photoresist and has an etch rate of $50 \mathrm{~A}^{\circ} / \mathrm{s}$ at $40^{\circ} \mathrm{C}$. Etching using Nichrome Etchant TFN (Nitric acid and Ceric Ammonium Nitrate) at $35.5^{\circ} \mathrm{C}$, resulted successfully in an etch of 8 seconds while having a step height profile of $506 A^{\circ}$. Repeating the procedure in a second attempt resulted in a longer etch time of 16 seconds etch and a step height of $455 A^{\circ}$.

Having prepared new patterned wafers, a sliver (a very small piece) and a quarter piece of wafer were used to conduct the third attempt. The etching time was 18 seconds and 24 seconds respectively. Residual NiCr was observed in the step region shown in figure $5.1 \mathrm{E}$. In addition, the lines appeared to be over-etched as the line definition was very uneven and rough yet continuous. The etchant appears to saturate either by repetitive usage or loading effect of sample size and consequently requires longer etch times. In order to get a satisfactory etch rate we used $150 \mathrm{ml}$ of etchant with vigorous agitation as suggested by the manufacturer.

$\mathrm{NiCr}$ had to be passivated for electrical insulation and environmental protection. The de- 
vice will be operated at high temperature around $400^{\circ} \mathrm{C}$ and will be exposed to TMAH etching later in the fabrication process. Silicon nitride was used due to its attractive properties like high thermal stability, good dielectric behaviour, chemical inertness and excellent barrier properties. It also helps to prevent oxidation of the metal at elevated temperature. The targeted thickness of $200 \mathrm{~nm}$ was deposited from a 3" magnetron source in a Varian M2000 sputtering chamber with $25 \mathrm{sccm}$ of $\mathrm{Ar} / 15 \mathrm{sccm}$ of $N_{2}$ gas at 4 mTorr gas pressure and 200 $\mathrm{W}$ radio frequency power. The chuck temperature was $125^{\circ} \mathrm{C}$ and the deposition time was one hour with additional 15 minutes for cooling. The actual thickness achieved was $2348 A^{\circ}$ which was measured on a Nano metric Nanospec/AFT.

For connecting gold bond pads to NiCr, via's were etched through the nitride. The mask CU320 - 02 was used following the same photoresist process as for metal patterning. The etching of the silicon nitride was completed in a Technics PE-II plasma etcher. Prior to etching, the chamber is pumped to base pressure of 0.053 Torr, then it is conditioned for 5 minutes at $100 \mathrm{~W}$ rf power and 300 mTorr pressure in $\mathrm{O}_{2}$. This is followed by the PR descum of the wafer for 1 minute at 100W rf power and 300 mTorr pressure in $\mathrm{O}_{2}$. Now ,the conditioning of the chamber is done for 5 minutes at $100 \mathrm{~W}$ rf power and 300 mTorr pressure in $\mathrm{CF}_{4} \mathrm{O}_{2}$. Finally, the wafer is etched for 30 second at $100 \mathrm{~W}$ rf power and 300 mTorr pressure in $\mathrm{CF}_{4} \mathrm{O}_{2}$. The etch step was repeated 3 more times for 30s each time. This allowed monitoring of etch status of the sample thereby reducing the possibility of over-etching.

For lift-off patterning mask CU 320-04 was used, a vapor phase hexamethyldisilazane (HMDS) is applied as an adhesion promoter for photo resist S1811. A layer of Lift-Off Resist (LOR)10B spin at $1500 \mathrm{rpm}$ with a spread speed of $3000 \mathrm{rpm}$ followed by S1811 which is flood coated on static wafer at 1000rpm for 10 seconds and $4000 \mathrm{rpm}$ for 40 seconds to form bond pads around the micro heaters. The resist is soft baked at $105^{\circ} \mathrm{C}$ for one minute with an ex- 
posure time of 43 seconds in the mask aligner and then followed the same resist process to develop it.

Gold was thermally evaporated on the nitride layer from a base pressure of $1.5 * 10^{-7}$ Torr. The deposition rate was $1 A^{\circ} / s$ with a supply of $70 \mathrm{~V}$ and $6.5 \mathrm{~A}$, and the deposition time was 500 seconds.

To lift-off the photoresist, the samples were immersed in two baths of 1165 Microposit Remover at $80^{\circ} \mathrm{C}$. The sample is placed in Bath A for 10 minutes and then in Bath B to clean off any remaining material for 10 minutes, followed by a rinse in DI (deionized) water for 5 minutes. It is preferable to have a clean desirable test pads for testing purposes.

After all this, etching windows were needed to access the underlying silicon to release the structure. To form the window, layers of nitride and oxide must be removed. Mask CU320 - 03 was used for patterning these windows following by the same photolithography process used in previous masking steps. Since the first layer was nitride, the etching was performed in the Technics plasma etcher. The process was as described above, with a 5 minute condition in $\mathrm{O}_{2}$, a 1 minute PR descum, and a 5 minute condition in $\mathrm{CF}_{4} \mathrm{O}_{2}$. Finally, the wafer was etched for 9 minutes in $\mathrm{CF}_{4} \mathrm{O}_{2}$ (see appendix for run sheet). After etch completion, photoresist was removed in a Plasma Preen $\mathrm{O}_{2}$ reactor in intervals of 5 minutes in $\mathrm{O}_{2}, 5$ minutes cooling, for 3 iterations.

The next step was to remove the layer of oxide. The layer of oxide was etched in buffered oxide etch (BOE), a 6:1 solution of aqueous ammonium fluoride and hydrofluoric acid. Typical etch rates of oxide in this solution vary from $1000 A^{\circ} / \mathrm{min}$ to $1200 \mathrm{~A}^{\circ} / \mathrm{min}$ with fluctuations in concentration and ambient temperature. A slight amount of over etching is desired to ensure that the silicon underneath is exposed. The samples were immersed in BOE for 3 minutes and 15 seconds until a hydrophobic silicon surface was observed. It was important 
to ensure that the oxide layer was completely removed since TMAH (which is the next step) cannot etch oxide.

Wet anisotropic etching is crystal orientation dependent and etches much faster in one direction than in another. Etching a rectangular hole in a (100)-Si wafer results in a pyramid shaped etch pit with $54.7^{\circ}$ walls. A commonly used anisotropic etchant for silicon is $\mathrm{KOH}$ (Potassium Hydroxide), where $\mathrm{Si}<111>$ planes etch approximately 100 times slower than other planes. Issues associated with wet anisotropic etching are :

- contamination,

- dependent on orientation (wafer orientation and mask alignment to crystal planes is important),

- etch rate varies with temperature and concentration, For this work the wet anisotropic etch TMAH was chosen over potassium hydroxide as an anisotropic etchant due to higher etch rate and greater selectivity to silicon over silicon dioxide. Moreover, the Carleton University Micro-fabrication Facility does not allow $\mathrm{KOH}$ in the lab due to the risk of contamination of CMOS processes due.

The wafer was submerged in a beaker of tetramethylammonium hydroxide (TMAH 25\%) at $90^{\circ} \mathrm{C}$ for 2 hours 39 minutes and 5seconds. A reflux condenser was attached to the beaker, and the TMAH was continuously stirred with a magnetic stir bar for the duration of the etch. According to the design, the maximum width of opening is $335 \mu \mathrm{m}$. Based on this value and the angle between the 111 plane and the 100 surface of $54.7^{\circ}$, the required depth of silicon to be etched is $237 \mu \mathrm{m}$. An etch rate was found to be $0.0 .86 \mu / \mathrm{min}$ using a test wafer in the TMAH bath. This etch rate results in a total required etch time of 4 hours 35 minutes. To ensure that all silicon has been etched away, the wafer was immersed in TMAH for a total of 4 hours and 48 minutes. The designs were inspected under an infinity analyser micro- 
scope. The underlying silicon seemed to be etched entirely. The structure appeared to be suspended. Figure 5.3 shows the the suspended structures after the TMAH etching. The nitride/oxide layer in the figure is the yellow coloured area around the suspended microhotplate. The dark areas around the suspended structures are the silicon pits, that were created after TMAH etching.
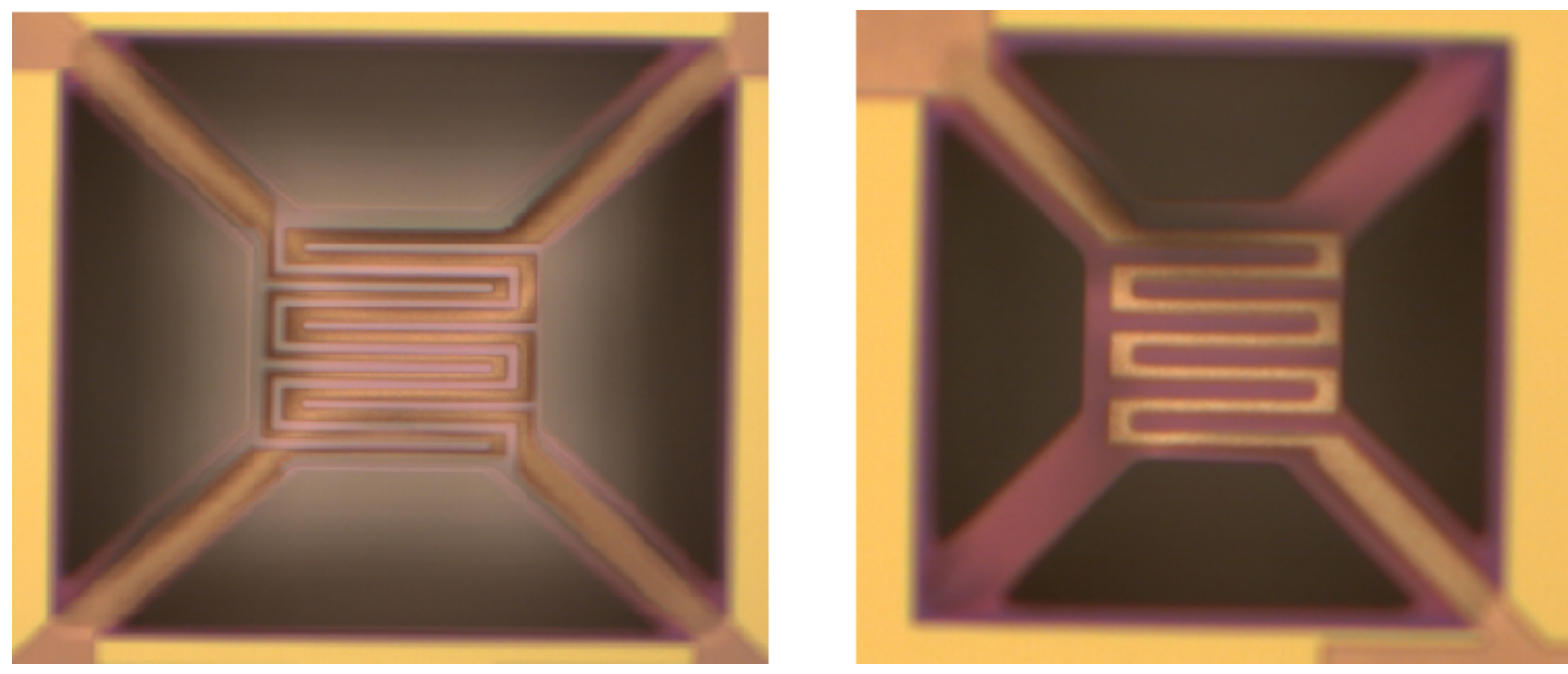

Figure 5.2: Suspended micro-hotplate structure showing the heater is suspended over a cavity beneath.

At this stage, the device fabrication is complete and the micro-hotplate performance and feasibility can to be tested. The testing procedure and methods along with the results are described in chapter 6 . 


\subsection{Fabrication Issues}

During the fabrication of the micro-hotplate, issues occurred in the process stages. This began very early in mask making when the fudicial marks on the via mask were not present. A new plate had to be made as a result of this error. On further processing during mask making, the etch mask also had some minor issues appearing at the contact print stage, where the fudicial marks had to be centred in the tool in order to print clearly, enabling alignment of the printed copy for step and repeat.

The major issue with this project was found in the deposition of NiCr. This process is done in the Balzers Airco Temescat Model CV8 with Inficon IC/4 Plus deposition controller. According to the calculations a $50 \mathrm{~nm}$ thick layer is required for this device. During the first attempt, NiCr deposition was completed using electron-beam evaporation on a glass substrate. A significant number of pinholes were observed in the film under dark-field imaging in an optical microscope.

The glass substrates are susceptible to charging, which can attract particles. However, the substrates went through a glassware clean prior to loading in the evaporator, and the density of pinholes in the film is likely not due to particles on the glass.

Three attempts were made to e-beam deposit NiCr using graphite crucible liners, however all three attempts resulted in cracked liners. The crucible most likely cracked upon cooling and it became obvious that that a more compatible crucible was required. During these depositions, spitting of material from the source was apparent.

The next attempt involved e-beam evaporation using a Tantalum boat to hold the NiCr. This again resulted in a cracked crucible liner, although the deposition proceeded within minimal spitting from the source. However the NiCr appeared to alloy with the boat material, and the boat quickly failed. 
Finally, an attempt was made to thermally evaporate NiCr from a tungsten boat, and this process created films that appeared to be of high quality.

Etching of $\mathrm{NiCr}$ also proved to be a challenge. Initially Aqua Regia, a solution using $\mathrm{HCl}$ : $\mathrm{HNO}_{3}: \mathrm{H}_{2} \mathrm{O}=1: 1: 3$ respectively, was was tested as a NiCr etchant. The test sample of nichrome coated glass was left in the aqua regia solution for 3 hours without visible removal of the NiCr layer. Then a solution from Transene, nichrome etchant TFN (nitric acid and ceric ammonium nitrate) was tested. Sample pieces from newly patterned wafers were used to test the etching. The etching time is 18 seconds and 24 seconds for a quarter wafer respectively. A difference in color of oxide around the heater and away from the heater was observed. It seems that the etchant is slightly attacking the oxide. The thickness of the oxide film was evaluated using a Tencor Nano-Spec optical thickness measuring tool. These measurements represented the two different oxide thickness's. Oxide thickness $3343 A^{\circ}$ is where the residue is near/on $\mathrm{NiCr}$ lines. The open areas represent the field area $3189 A^{\circ}$ that appears to be free of residual metals. The pre-made etchant was effective, with an etch rate of $\sim 19 A^{\circ} / \mathrm{sec}$, however this was much slower than the $50 A^{\circ} / \mathrm{sec}$ rate specified by the manufacturer.

Due to the large discrepancy in etch rate, it was necessary to contact the supplier of Transene. It was recommended by the supplier to use vigorous agitation to produce the desired etch rate at the specified temperature. So having the knowledge of the proper conditions and process controls (temperature) the etch rate for the NiCr etch from Transene was indeed $50 A^{\circ} /$ sec. The changes in color in the oxide regions could indicate probable issues with lithography (inadequate develop or exposure time to remove unwanted PR); or a possibility of improper agitation of NiCr etchant (not vigorous enough). Figure 5.4 shows the difference in oxide colours after NiCr etching is complete. 


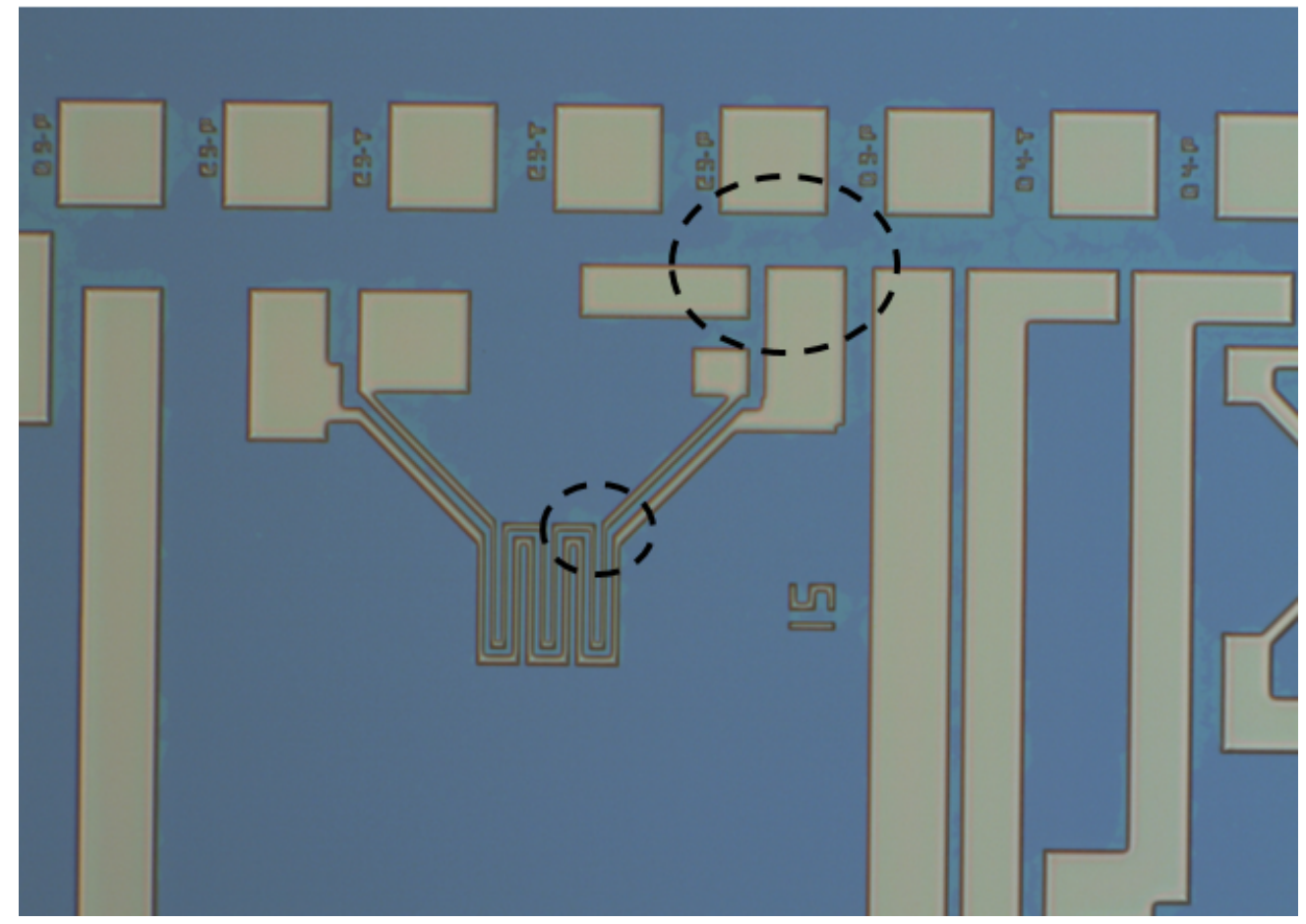

Figure 5.3: Difference in oxide color after etching with nichrome etchant TFN. 


\section{Chapter 6}

\section{Results and Discussion}

This chapter provides measurement results for the fabricated hotplate design. Resistance and temperature coefficient of resistance for the NiCr material were investigated. These are key parameters in determining the thermal performance of the hotplate element and are important considerations in fabrication of a micro-hotplate for sensing applications.

\subsection{Characterisation of Nichrome}

The characterisation of the electrical properties of the device was required to infer the operating temperature of the micro-hotplate. To measure the temperature coefficient of resistance(TCR) the layout includes Van der Pauw (Greek Cross) test structures. This structure is not a suspended structure and has been fabricated on the oxide layer of the wafer. The test structure could be seen in figure 6.1. This structure is a widely used form for Van der Pauw testing, as it gives precise resistivity data and is easy to design. The resistivity of any material is a function of resistivity and dimensions of the structure. To measure an accurate value of resistance a known current is applied to adjacent bond pads, and voltage is measured be- 
tween the remaining two pads. The Van der Pauw method requires that the sample:

- be of insignificant but uniform thickness in comparison to the area of the structure,

- be symmetrical in shape,

- be uniform in composition, and

- have contacts on the perimeter of the structure.

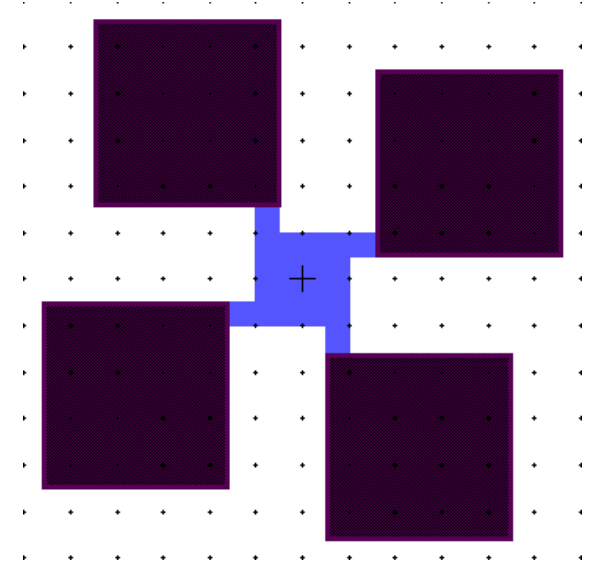

Figure 6.1: Vander Pauw Structure for measuring sheet resistance. 


\subsubsection{Theoretical Value of Sheet Resistance at Room Temperature}

The theoretical value of sheet resistance can be calculated based on the dimensions of our design. The resistance of a metal line is described by :

$$
R=\frac{\rho . l}{A}
$$

Where:

$R$ is resistance of the test structure,

$\rho$ is the resistivity of nichrome,

$l$ is the length and

$A=($ width $*$ thickness $)$ is the cross sectional area of the test structure.

Since the test structure is a square, $(w=l)$. Therefore,

$$
\begin{gathered}
R=\frac{\rho . l}{w \cdot t} \\
R=R_{s}=\frac{\rho}{t}
\end{gathered}
$$

The published value of bulk resistivity $\left(\rho\right.$ ) of nichrome is $1.1 * 10^{-6} \Omega \mathrm{m}$ and the thickness of deposited nichrome is $50 \mathrm{~nm}$, therefore

$$
R_{S}=\frac{1.1 * 10^{-6}}{50 * 10^{-9}}=22 \Omega
$$

The calculated value of $R_{s}$ is $22 \Omega / \square$. 


\subsubsection{Measured Value of Sheet Resistance at Room Temperature}

As mentioned earlier we used Van der Pauw technique to measure the sheet resistance. For this the equivalent sheet resistance is given by

$$
R_{s}=\frac{\Pi R}{\ln (2)}
$$

Where:

$R$ is the measured resistance of the structure, $R_{S}$ could be further simplified to,

$$
R_{s}=4.5 R
$$

To measure the sheet resistance a HP 4155A semiconductor parameter analyser(SPA) was used. We sourced a current and obtained the corresponding values of voltage drop (VM1VM2) across the test structure. The sourced current was varied from $0 \mu A$ to $0.5 m A$. We acquired the values from the SPA by using a general purpose interface bus (GPIB). We were able to plot a V versus I for this data and were able to calculate R from the slope of the line.

To further simplify our equations we get the following:

$$
\begin{gathered}
R=\frac{V}{I} \\
R=\frac{V_{D I F F}}{I}
\end{gathered}
$$

$V_{D I F F}=(\mathrm{VM} 1-\mathrm{VM} 2)$ is the differential voltage and $I$ is the current. 
Substituting the value for $\mathrm{R}$ from equation 6.9 in equation 6.7 , we get

$$
R_{s}=\frac{4.5 V_{D I F F}}{I}
$$

From the V versus I graph, we obtained the sheet resistance at room temperature as $5.3 \Omega$, which after applying the correction factor of 4.5 , we get $23.95 \Omega / \square$, where as our calculated value was $22 \Omega / \square$. Our measured value is within a range of $10 \%$. This variation might be the result of fabrication process variations. 


\subsubsection{Temperature Coefficient of Resistance (TCR)}

The temperature coefficient of resistance (TCR) of the metal layer was also determined using our test structure by Van der Pauw technique. For this we placed the wafer on a temperature controlled thermo-chuck 'Alpha' series system as shown in figure 6.2. Since our test structure is not suspended in the air, it would attain the same temperature as the bulk wafer.

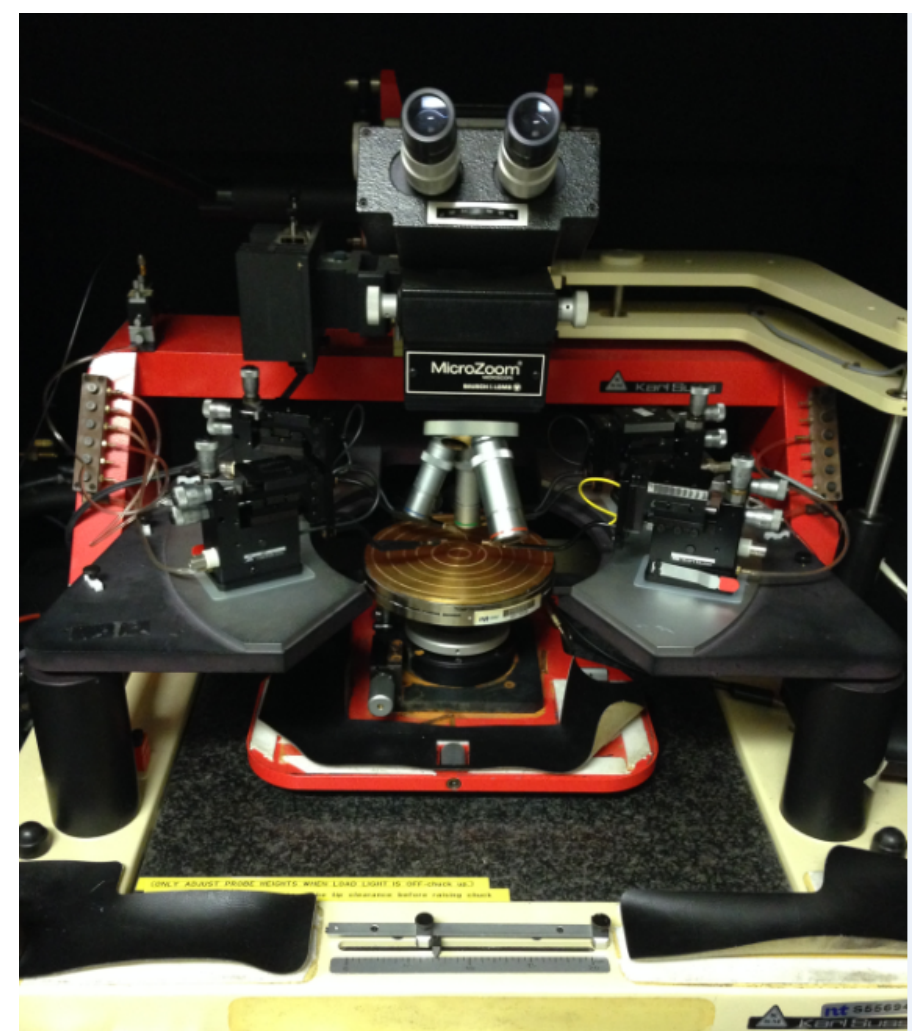

Figure 6.2: Temperature controlled thermo-chuck 'Alpha' Series system.

The temperature variation range of the thermo-chuck was from $0^{\circ} \mathrm{C}$ to $200^{\circ} \mathrm{C}$. We varied the temperature of the chuck from $20^{\circ} \mathrm{C}$ to $180^{\circ} \mathrm{C}$. The source current was varied as before, from $0 \mu A$ to $0.5 m A$. The corresponding values of voltage were recorded. We calculated the slope of the $\mathrm{V}$ versus I graph to get the value of resistance. We took at least 4 measurements for each set temperature, and then took an average of these values to get the value of resistance. The temperature was then increased in steps up to $180^{\circ} \mathrm{C}$. Table 6.1 shows the measured 
values of resistance versus temperature.

\begin{tabular}{|c|c|}
\hline Temperature $\left({ }^{\circ} \mathrm{C}\right)$ & Resistance $(\Omega)$ \\
\hline 20 & 23.95039276 \\
\hline 40 & 23.96929826 \\
\hline 80 & 23.98402955 \\
\hline 120 & 24.01455416 \\
\hline 140 & 24.04667609 \\
\hline 150 & 24.05043086 \\
\hline 170 & 24.05665588 \\
\hline 180 & 24.06501603 \\
\hline
\end{tabular}

Table 6.1: Resistance versus Temperatures

These values were plotted on a graph. Figure 6.3 shows the graph for this table.

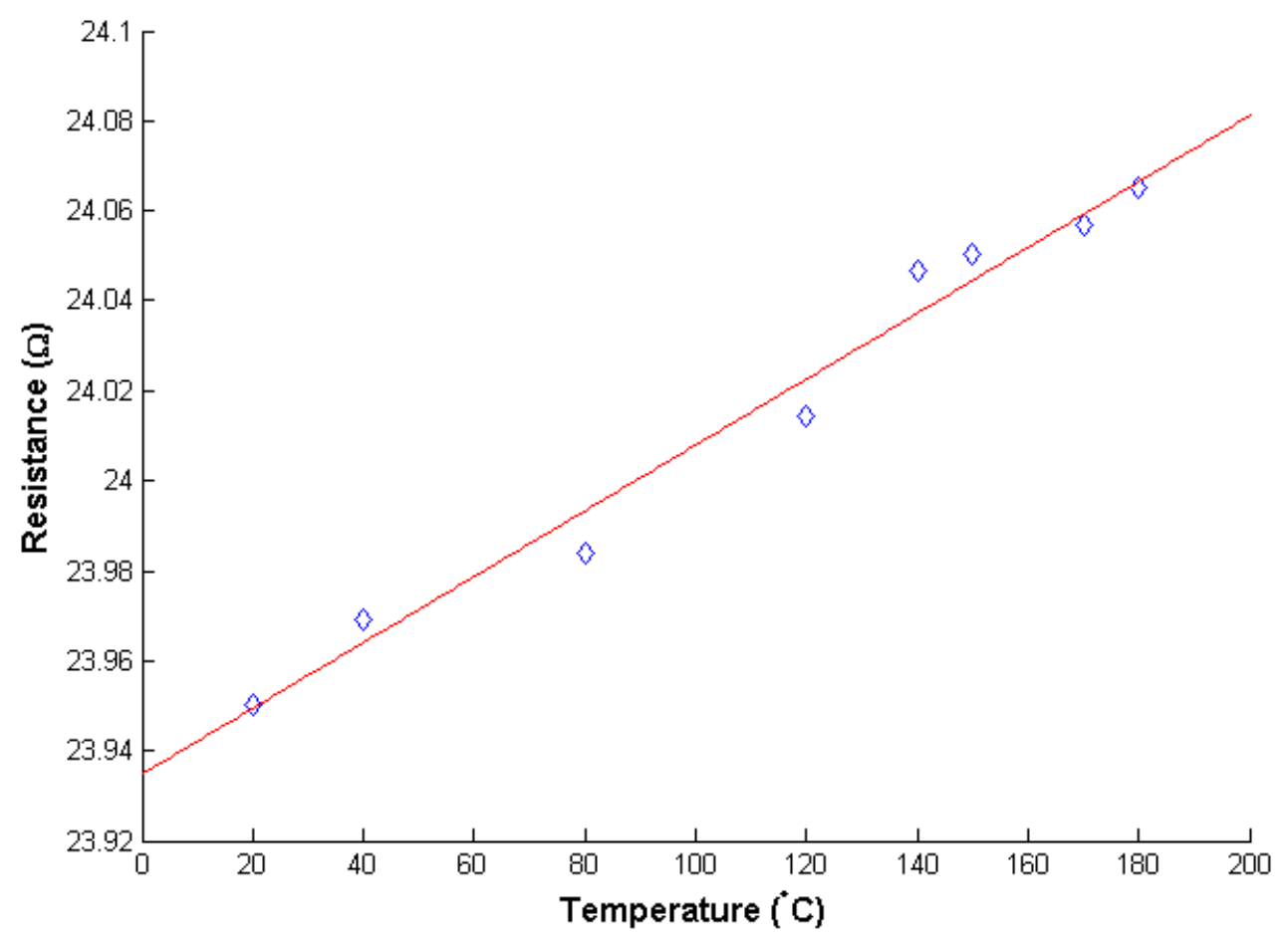

Figure 6.3: Resistance vs Temperature for Test Structure.

We calculated the TCR from figure 6.3 by using equation 6.10 .

$$
\alpha=\frac{\Delta R}{\Delta T} \cdot \frac{1}{R_{O}}
$$


Where: $\alpha$ is Temperature coefficient of resistance,

$\Delta R$ is change in resistance $(\Omega$,

$\Delta T$ is change in temperature ${ }^{\circ} C$ and $R_{o}$ is intial resistance $(\Omega)$

Normalized TCR helps us understand better, the percentage change in the resistance per unit change in temperature. Figure 6.4 below shows the normalised value of resistance. From the slope of the line the measured TCR for Nichrome is about $3 \times 10^{-5} /{ }^{\circ} \mathrm{C}$. This value is comparable to values reported by other people. From Figure 6.3, the slope of the line is $73.2 \times 10^{-5} \Omega /{ }^{\circ} \mathrm{C}$ with the uncertainity in the slope being $4.9 \times 10^{-5} \Omega /{ }^{\circ} \mathrm{C}$.

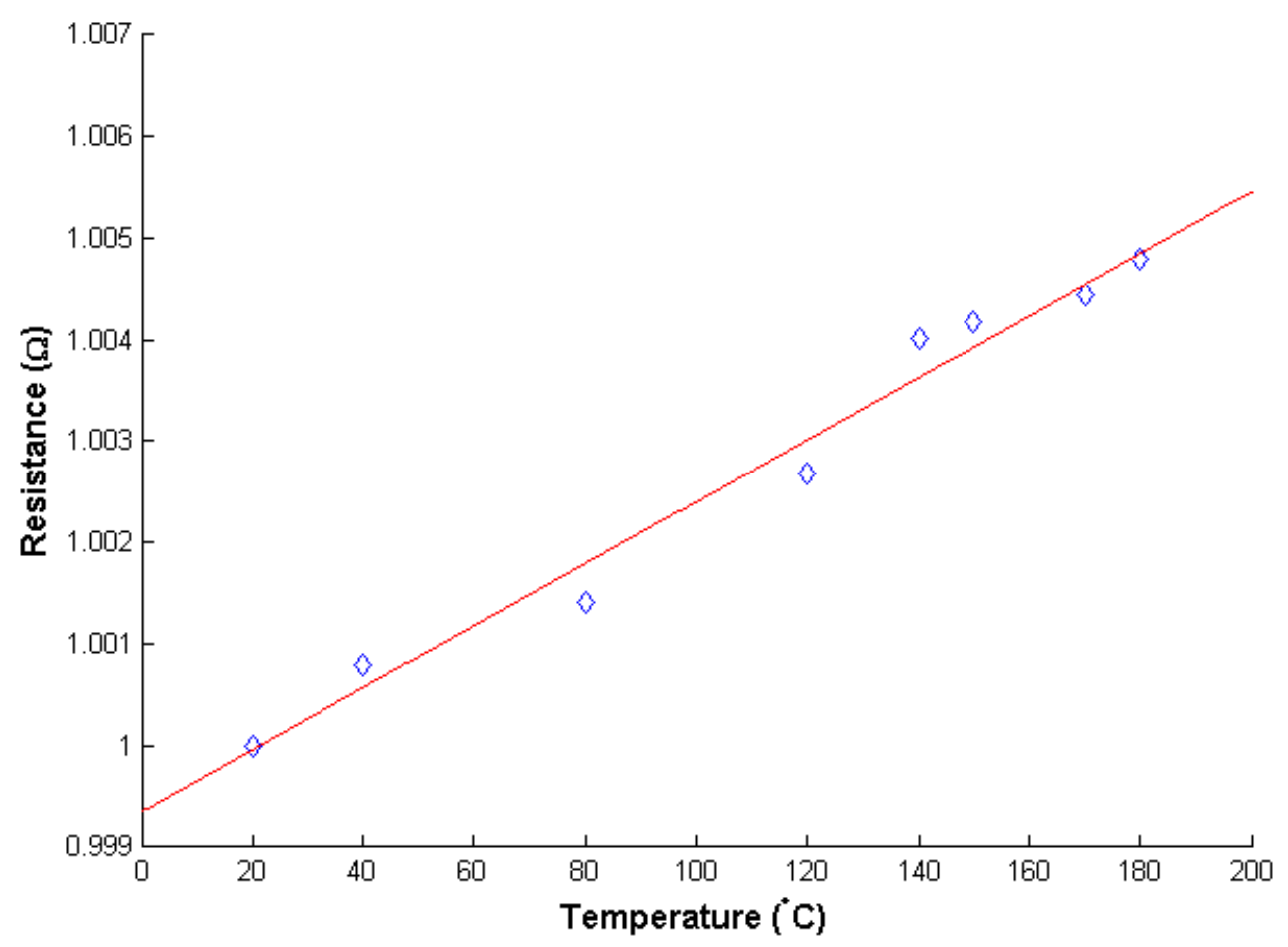

Figure 6.4: Normalised Resistance vs Temperature for Test Structure. 


\section{2 micro-hotplate Testing}

The next step was to proceed with testing of released micro-hotplates. The layout for the first device tested (design 9) is shown with dimensions in Figure 6.5. We planned to use the TCR obtained from the test structure to predict the operating temperature of the device.

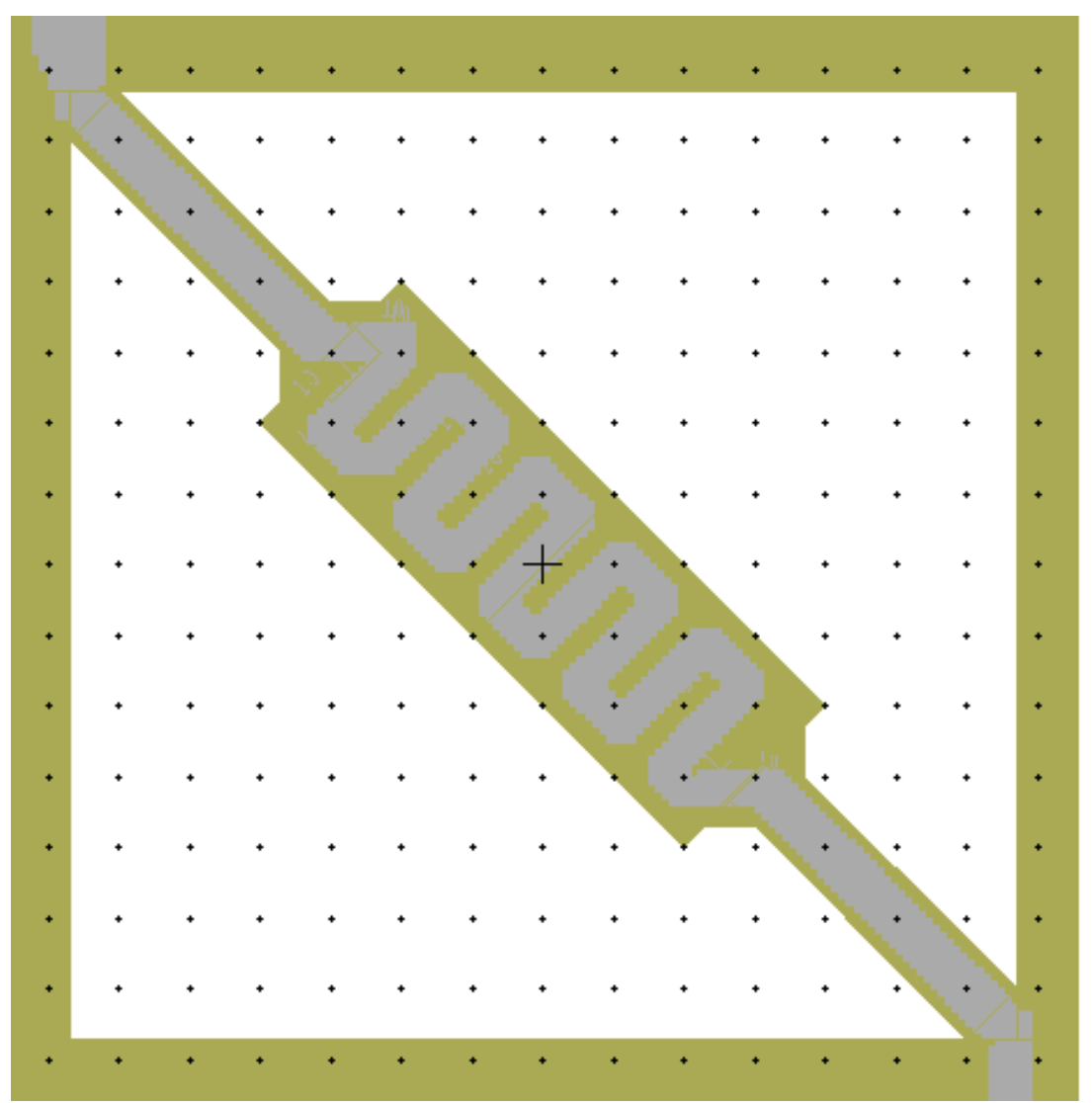

\section{Oxide}

Nichrome

Figure 6.5: Layout of Device (Design 9).

As a first step the total number of squares for the device were calculated and multiplied with the sheet sheet resistance mentioned in section 6.1.2.. Table 6.2 shows the number of squares calculated. 


\begin{tabular}{|c|c|}
\hline Full squares & 56 \\
\hline Half Squares & 1 \\
\hline Corners & 17 \\
\hline Sheet Resistance & $23.95 \Omega$ \\
\hline
\end{tabular}

Table 6.2: Number of Squares of design 9

The sheet resistance is $23.95 \Omega / \square$, the total resistance of the device becomes

$$
R=56 * 23.95+1 * 0.5 * 23.95+17 * 0.6 * 23.95=1600 \Omega
$$

The resistance of the device was measured at room temperature. A small current was passed through our test structure. This was done to avoid self-heating of the resistor, since the value of resistance changes as the heater heats up. A current was applied in the range of 0.3-0.6 mA. The resistance didn't change for this range, hence concluding that there was no selfheating. The value of resistance started to change for values of current greater than $0.6 \mathrm{~mA}$. This process gave the resistance of the heater as $1704 \Omega$ and the theoretical value of the resistance of the heater was $1600 \Omega$ this was within $6.5 \%$. The difference in the value of the resistance could be attributed to fabrication process variations.

\subsubsection{Original Test Plan}

The original test plan was to vary the voltage from $0 \mathrm{~V}-6 \mathrm{~V}$ and measure the corresponding current and temperature using the TCR obtained previously. Resistance was found using a two point measurement for applied voltages in this range. Using the previously measured TCR value, corresponding temperatures can be calculated for a voltage bias value. Figure 6.6 shows the current vs voltage graph for one of the devices. Based on the values in the graph, the calculated maximum operating temperature is around $1400^{\circ} \mathrm{C}$, which is not possible 
since the melting point of nichrome is $1400^{\circ} \mathrm{C}$.

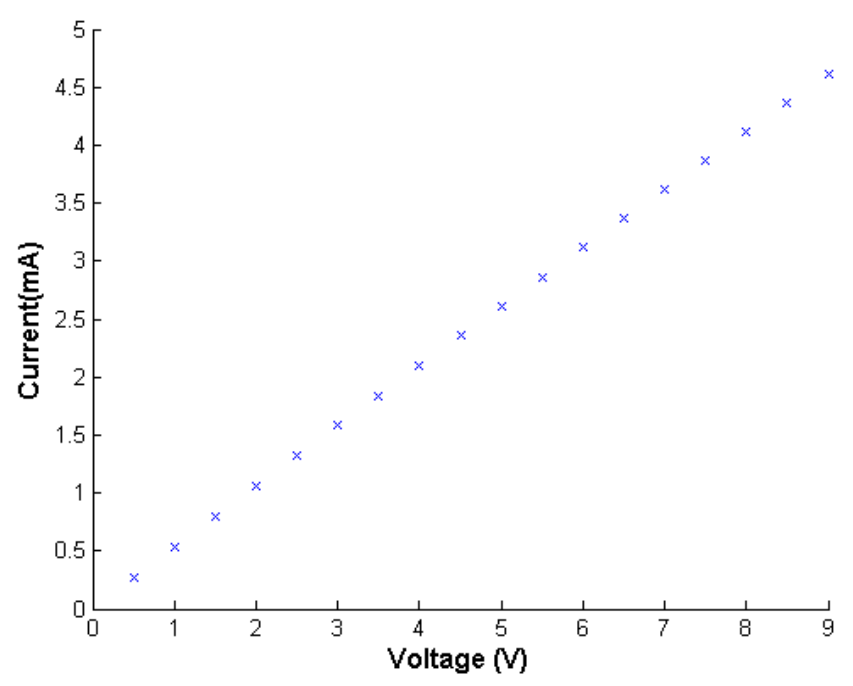

Figure 6.6: Measured current vs. voltage.

This discrepancy might lead us to the following reasons:

1. The measured TCR was incorrect.

2. The TCR of the nichrome heater changed after we applied a voltage.

The first scenario was unlikely since the calculated TCR was similar to values reported by other researchers, and measurements were carefully repeated multiple times [1]. The second theory was more convincing. The TCR that we have reported was calculated based on the resistance values taken by varying the temperature from $20^{\circ} \mathrm{C}$ to $180^{\circ} \mathrm{C}$ whereas our desired operating temperature was around $400^{\circ} \mathrm{C}$. This supports the theory that as we increased the voltage drop across the heater, the nichrome temperature increases, resulting in annealing and thus changing the properties, which appears as a change in TCR. This theory was also plausible since the maximum temperature the wafer was exposed to after metal deposition was $200^{\circ} \mathrm{C}$ and our device wasn't annealed in the oven at any point after this.

This led to a change in the test plan. As the temperature could not be accurately predicted from the original TCR, testing focused on how the resistance and TCR of the device changed 
with increasing bias.

\subsubsection{Modified Test Plan}

A Keithley source meter was used to vary the applied voltage. This test was done using a two point measurement. The voltage was varied in the range of $0-6 \mathrm{~V}$ and the corresponding value of current was recorded to calculate the change in resistance with the change in voltage. The step size of voltage was $0.5 \mathrm{~V}$. When voltage was changed, it was necessary to wait for about 10 seconds for the current value to settle down before measuring it and applying the next step of $0.5 \mathrm{~V}$. The voltage was not varied from $0 \mathrm{~V}-6 \mathrm{~V}$ in the first trial, since an abnormal behaviour was observed, as explained in the following section.

\subsubsection{Non-Linear Resistance Behaviour}

As the voltage across the resistor is increased, an abnormal behaviour becomes apparent. Up to a certain value of input voltage, the resistance increased linearly, but as soon as it reached a specific voltage (much earlier than the intended value of $6 \mathrm{~V}$ ) the value of resistance started to fall. It would take at least 10-15 minutes for the value of resistance to become stable and this value was lower than the instantaneous resistance value that acquired just before the resistance became unstable.

To condition the device, the voltage was increased until the resistor started to exhibit a nonlinear behaviour. When resistance stabilizes, testing was resumed, this time taking the device to a higher value than during the previous trial. After doing multiple trials, it was observed that the first non-linearity occurs in the vicinity of $4.5 \mathrm{~V}$. For the first trial, the input voltage was varied from $0 \mathrm{~V}-4.5 \mathrm{~V}$, with steps of $0.5 \mathrm{~V}$. As mentioned earlier, waiting time 
for the device to settle down is about 15 minutes. For the next trial the starting value of the resistance, i.e. resistance @ $0.5 \mathrm{~V}$, was much lower than in the previous trial. The same procedure was followed as in the previous trial, but this time the applied voltage range was from $0 \mathrm{~V}-5 \mathrm{~V}$. The device resistance remained stable until $4.5 \mathrm{~V}$, the previous maximum applied voltage for the device. Figure 6.7 shows the resistance vs applied voltage. This test cycle was continued until the voltage across the device reaches $6 \mathrm{~V}$.

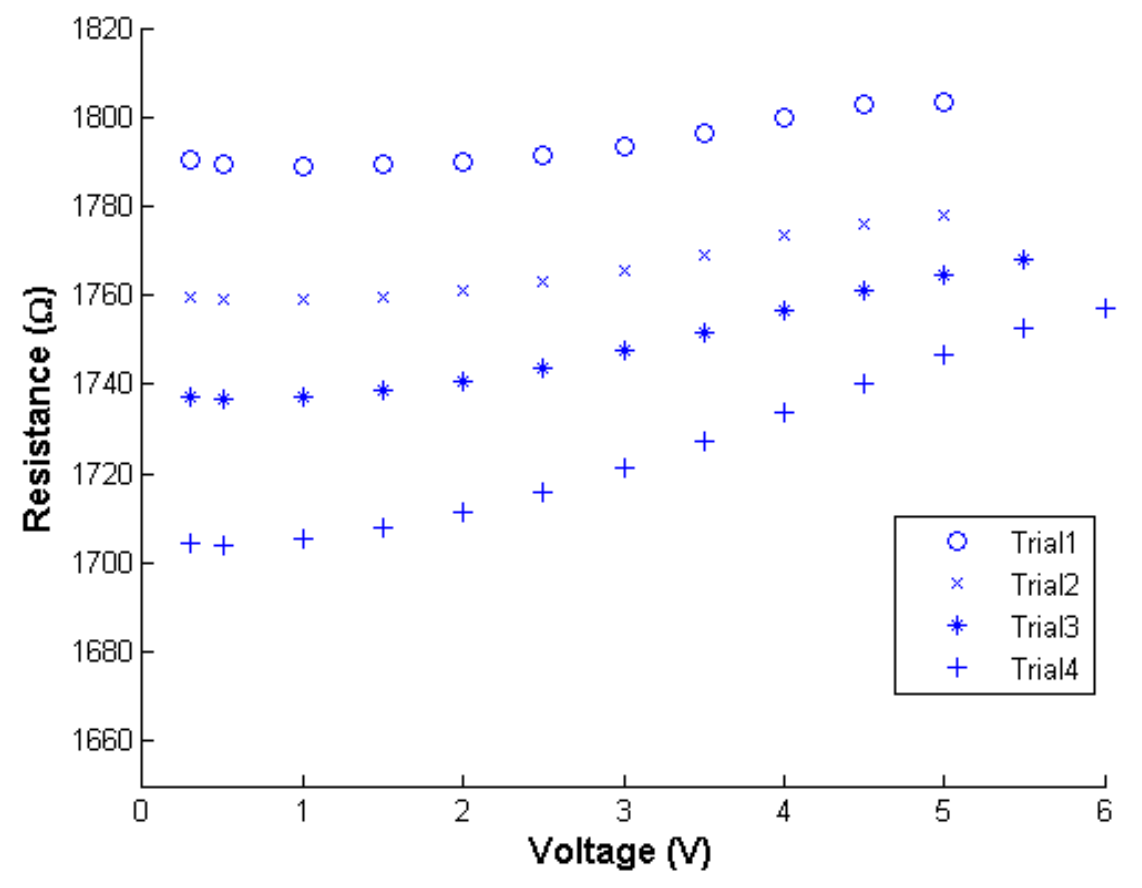

Figure 6.7: Resistance vs. voltage during initial cycling

\subsubsection{Repeatability}

After the device has self-annealed, i.e. settled down and achieved equilibrium from $0 \mathrm{~V}-6 \mathrm{~V}$, verification was conducted to see if the device followed the same characteristic for repeated voltage sweeps. The applied voltage was varied from $0 \mathrm{~V}-5 \mathrm{~V}$ and the value of resistance was calculated for repeated measurements. Figure 6.8 shows the device behaviour for the range 
mentioned above.

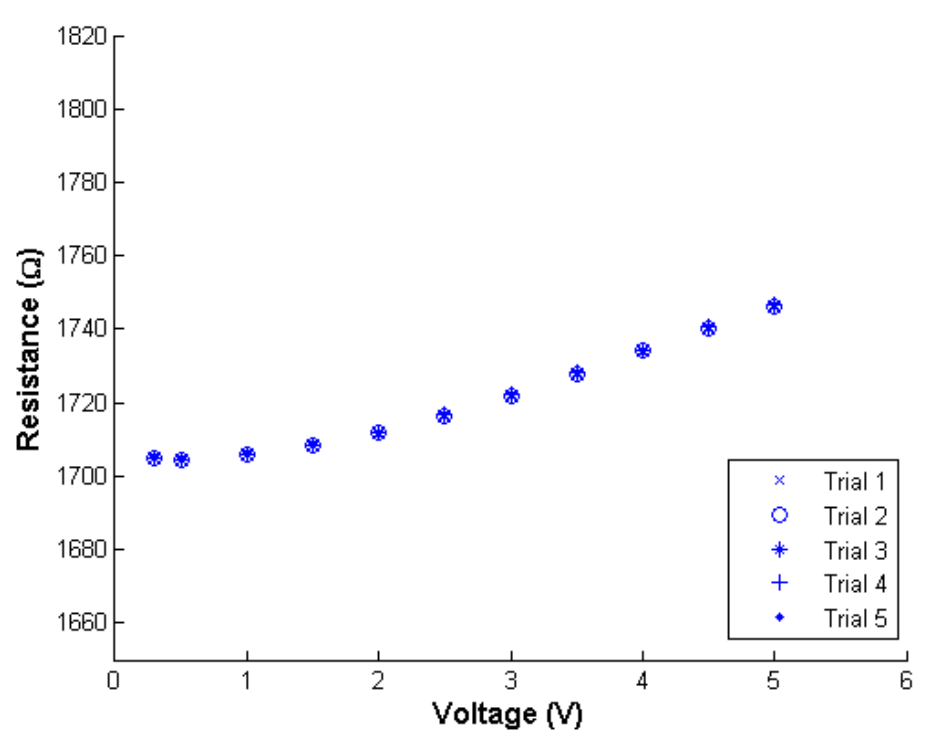

Figure 6.8: Resistance vs. voltage repeatability measurements

Five different trials for measurements were taken for the range mentioned. It can be concluded from the graph that the values were close to each other. The standard deviation was calculated at two random values of voltage on these curves i.e. $2 \mathrm{~V}$ and $4 \mathrm{~V}$. The standard deviation was $0.149416 \mathrm{~V}$ and $0.168775 \mathrm{~V}$ and the variance is $0.022325 \mathrm{~V}^{2}$ and $0.022479 \mathrm{~V}^{2}$ for the two voltage points respectively. We see that these values are close to each other and the resistance is quite repeatable from $0 \mathrm{~V}-5 \mathrm{~V}$.

\subsubsection{Optical Emission}

The apparent change in the NiCr TCR under bias made the device resistance difficult to correlate with temperature. To ensure that the device was heating up to a considerable value, the device was biased to a high input voltage and observed under the microscope to look for thermal emission of visible light. The device was given a bias voltage $3 \mathrm{~V}$ greater than the 
stable value that it had previously reached. An orange-red glow was seen from the device with a bias voltage of $9 \mathrm{~V}$. Figure 6.9 shows a camera image taken through the microscope eyepiece.

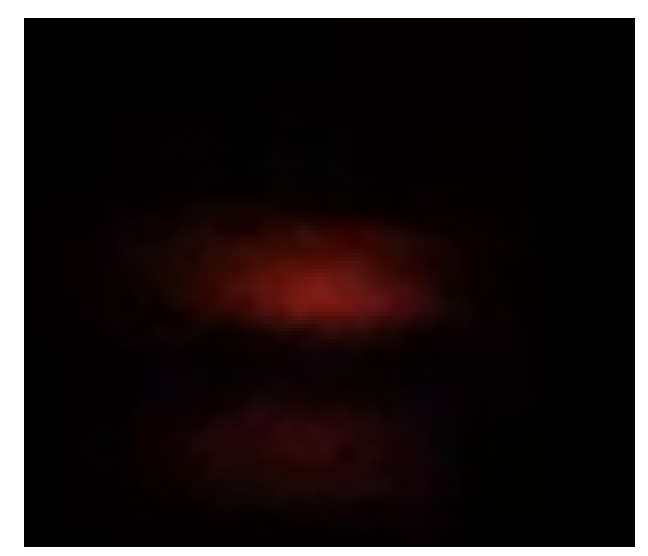

Figure 6.9: Thermal emission from the device

This glow suggests that the device was operating at least in the range of $700^{\circ} \mathrm{C}-900^{\circ} \mathrm{C}$. Based on the measured resistance when glowing and the original TCR measured on the heated chuck, the device appears to be operating at $1432^{\circ} \mathrm{C}$, which is not possible since the melting point of Nichrome is around $1400^{\circ} \mathrm{C}$.

\subsubsection{Voltage increase and decrease with the same steps}

To ensure that the device has become predictable and repeatable, the micro-hotplate was first biased at fixed steps in input voltage of $0.5 \mathrm{~V}$ in the stable range of $0 \mathrm{~V}-5 \mathrm{~V}$. Once the device reached the maximum voltage, the input voltage was decreased with the same step size of 0.5V. Figure 6.10 shows the corresponding value of resistance for ascending steps as well as descending steps. It was observed that the behaviour (Resistance) of the heater for a given input voltage was exactly the same in both directions. This ensured that the device has indeed become stable for the given voltage range. 


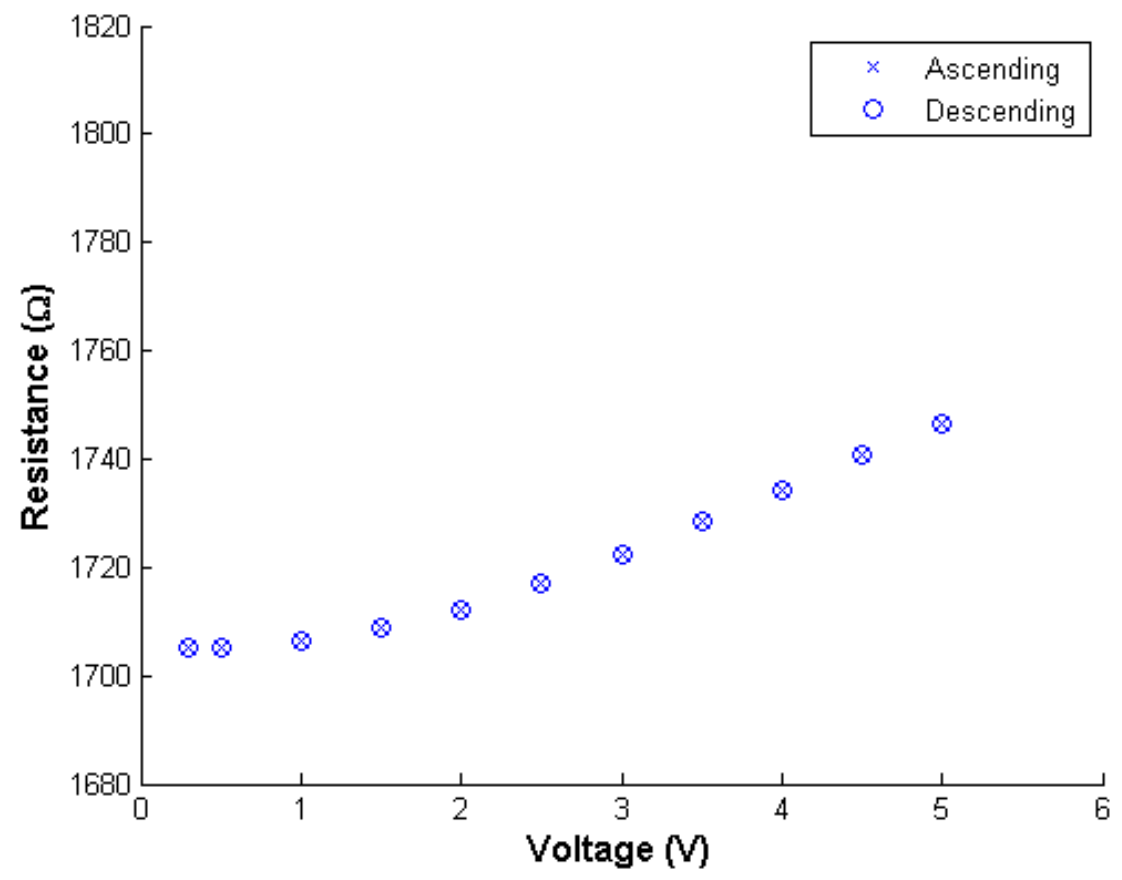

Figure 6.10: Resistance with Increasing and Decreasing Voltage 


\section{Chapter 7}

\section{Conclusion and Future Work}

It was found that the TCR of thermally evaporated nichrome changed due to self-heating as a result of bias voltage. Based on the measured resistance at a voltage bias of $9 \mathrm{~V}$ and the NiCr TCR measured at low temperature, the calculated temperature of the device was $1432^{\circ} \mathrm{C}$, which was not possible since the melting point of nichrome is $1400^{\circ} \mathrm{C}$. This indicates that the TCR of the nichrome film increased with successive self-heating of the heater. A higher value of TCR would correspond to a lower operating temperature.

Initially the NiCr resistance as a function of applied voltage was found to become non-linear as bias was increased. By cycling the applied voltage to successively higher values, the resistance became linear and repeatable over a range of voltages. Subsequently the voltage across the device was first increased and then decreased with the same steps and the device gave exactly the same output both ways. This indicated stable and predictable resistance values.

Taking the above method into consideration, the devices were annealed for a given range $0 \mathrm{~V}-6 \mathrm{~V}$ using heater self-heating instead of putting it in an oven. This enabled the device to act in a predictable manner. An orange-red glow was also seen coming out of the device for 
a known input voltage. This suggests that the device was operating at around $700^{\circ} \mathrm{C}-900^{\circ} \mathrm{C}$, which is much more than the intended range of operation $400^{\circ} \mathrm{C}$.

As future work, the correct TCR of Nichrome can be determined by putting the wafer in an oven and heating up to $450^{\circ} \mathrm{C}$ since the intended operating temperature is around $400^{\circ} \mathrm{C}$. If the correct TCR of nichrome can be accurately determined, then the operating temperature of the micro-hotplate can be monitored. Thermal emission can be measured using pyrometer, to determine the peak wavelength emission and the operating temperature. These MHP can then be modified to emit a narrowband of infrared emission to be used successfully as an emitter for $\mathrm{CO}_{2}$ sensing applications. 


\section{Bibliography}

[1] D.Surajit,A.Jamil, "Comparative Study on Temperature Coefficient of Resistance(TCR) of the E-beam and Sputter Deposited Nichrome Thin Film for Precise Temperature Control of Microheater for MEMS Gas Sensor", Physics of Semiconductor Devices, pp. 495-497, 2014.

[2] M.Santamouris, A.Synnefa, M.Asssimakopoulos, I.Livada, K.Pavlou, M.Papaglastra, N.Gaitani, D.Kolokotsa, V.Assimakopoulos," Experimental investigation of the air flow and indoor carbon dioxide concentration in classrooms with intermittent natural ventilation," Energy and Buildings, vol. 40, pp.1833 - 1843, 2008.

[3] Pierre Barritault, Mickael Brun, Serge Gidon, Sergio Nicoletti, "Mid-IR source based on a free-standing micro-hotplate for autonomous CO2 sensing in indoor applications", Sensors and Actuators A: Physical, vol. 172, pp.379-385, 2011.

[4] M.Zanini, J.H.Visser, L.Rimai, R.E.Soltis, A.Kovalchuk, D.W.Hoffman, E.M. Logothetis, U.Bonne, L.Brewer, O.W.Bynum and M.A.Richard," Fabrication and properties of a Sibased high-sensitivity microcalorimetric gas sensor", Sensors and Actuators A: Physical, vol. 48, pp. 187-192, 1995.

[5] W.Konz, J.Hildenbrand, M.Bauersfeld, S.Hartwig, A.Lambrecht, V.Lehmann and J. Wollenstein, "Micromachined IR-source with excellent blackbody like behaviour (Invited 
Paper)", Smart Sensors, Actuators, and MEMS, vol. 5836, pp. 540-548, 2005.

[6] L.MeleL, F.Santagata, E.Iervolino, M.Mihailovic, T.Rossi, A.T.Tran, H.Schellevis, J.F.Creemer and P.M Sarro, "Sputtered molybdenum as conductive material for hightemperature micro-hotplates", Solid-State Sensors, Actuators and Microsystems Conference, pp.2690-2693, 2011.

[7] Yi.Xian, Jianjun Lai, Huafeng Liang and Xiaofeng Zhai, "Fabrication of a MEMS microhotplate", Journal of Physics: Conference Series, vol. 276, pp. 012098, 2011.

[8] Chang Liu, "Foundations of MEMS", Prentice-Hall, 2005.

[9] S.Z.Ali,F.Udrea, W.I.Milne and J.W.Gardner, "Tungsten-Based SOI micro-hotplates for Smart Gas Sensors", Micro electromechanical Systems, Journal of, vol.17, pp.1408-1417, 2008.

[10] Sheng, Lie-yi, Zhenan Tang, Jian Wu, Philip CH Chan and Johnny K O Sin, "A low-power CMOS compatible integrated gas sensor using maskless tin oxide sputtering", Sensors and Actuators B: Chemical, vol. 49, pp. 81-87, 1998.

[11] Andreas Hierlemann and Henry Baltes, "CMOS-based chemical microsensors", The Analyst, vol. 128, pp. 15-28, 2003.

[12] John O.Dennis, Farooq Ahmad and M.Haris Khir, " CMOS Compatible Bulk Micromachining", Advances in Micro/Nano Electromechanical Systems and Fabrication Technologies, pp. 119-137, 2013.

[13] F.Solzbacher, C.Imawan, H.Steffes, E.Obermeier, M.Eickhoff, "New SiC/HfB2 based low power gas sensor", Sensors and Actuators B:Chemical, pp. 111-115, 2001. 
[14] J Hildenbrand, C.Peter, F.Lamprecht, A. Kürzinger, F.Naumann, M. Ebert, R Wehrspohn, J.GKorvink and J. Wöllenstein, " Fast transient temperature operating micromachined emitter for mid-infrared optical gas sensing systems: design, fabrication, characterization and optimization", Microsystem Technologies, vol. 16, pp.745-754, 2010.

[15] Woo-Jin Hwang, Kyu-Sik Shin, Ji-Hyoung Roh, Dae-Sung Lee and Sung-Hoon Choa, "Development of Micro-Heaters with Optimized Temperature Compensation Design for Gas Sensors", Sensors (Basel, Switzerland), vol. 11, pp. 2580-2591, 2011.

[16] Mahanth Prasad, R.P.Yadav, V.Sahula, V. K.Khanna, "Design and simulation of Pt-based micro-hotplate and fabrication of suspended dielectric membrane by bulk micromachining", Physics of Semiconductor Devices, vol.8549, pp. 85491C-85491C, 2012.

[17] Kun Qian, Fangqiang Li, Haisheng San and Xuyuan Chen, "Modeling and thermal analysis of silicon infrared emitter based on SOI wafer," Nano/Micro Engineered and Molecular Systems (NEMS), 2010 5th IEEE International Conference on, pp. 114-117, 2010.

[18] Eui-Bok Lee, In-Sung Hwang, Jung-Ho Cha, Ho-Jun Lee, Won-Bae Lee, James Jungho Pak, Jong-Heun Lee and Byeong-Kwon Ju, " Micromachined catalytic combustible hydrogen gas sensor", Sensors and Actuators B: Chemical, vol 153 pp. 392-397, 2011.

[19] Guo Bin, A.Bermak, Philip C.H.Chan, Yan Gui-Zhen, "An Integrated Surface Micromachined Convex micro-hotplate Structure for Tin Oxide Gas Sensor Array", Sensors Journal, IEEE, vol.7, pp.1720-1726, 2007.

[20] J. Cerdà Belmonte, J. Puigcorbé, J. Arbiol, A. Vilà, J.R. Morante, N. Sabaté, I. Gràcia and C. Cané, "High-temperature low-power performing micromachined suspended microhotplate for gas sensing applications", Sensors and Actuators B: Chemical, vol 114, pp. 826-835, 2006. 
[21] J.F.Creemer, D.Briand, H.W.Zandbergen, W.van der Vlist, C.R. de Boer, N.F. de Rooij, P.M.Sarro, " Micro-hotplates with TiN heaters",Sensors and Actuators A: Physical, vol. 148, pp. 416-421, 2008.

[22] L. Mele, F. Santagata, E. Iervolino, M. Mihailovic, T. Rossi, A.T. Tran, H. Schellevis, J.F. Creemer, P.M. Sarro, " A molybdenum MEMS micro-hotplate for high-temperature operation",Sensors and Actuators A: Physical, vol 188, pp. 173-180, 2012.

[23] Lei $\mathrm{Xu}$, Tie Li, Xiuli Gao and Yuelin Wang, "A high heating efficiency two-beam micro-hotplate for catalytic gas sensors," Nano/Micro Engineered and Molecular Systems (NEMS)2012 7th IEEE International Conference on, pp. 65-68, 2012.

[24] Jiaqi Wang, Zhenan Tang; Jinfeng Li; Fengtian Zhang, "A MicroPirani Pressure Sensor Based on the Tungsten micro-hotplate in a Standard CMOS Process", Industrial Electronics, IEEE Transactions on, vol.56, pp. 1086-1091, 2009.

[25] I.Elmi, S.Zampolli, E.Cozzani, M.Passini, G.C Cardinali and M.Severi "Development of Ultra Low Power Consumption Hotplates for Gas Sensing Applications", Sensors 2006, 5th IEEE Conference on, pp. 243-246, 2006.

[26] M.S.Jalali, S.Kumar, M.Madani, Tzeng Nian-Feng, "Microhotplates for low power, and ultra dense gaseous sensor arrays using recessed silica aerogel for heat insulation", Sensors Applications Symposium (SAS), pp. 133-136, 2013.

[27] Andrew Pike, Julian W Gardner, " Thermal modelling and characterisation of micropower chemoresistive silicon sensors", Sensors and Actuators B: Chemical, vol. 45, pp. 19-26, 1997. 
[28] F.T.Zhang, Z.Tang, J.Yu and R.C.Jin, "A micro-Pirani vacuum gauge based on microhotplate technology ", "Sensors and Actuators A: Physical, vol. 126, pp. 300 - 305, 2006.

[29] O.Sidek, M.Z.Ishak, M.A.Khalid, M.Z Abu Bakar and M.A Miskam, "Effect of heater geometry on the high temperature distribution on a MEMS micro-hotplate", Quality Electronic Design (ASQED), 2011 3rd Asia Symposium on, pp. 100-104, 2011.

[30] K.R.Williams, K.Gupta, M.Wasilik, "Etch rates for micromachining processing-Part II", Micro electromechanical Systems, Journal of, vol.12, pp.761-778, 2003.

[31] Hadi Ghasemzadeh Momen, "MEMS Introduction and Applications", Ph.D. dissertation, Dept. Electrical Engineering, Istanbul Technical University, 2012. 


\section{Appendix A}

\section{Layout and Run sheet}

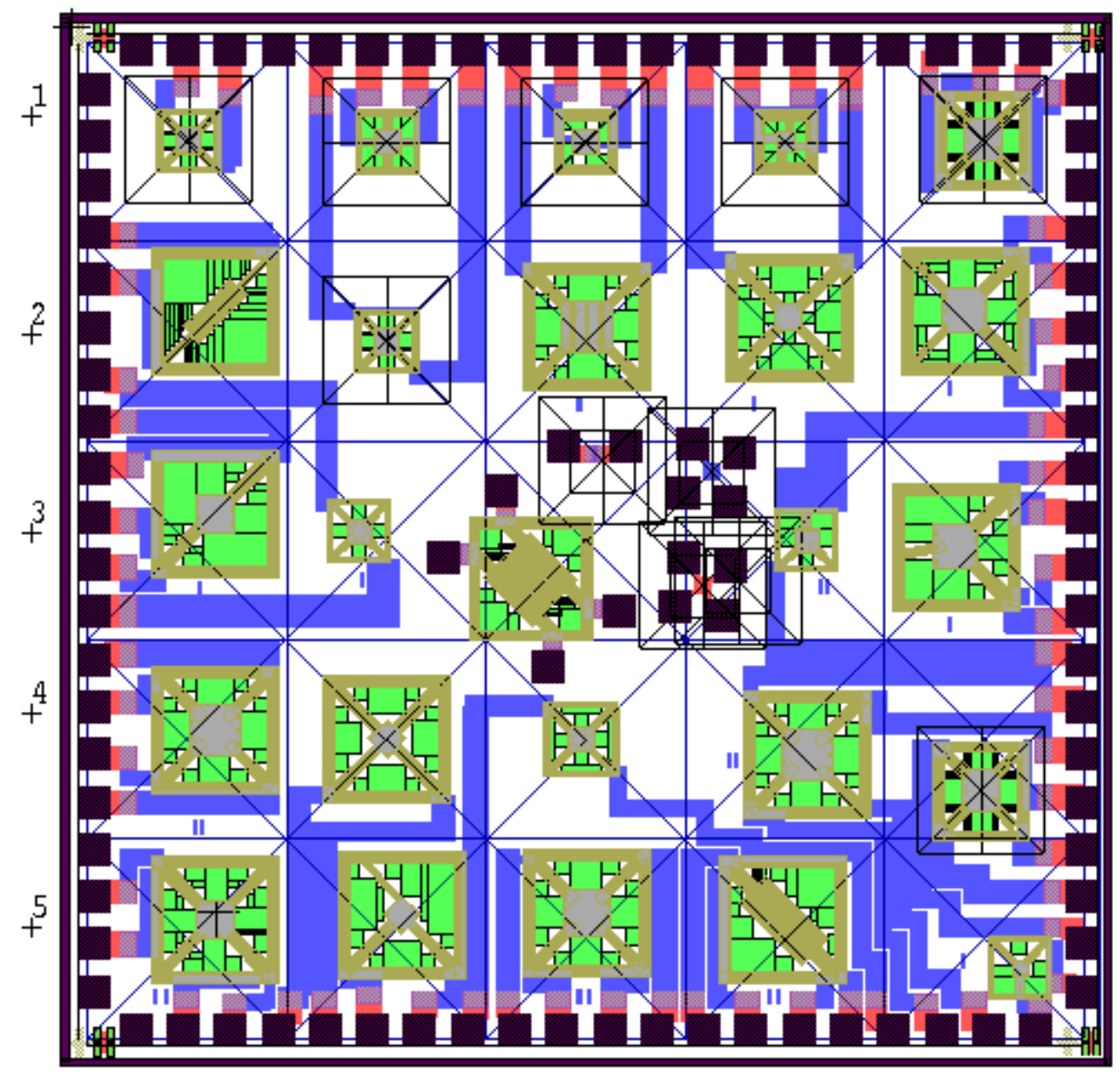

Figure A.1: (The LEdit layout design for the micro-hotplate ). 
STARTING MATERIAL:

The wafers are:

$3 \times 1000 \mathrm{~A}^{\circ} \mathrm{Chlorinated}$ oxide, n-type, and 2" wafer $<100>$ orientation with resistivity $1-10 \Omega \mathrm{cm}$.

2 X Bare Silicon, p-type, and 2" wafer $<100>$ orientation with resistivity $1-10 \Omega \mathrm{cm}$.

3 X $3000 \mathrm{~A}^{\circ}$ oxide, p-type, and 2 " wafer $<100>$ orientation with resistivity $1-10 \Omega \mathrm{cm}$.

Outline:

\section{OXIDATION}

2. METAL DEPOSITION (NICHROME)

3. METAL PATTERNING

4. METAL ETCHING

5. NITRIDE DEPOSITION

6. ETCH VIAS THROUGH NITRIDE

7. ETCH THROUGH NITRIDE FOR HOTPLATE

8. GOLD LIFT OFF PATTERNING

9. GOLD DEPOSITION-LIFTOFF-50 NM

10. GOLD LIFT OFF

11. TMAH ETCHING 
1. OXIDATION

Apex recipe\# Apex Run\#

a) RCA clean

b) Oxidation tube temperature $1100^{\circ} \mathrm{C}$

$\begin{array}{ll}5 \text { min preheat } & \mathrm{O}_{2} \\ \text { 2" every } 3 \text { sec push } & \mathrm{O}_{2} \\ 10 \text { min oxidation } & \text { dry } \mathrm{O}_{2} \\ 15 \text { min oxidation } & \text { wet } \mathrm{O}_{2} / \mathrm{H}_{2} \\ 40 \text { min anneal } & \mathrm{N}_{2} \\ \text { 2" every } 4 \text { sec pull } & \mathrm{N}_{2} \\ 10 \text { min cool } & \mathrm{N}_{2}\end{array}$

Target thickness: $3000 \mathrm{~A}^{\circ}$

Thickness measured on centre wafer: $3198 \mathrm{~A}^{\circ}$

2. METAL DEPOSITION (NICHROMI) Apex recipe\#___ Apex Run\#

\begin{tabular}{|c|c|c|c|c|c|c|}
\hline Xtal & Pellets & Cryo regen & Cryo Temp & $\begin{array}{c}\text { Base } \\
\text { pressure }\end{array}$ & Dep. rate & $\begin{array}{c}\text { E-beam } \\
\text { /thermal }\end{array}$ \\
\hline $0 \%$ & $\begin{array}{c}\text { NiCr } 1 / 3 \text { of } \\
\text { the one }\end{array}$ & 39 & 12 & $3.2 \times 10^{-7}$ & $2 \mathrm{~A}^{\circ} / \mathrm{s} / 80 \mathrm{~V}$ & Thermal \\
\hline
\end{tabular}

Comments: Tungsten (W) small boats works.

\section{METAL PATTERNING Mask CU-320-01}

a) Plasma Preen condition, HMDS oven, apply S1811 photoresist, prebake, expose, Develop, post bake, and descum (See Appendix A for standard photoresist procedure)

\begin{tabular}{|l|l|l|l|l|l|}
\hline Run & Time & Duty cycle & Flow & Base press & After $\mathrm{O}_{2}$ press \\
\hline 2 & $5 \mathrm{~min}$ & 100 & 300 & 0.059 & 5 \\
\hline
\end{tabular}

For Descum:

\begin{tabular}{|l|l|l|l|l|l|}
\hline Run & Time & Power & Pressure & Base press & Gas \\
\hline 2 & $1 \mathrm{~min}$ & $100 \mathrm{~W}$ & 300 mTorr & 0.061 & $\mathrm{O}_{2}$ \\
\hline
\end{tabular}

Comments: 


4. METAL ETCHING _ Apex recipe\#__ Apex Run\#

a) NiChrome Etchant, conditions: Transene 's etchant

DI rinse

Compatible with both $+/-\mathrm{PR}$.

$50 \mathrm{~A}^{\circ} / \mathrm{s} @ 40^{\circ} \mathrm{C}$

$1^{\text {ST }}$ ATTEMPT

Used the $\mathrm{NiCr}$ etch $@ 37.5^{\circ} \mathrm{C}$ tested on glass etched in $8 \mathrm{sec}$. Profile checked approx. $506 \mathrm{~A}^{\circ}$

$2^{\text {nd }}$ ATTEMPT: $15-16 \mathrm{sec}$, saturated solution. Profile again checked $455 \mathrm{~A}^{\circ}$.

$3^{\mathrm{ND}}$ ATTEMPT

Etch 1 for $18 \mathrm{sec}$ on sliver (smaller piece).

Etch 2 for $24 \sec$ on $1 / 4$ of 2 " wafer piece

Comments: Some residue left in the steps areas. Seems over etched as the line definition is choppy although continuous.

\section{NITRIDE DEPOSITION-200 NM}

a) Sputter Coat Conditions: (Lab log book)-done by Rick in Varian Sputter

\begin{tabular}{|l|l|l|l|l|l|}
\hline Target & Run/Wafer & Target spacing & Gas flow & Base press & Gas \\
\hline Si Undoped & $1 /$ test piece & $4{ }^{\prime \prime}$ & $\begin{array}{c}25 \mathrm{sccm} \mathrm{Ar} \\
15 \mathrm{~N}_{2} \mathrm{sccm}\end{array}$ & $2.7 \mathrm{X} 10^{-7}$ & $\mathrm{Ar} / \mathrm{N}$ \\
& & & & \\
\hline
\end{tabular}

\begin{tabular}{|c|c|l|l|l|}
\hline Power & Gas pressure & Throttle valve & Dep Time & Chuck temp \\
\hline $200 \mathrm{~W}$ RF & 4 mTorr & $41 \%$ & $\begin{array}{l}30 \text { min }+30 \\
\text { min }\end{array}$ & $125^{\circ} \mathrm{C}$ \\
\hline
\end{tabular}

$\mathrm{RF}$-radio frequency

Comments: $30 \mathrm{~min}$ deposition $+15 \mathrm{~min}$ cooling $+30 \mathrm{~min}$ deposition Achieved thickness $2348 \mathrm{~A}^{\circ}$

\section{PATTERNING Mask CU-320-02}

a) Plasma Preen condition, HMDS oven, apply S1811 photoresist, prebake, expose,

Develop, post bake, and descum

(See Appendix A for standard photoresist procedure)

\begin{tabular}{|l|l|l|l|l|l|}
\hline Run & Time & Duty cycle & Flow & Base press & After $\mathrm{O}_{2}$ press \\
\hline 2 & $5 \mathrm{~min}$ & 100 & 300 & 0.059 & 5 \\
\hline
\end{tabular}

For Descum:

\begin{tabular}{|l|l|l|l|l|l|}
\hline Run & Time & Power & Pressure & Base press & Gas \\
\hline 2 & $1 \mathrm{~min}$ & $100 \mathrm{~W}$ & $300 \mathrm{mT}$ Tr & 0.061 & $\mathrm{O}_{2}$ \\
\hline
\end{tabular}

Comments: 


\section{ETCH VIAS THROUGH NITRIDE}

a) Plasma etch nitride

\begin{tabular}{|l|l|l|l|l|l|l|}
\hline Run & Time & Power & Pressure & $\begin{array}{l}\text { Base } \\
\text { pressure }\end{array}$ & Gas & Comments \\
\hline 1 & $5 \mathrm{~min}$ & 100 & 300 & 0.053 & $\mathrm{O}_{2}$ & Conditioning \\
\hline 2 & $1 \mathrm{~min}$ & 100 & 300 & 0.040 & $\mathrm{O}_{2}$ & Conditioning \\
\hline 3 & $5 \mathrm{~min}$ & 100 & 300 & 0.059 & $\mathrm{CF}_{4} / \mathrm{O}_{2}$ & Conditioning \\
\hline 4 & $30 \mathrm{sec}$ & 100 & 300 & 0.059 & $\mathrm{CF}_{4} / \mathrm{O}_{2}$ & Conditioning \\
\hline 5 & $30 \mathrm{sec}$ & 100 & 300 & 0.057 & $\mathrm{CF}_{4} / \mathrm{O}_{2}$ & $\begin{array}{l}\text { Did a PR } \\
\text { swab that } \\
\text { Nitride has } \\
\text { been } \\
\text { removed }\end{array}$ \\
\hline 6 & $30 \mathrm{sec}$ & 100 & 300 & 0.057 & $\mathrm{CF}_{4} / \mathrm{O}_{2}$ & $\begin{array}{l}\text { Some } \\
\text { smooth NiCr } \\
\text { areas }\end{array}$ \\
\hline 7 & $30 \mathrm{sec}$ & 100 & 300 & 0.058 & $\mathrm{CF}_{4} / \mathrm{O}_{2}$ & $\begin{array}{l}\text { Cracking } \\
\text { appears }\end{array}$ \\
\hline
\end{tabular}

\section{GOLD LIFT OFF PATTERNING Mask CU-320-03}

a) Plasma Preen condition, HMDS oven, LOR-10B, apply S1811 photoresist, prebake, expose, Develop, and descum

(See Appendix A for standard photoresist procedure)

LOR 10B - $1500 \mathrm{rpm}$ spread speed and $3000 \mathrm{rpm}$ spin speed, $180^{\circ} \mathrm{C}$ for 5 min exposed for $43 \mathrm{sec}$. Descum

\begin{tabular}{|l|l|l|l|l|l|}
\hline Run & Time & Power & Pressure & Base press & Gas \\
\hline 2 & $1 \mathrm{~min}$ & $100 \mathrm{~W}$ & $300 \mathrm{mTorr}$ & 0.061 & $\mathrm{O}_{2}$ \\
\hline
\end{tabular}

\section{GOLD DEPOSITION-LIFTOFF-50 nm}

Target thickness: $50 \mathrm{~nm}$

Conditions:

\begin{tabular}{|c|c|c|c|c|c|c|}
\hline Xtal & Film & Cryo regen & Cryo Temp & $\begin{array}{c}\text { Base } \\
\text { pressure }\end{array}$ & Dep. rate & $\begin{array}{c}\text { E-beam } \\
\text { thermal }\end{array}$ \\
\hline $0 \%$ & $\mathrm{Au}$ & 52 & $12 \mathrm{~K}$ & $1.5 \times 10^{-7}$ & $1 \mathrm{~A}^{\circ} / \mathrm{s}$ & Thermal \\
\hline
\end{tabular}

Comments: $70 \mathrm{~V}, 6.5 \mathrm{~A}$ for $500 \mathrm{sec}$ 


\section{GOLD LIFT OFF}

1165 Used at $80^{\circ} \mathrm{C}$ : Bath A really dirty for $10 \mathrm{~min}$

Bath B to clean off the residual gold for $10 \mathrm{~min}$

Rinse in DI water for $5 \mathrm{~min}$

\section{PATTERNING Mask CU-320-04}

b) Plasma Preen condition, HMDS oven, apply S1811 photoresist, prebake, expose, Develop, post bake, and descum (See Appendix A for standard photoresist procedure)

12. ETCH THROUGH NITRIDE FOR HOTPLATE Apex recipe\# Apex Run\#
a) Plasma etch nitride

\begin{tabular}{|l|l|l|l|l|l|l|}
\hline Run & Time & Power & Pressure & $\begin{array}{l}\text { Base } \\
\text { pressure }\end{array}$ & Gas & Comments \\
\hline 1 & $5 \mathrm{~min}$ & 100 & 300 & 0.053 & $\mathrm{O}_{2}$ & Conditioning \\
\hline 2 & $1 \mathrm{~min}$ & 100 & 300 & 0.062 & $\mathrm{O}_{2}$ & PR descum \\
\hline 3 & $5 \mathrm{~min}$ & 100 & 300 & 0.057 & $\mathrm{CF}_{4} / \mathrm{O}_{2}$ & $\begin{array}{l}\text { Conditioning } \\
\mathrm{O}_{2} / \mathrm{CF}_{4} \mathrm{O}_{2}\end{array}$ \\
\hline 4 & $2 \mathrm{~min}$ & 100 & 300 & 0.055 & $\mathrm{CF}_{4} / \mathrm{O}_{2}$ & $\begin{array}{l}\mathrm{Conditioning} \\
\mathrm{O}_{2} / \mathrm{CF}_{4} \mathrm{O}_{2}\end{array}$ \\
\hline 5 & $2.5 \mathrm{~min}$ & 100 & 300 & 0.063 & $\mathrm{CF}_{4} / \mathrm{O}_{2}$ & \\
\hline 6 & $4.5 \mathrm{~min}$ & 100 & 300 & 0.061 & $\mathrm{CF}_{4} / \mathrm{O}_{2}$ & \\
\hline
\end{tabular}

\section{BUFFERED OXIDE ETCH}

Apex recipe\# Apex Run\#

A 6:1 in a solution of aqueous ammonium fluoride and hydrofluoric acid. Etch rate: $800 \mathrm{~A} / \mathrm{min}$ to etch thermally grown oxide.

Approximately $2500 \mathrm{~A} / \mathrm{min}$,

Samples immersed in BOE for 3 minutes and 15 seconds 
Carleton University 6 Amrita Muhammad Micro hotplate Processing

\section{TMAH ETCH}

Tetramethylammonium hydroxide (TMAH $25 \%$ at $90^{\circ} \mathrm{C}$ ) for 2 hours 39 minutes and 5 seconds

\section{Standard Photoresist Procedure}

\section{APPENDIX A:}

a) Condition - $5 \mathrm{~min}$ in Plasma Preen

a) HMDS vacuum oven $\sim 30 \mathrm{~min}$ recipe Flood coat and spin HMDS(Used before HMDS oven)

HMDS babe: $105 E C$ C 60 sec (formalily used with spun on HMDS)

c) Flood coat and spin Shipley S1811 resist (4,000 RPM, $30 \mathrm{sec}$ spin)

d) Prebake $105^{\circ} \mathrm{C}$ for $60 \mathrm{sec}$

e) Align and expose for $25 \mathrm{sec}$.

f) Develop $60 \mathrm{sec}$ undiluted MF321 with gentle agitation, rinse $60 \mathrm{sec}$

g) Inspect

h) Post bake $120^{\circ} \mathrm{C} 5 \mathrm{~min}$

i) Descum Technics Planar Etch II $100 \mathrm{~W} 60 \mathrm{sec} \mathrm{O}_{2}$

\section{B: Preparation of Aqua Regia for Nichrome etching}

a) Pour water into beaker maintaining $45^{\circ} \mathrm{C}$ using thermocouple.

b) In separate beaker dispense $\mathrm{HCl}$ followed by $\mathrm{HNO}_{3}$ -allow the solution to age for $90 \mathrm{sec}$. -it will turn yellow.

c) Carefully add mixture to warmed DI (maintain temperature of $45^{\circ} \mathrm{C}$ )

\section{C: Plasma Preen Condition}

To remove $\mathrm{PR}-5+5+5\left(15\right.$ minutes total in $\left.\mathrm{O}_{2}\right)$

NB: Let the system cool for 5 minutes intervals.

D: Aligner and spinner

$1000 \mathrm{rpm}$ for 10 second and $4000 \mathrm{rpm}$ for 30 seconds. 
Appendix B

Shipley Photoresist 


\section{SHIPLEY \\ MICROPOSIT $S 1800^{\circledR}$ SERIES PHOTO RESISTS}

MICROPOSIT S1800 SERIES PHOTO RESISTS are positive photoresist systems engineered to satisfy the microelectronics industry's requirements for advanced IC device fabrication. The system has been engineered using a toxicologically safer alternative casting solvent to the ethylene glycol derived ether acetates. The dyed photoresist versions are recommended to minimize notching and maintain linewidth control when processing on highly reflective substrates.

\section{MICROPOSIT S1800 SERIES PHOTO RESISTS FEATURE:}

Product Assurance

- Lot-to-lot consistency through state-of-the-art physical, chemical and functional testing

- Filtered to $0.2 \mu \mathrm{m}$ absolute

Coating Properties

- ${ }^{1}$ Cellosolve ${ }^{\circ}$ Acetate and xylene free

- Striation-free coatings

- Excellent adhesion

- Excellent coating uniformity

- A variety of standard viscosities are available for single-layer processing

\section{Exposure Properties}

- Optimized for G-Line exposure

- Effective for broad-band exposure

- Reflective notch and linewidth control using dyed versions

Develop Properties

- Optimized for use with the MICROPOSIT ${ }^{\$} \mathrm{MF}^{\star}-319$ Metal-Ion-Free DEVELOPER family

- Compatible with Metal-lon-Bearing MICROPOSIT DEVELOPERS

Removal Property

- Residue-free photoresist removal using standard MICROPOSIT REMOVERS

\begin{tabular}{|c|c|}
\hline \multicolumn{2}{|r|}{$\begin{array}{c}\text { High Resolution Process Parameters } \\
\text { (Refer to Flqure 1) }\end{array}$} \\
\hline Substrate: & Polysllicon \\
\hline Photoresist: & MICROPOSIT"S1813* PHOTO RESIST \\
\hline Coat: & $12,300 \AA$ \\
\hline Sottoake: & $115^{*} \mathrm{C} / 60 \mathrm{sec}$. Hotplate \\
\hline Exposure: & Nlkon 1505 G6E, G-LIne (0.54 NA), $150 \mathrm{~mJ} / \mathrm{cm}^{2}$ \\
\hline Develop: & MICROPOSIT* MF*-321 DEVELOPER \\
\hline & $15+50$ sec. Double Spray Puddle (DSP) @ $21^{\circ} \mathrm{C}$ \\
\hline
\end{tabular}

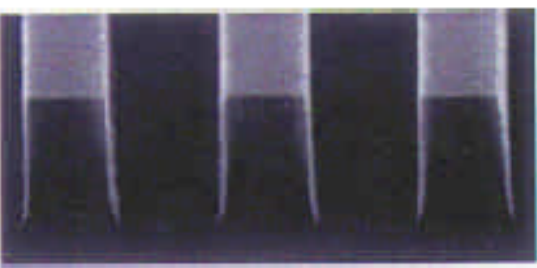

$0.80 \mu \mathrm{m}$ Lines/Spaces

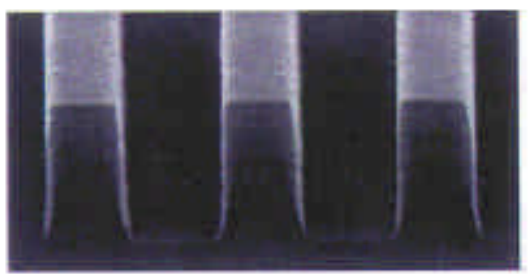

$0.70 \mu \mathrm{m}$ Lines/Spaces

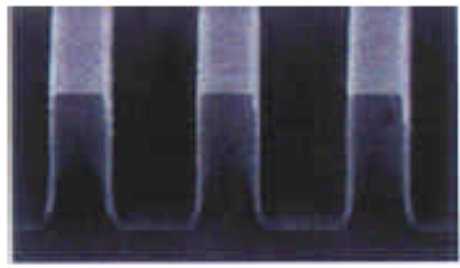

$0.60 \mu \mathrm{m}$ Lines/Spaces

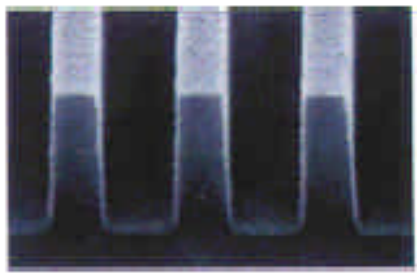

$0.50 \mu \mathrm{m}$ Lines/Spaces

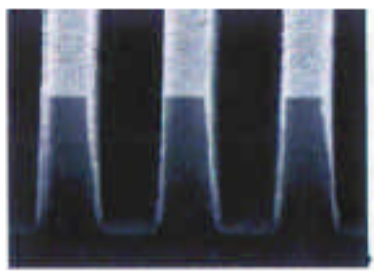

$0.48 \mu \mathrm{m}$ Lines/Spaces

Masking Linearity SEMS Figure 1. 